NBSIR 77-1251

DO NOT REVOY

\title{
Considerations in Establishing Performance Criteria for Structural Firefighters' Helmets
}

Nicholas J. Calvano

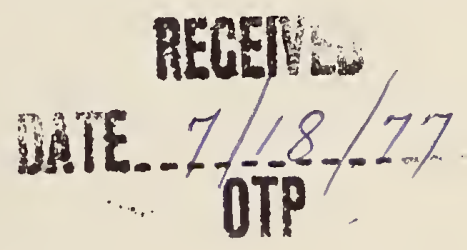

Product Engineering Division

Institute for Applied Technology

May 1977

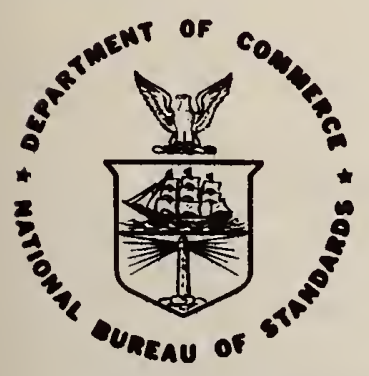

U. S. DEPARTMENT OF COMMERCE

NATIONAL BUAEAU OF 8TANDARDS 



\section{CONSIDERATIONS IN ESTABLISHING PERFORMANCE CRITERIA FOR STRUCTURAL FIREFIGHTERS' HELMETS}

Nicholas J. Calvano

Product Engineering Division Institute for Applied Technology

May 1977

U.S. DEPARTMENT OF COMMERCE, Juanita M. Kreps, Secretary

Dr. Sidney Harman, Under Secretary

Jordan J. Baruch, Assistant Secretary for Science and Technology

NATIONAL BUREAU OF STANDARDS. Ernest Ambler, Acting Director 
Table of Contents

Introduction . . . . . . . . . . . . . . . . . 1

Helmet Construction ................ 2

Shel1.................. . . . 3

Energy Absorbing System . . . . . . . . . . . . 4

Chin Strap ................ . 5

Ear Protectors ............... . . 5

Head Protection . . . . . . . . . . . . . . 6

Predicting Head Injury ............... 7

Physiological Considerations . . . . . . . . . . 9

Impact Attenuation . . . . . . . . . . . . . . 10

Considerations in Establishing a Test

Method for Impact Attenuation . . . . . . . . . . . .10

Impact Attenuation Tests . . . . . . . . . . 12

Considerations in Establishing

Impact Performance Criteria . . . . . . . . . . . . . . 12

Penetration Resistance . . . . . . . . . . . . . 14

Heat Resistance ................... . . 14

High Temperature Requirements . . . . . . . . . . 16

Flammability . . . . . . . . . . . . . . . 17

Chin Strap/Retention System . . . . . . . . . . . 17

Electrical Resistance .................. 18

Visibility. . . . . . . . . . . . . . . . 18

Summary .................... . . . . . . . . . .

Appendix 1. Test results

Appendix 2. Correspondence from Firefighters

Appendix 3. Model Performance Criteria 
Wayne State University tolerance curve Log-log plot of Wayne State University curve ANSI Z89. 1 test apparatus ANSI 290.1 test apparatus Helmet positioned for front impact Helmet positioned for rear impact Helmet positioned for top impact Helmet positioned for side impact ANSI 290.1 ball/socket Acceleration-time curves from impact tests Fully lined helmet with GRP shell Cutaway section of fully lined helmet with GRP shell Fully lined helmet with polycarbonate shell Cutaway section of fully lined helmet with polycarbonate shell

Sling suspension fire helmet with GRP shell

Sling suspension fire helmet with suspension system removed

Sling suspension fire helmet with polycarbonate shell

Football helmet with dual padding system

Football helmet with padded suspension system

Football helmet with 8 point webbing suspension system

Football helmet with 8 point webbing suspension system plus peripheral padding

Football helmet with compartmentalized plastic foam with channels for pneumatic energy absorption 
Football helmet with hydraulic energy absorption system

24,25 Heat damaged fire helmet from field

$26-33$

Fire helmets after high temperature laboratory test 


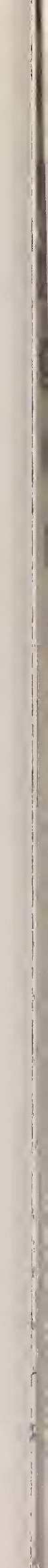




\section{Introduction}

Helmets intended for use in fighting structural fires are designed to protect the wearer from injury caused by falling objects, flames, and heat. The helmet also should protect the user from serious head injury during falls from vehicles, down stairs, ladders or through collapsing floors. But in order to realistically satisfy the needs of the firefighters it is important that the protection be provided at reasonable cost and without seriously compromising comfort. The optimum helmet design, then, is one which combines the correct balance of protection, cost, and comfort.

Althnigh many combinations of materials and designs are used to manufacture firefighters' helmets in the United States, all of the helmets can be divided into two major groups - sling suspension and fully lined. Details of helmet construction are discussed in the next section. For now, it is sufficient to point out that the sling suspension helmets utilize a nylon webbing which is fastened to the shell at four points and rests on the crown of the head, while the fully lined helmets have a foamed plastic lining in contact with the inside surface of the she11.

Helmet manufacturers, in designing their product, and users, in making their selection, must balance protection against cost, size, weight and comfort. This necessarily imposes constraints on helmet designs. The problem then reduces to the questions "How much protection is the user willing to trade for comfort, and how much is he willing to pay?" To get a better understanding of the needs of firefighters and the 
current state-of-the-art in firehelmet design a project was initiated by the National Bureau of Standards. Not long after the project began, the responsibility was transferred to the National Fire Prevention Control Administration who continued to support it.

This report summarizes the tests that were conducted on various types of fire helmets to determine their relative effectiveness in mitigating the effects of hostile fire environments. It also reflects the needs of users as perceived by firefighters, fire administrators and safety officers.

It is important to note that this study was restricted to the structural fire environment and does not address special needs of firefighters : $:$ h devote most of their time to fighting brush fires or crash fires. Nor was this study intended to be an exhaustive evaluation of fire helmets manufactured in this country. Finally, the question of compatibility of helmets with other equipment such as breathing apparatus was not addressed.

The work described in this report culminated in a proposed standard for fire helmets which is included in appendix 3.

\section{Helmet Construction}

Fire helmets are designed with (1) a hard outer shell to shed water and debris, to protect against penetration and to distribute the energy of an impacting object; (2) an inner liner or suspension system to absorb any impact energy delivered to the shell and (3) a chin strap or retention system to hold the helmet securely on the head. 
Shell

The outer shells of firefighters' helmets are constructed of polycarbonate, glass reinforced plastic (GRP), leather, aluminum or layered fabric in a phenolic matrix. The phenolic shells were discontinued for a while but have recently been reintroduced.

Polycarbonate is a tough thermoplastic material with outstanding resistance to impact. Because polycarbonate can be processed easily with conventional plastics molding equipment, helmets with polycarbonate shells can be manufactured at a reasonable cost. The combination of low cost and high strength to weight ratio makes polycarbonate a desirable material for helmet shells. However, some of the properties that make polycarbonate easy to process also make it a marginal material for firefighters' helmets. It starts to soften at about $150 \mathrm{C}$ (300 F) and at about $200 \mathrm{C}(390 \mathrm{~F})$ many of the polycarbonate helmets on the market today will begin to deform. To compensate for the relatively low heat distortion temperature, some manufacturers have raised the thermal capacity by increasing the shell thickness. The trade-off for the resulting higher heat distortion temperature is higher cost and more weight. Another shortcoming of polycarbonate is its susceptibility to attack by some common organic solvents. Exposure to solvents such as carbon tetrachloride, benzene, and methylene chloride may cause the shell to crack.

Glass reinforced plastic (GRP) is also used as a shell material for fire helmets. Woven fiberglass is impregnated with a polyester resin, shaped and cured on a mandrel. Helmet shells fabricated of this material have demonstrated high resistance to heat, flames and 
chemicals. However, GRP is less resistant to impact damage than polycarbonate. Also, because shells fabricated from GRP must be essentially hand made, the cost is necessarily higher than shells molded of thermoplastic materials.

Leather shells are also hand-produced and are relatively expensive. Heat and chemical resistance of leather helmets is good and leather shells have the ability to deform and absorb some of the energy of impact. However, unless the user exercises considerable care in maintenance, the leather will dry out in time and become brittle.

Helmets made with aluminum shells are gradually disappearing. Although aluminum has the advantages of low cost, light weight, and ability to deform when impacted to absorb energy, it has the obvious disadvantage of being highly conductive to heat and electricity. Helmets with aluminum shells do not meet minimum performance requirements of any nationally recognized standard.

Energy Absorbing System

Between the head and the shell of the helmet is a system for absorbing impact energy. In firefighters' helmets produced today there are two types of energy absorbing system: (1) a webbing suspension similar to the type used in construction workers' helmets and (2) a foamed plastic liner (fully lined) which is usually found in motorcycle helmets.

Helmets utilizing the webbing suspension system are designed to meet the impact requirements of the ANSI Z89.1 standard for industrial hardhats and therefore offer excellent protection against impact to the top of the head but very little impact protection elsewhere. On the other hand, fully lined helmets, which are designed to meet the impact 
requirements of the ANSI 290.1 standard for vehicular helmets, provide good protection to the front, sides and back of the head, but do not attenuate the energy of blows to the top of the head as well as the webbing suspension. Also, the fully lined helmets tend to restrict evaporative cooling about the head, and are generally heavier than suspension helmets.

\section{Chin Strap}

The function of the chin strap is simply to keep the helmet on the head. Most chin straps on firefighters' helmets are made of leather, nylon webbing or an elastic cotton material. Fasteners are usually "D" rings, snaps or spring clips.

Some helmets have a nape strap which fits around the lower back of the head to prevent the helmet from flipping off when the wearer bends forward. Depending on the design of the helmet retention system, this additional strap may or may not be necessary. Ear Protectors

Generally, ear protectors are offered as an option for fire helmets and are designed to be tucked up into the helmet leaving the ears exposed, or pulled down over the ears for protection against heat.

Some firefighters object to the use of ear protection arguing that the ears serve as heat sensors to warn of dangerously high heat loads. Safety officers $1 / \& 2 /$ on the other hand, would prefer that fire helmets have integral ear protectors that would eliminate the prerogative of exposing the ears. 


\section{Head Protection}

Before a helmet can be evaluated for its ability to protect the head it is important to identify the parameters which should be measured and the threats to which the wearer might be exposed. For any protective headgear this task is accompanied by some uncertainty, but the problems are compounded with fire helmets because of the demanding and variable environment a firefighter encounters during normal operations.

Any discussion of head protection would be neither complete nor meaningful without some discussion of the mechanism of head injury and tolerance of the human head to impact.

Head injuries can generally be grouped into three categories: scalp, skull and brain. Injuries to the scalp can cause discomfort, bleeding and disfiguration but are not likely to cause a fatality if there is no accompanying injury to the brain or skul1.3/

Skull injuries can be categorized as linear, indented, depressed or crushed fractures. With all but the indented fracture, which occurs mainly in children when the bone is relatively flexible, the injury is identified by visible cracking in the skull. Fractures are usually caused by a blunt impact, and although they can occur without brain injury $4 /$, Guardjian reports that concussion is associated with 80 per cent of all linear skull fractures. 5/

Brain injury is the form of head injury that is of most interest to us because it is so common and covers the entire spectrum from mild, reversible concussion to fatal hemorrhage. It also establishes the threshold of serious head injury. 
Brain injuries are usually identified as laceration (tearing or cutting of the brain matter), contusions (bruising) or concussion (10ss of consciousness). Concussive brain injury is especially important because it is the most difficult injury to protect against; or stated another way, helmets that protect against concussion will generally protect against any serious head injury.

Concussion is probably caused by shear stress along the brain stem which results from intracranial pressure gradients induced by flow of the brain stem through the foramen magnum $6 /, \underline{7 /} \& \underline{8} /$. There is evidence to show that pressure gradients will occur along the axis of acceleration of a fluid filled container $\underline{9}$ which is a good representation of the human brain in a skull. Citing his own experiments and work performed by Seiller, Unterharnscheidt and Lindgres, Thomas 8 / infers that "acceleration is a potent cause of increased intercranial pressure" and "is a most important factor in concussion." Based on his laboratory studies with monkeys, Hodgsen $10 /$ claims that head acceleration is the one physical parameter most related to monkey head injury. Predicting Head Injury

Tolerance to closed head injury is hard to establish because it can occur without visible injury to the skull. The Wayne State University tolerance curve, shown in figure 1, 11/ was developed in the early $60^{\prime}$ 's to predict human tolerance to cerebral concussion. Based on experiments conducted on cadavers and animals, it is probably the best known device for predicting human tolerance to head impact. The WSU curve indicates that concussion is a function of time and acceleration. By replotting the WSU curve on $\log -\log$ coordinates, figure 2 , and 
using the slope of the resulting straight line as the exponent of acceleration, Gadd 12 / devised the Severity Index (SI) which represents a measure of human tolerance to impact. It is expressed mathematically as $S I=\int a^{2.5} d t$, where $a$ is acceleration in units of $g_{n}\left(g_{n}=9.80665\right.$ meters per second squared) and $t$ is time duration in seconds of the impact.

The Head Injury Criterion (HIC) was developed by Versace and may be considered a refinement of the Severity Index which has been criticized as being mathematically illogical. Newman $14 /$ points out that it is mathematically incorrect to represent the Wayne State University tolerance curve as a straight line defined by $a^{2.5} t$ and then use this expression in the integration of the acceleration-time impulse curve to obtain a Severity Index. The HIC avoids this by taking the average acceleration of a selected interval of the a- $t$ curve, raising it to the 2.5 power and multiplying by the duration of the selected interval.

Mathematically, HIC is expressed as

$$
H I C=\left[\frac{1}{t_{2}-t_{1}} \int_{t_{1}}^{t_{2}} \text { adt }\right]^{2.5}\left(t_{2}-t_{1}\right)
$$

where $a$ is the acceleration in $g_{n}{ }^{\prime} s$ and $t_{2}-t_{1}$ is the time interval which maximizes HIC.

Both SI and HIC attempt to make maximum use of biomechanical information provided by the Wayne State tolerance curve. The NOCSAE* standard for football helmets $\underline{15 /}$ uses an SI of 1500 as a rejection 
criterion. Other helmet standards such as FMVSS* $218 \underline{15 /}$ and ANSI** 290.1 17/ acknowledge the existence of the WSU tolerance curve by including time limits as well as maximum acceleration in their rejection criteria.

Physiological Considerations

Comfort, to a firefighter, means more than being physically at ease. It also refers to the ability to perform tasks without suffering from overexertion or heat exhaustion.

Lives and property frequently depend on the firefighters' ability to do strenous work quickly under the most demanding environmental conditions. They must raise and scale ladders, pull hoses up stairs, cut holes in walls, ceilings or floors with power tools, pull down ceilings with hooks, and sometimes rescue comrades or occupants who have been overcome by smoke - all of this while wearing approximately $27 \mathrm{~kg}$ (60 1b.) of protective equipment and carrying an additional 7-9 $\mathrm{kg}(15-20 \mathrm{lb}$.) of tools

The IAFF Firefighter Mortality Report 18/ cites heart disease as the leading cause of firefighter death and disability, and in a study of the New York City Fire Department covering the period 1970-1973, overexertion accounted for 11 per cent of the service connected accidents and $42 \%$ of the time lost.

*Federal Motor Vehicle Safety Standard

**American National Standards Institute 
Comfort and weight then, are important considerations in helmet designs. Some of the factors associated with helmet comfort include location of center of mass, fit, mass moment of inertia, and ability to allow dissipation of body heat through evaporative cooling of the head. In general, current helmets trade off protection for weight and comfort. That is, the heavier and less comfortable helmets are generally less susceptible to heat damage and provide more impact protection.

\section{Impact Attenuation}

Considerations in Establishing a Test

Method for Impact Attenuation

Berger $19 /$ suggests that an ideal test method should utilize a test head which duplicates the response of a human head to impacts. Such a headform was developed by Wayne State University $20 /$ and is now being used by NOCSAE in their standard test for football helmets. 15/ However, in two separate round robin tests $21 / \& 22 /$, data indicated that reproducibility with the headform was not satisfactory for a test method.

Probably the two best known and most used methods for testing helmets in this country are the falling ball/rigid headform method described in ANSI 289.1 23/ (fig. 3) and the falling headform/rigid anvil method described in ANSI 290.1 17/, Snel1 24/, and FMVSS 218 16/ (fig. 4). The $Z 89$ apparatus constrains impact tests to a small area on the top of the helmet while the 290 apparatus allows impacts to be delivered to all areas - top, front, sides and back (fig. 5, 6, $7 \& 8$ ).

Although most impacts to firefighters heads may result from debris falling on the top of the head, there is also a very real threat of serious impacts to other parts of the head. For example, there have been 
reports of firefighters being struck on the side, front, and back of the head by errant hose nozzles (appendix 2, letters 1,2), as a result of falls from ladders $25 /$, by collapsing walls and roofs $\underline{18 /}$ and from vehicular accidents en route to or from the fire 18/ (appendix 2, letters 2 and 3 ).

Having established that an important parameter in assessing head impact injury is acceleration, and that impact tests on firefighters' helmets should not be limited to the top, a logical choice for the test apparatus was the ANSI 290 set-up. The 290 apparatus measures the deceleration of a helmeted metal headform when dropped in guided freefall onto a steel anvil. A ball and socket arrangement (shown in fig. 4) permits positioning of the headform so that a helmet can be impacted at any location.

The magnesium $Z 90$ headform has been criticized as being too rigid to respond to impacts in a manner similar to a human head. However, for a test device, simulation of human response may not be as essential as the requirement of reproducibility. ASTM Round Robin tests have indicated that the 290 apparatus is a more reproducible system than the NOCSAE apparatus which uses a realistic headform. 21/ At the very least, the 290 apparatus provides one measure of a helmet's ability to attenuate the energy of impact.

It must be emphasized that the lack of information on in vivo human tolerance to head impacts, the broad distribution of impact tolerance from person to person, and the failure of the metal headform to duplicate the response of the human head, make it virtually impossible to measure the actual protection provided by a helmet. Instead, the helmet's ability to absorb the energy of a given impact is measured. 
As test headforms improve and more is learned about the tolerance of human heads to impacts, test methods will improve sufficiently to actually measure the amount of protection that a helmet affords in a given situation. Meanwhile, we must satisfy ourselves with the best available techniques. For fire helmets, the 290 type apparatus appears to come closest to satisfying the need.

Impact Attenuation Tests

Helmets were subjected to environmental conditioning (room temp., high temp., low temp., and wet) and dropped from a height of $183 \mathrm{~cm}$ onto a steel anvil. Results of the impact attenuation test (appendix 1) show clearly that the suspension type helmets consistently perform better than full: lined helmets when impacted on the top. On side, front, and rear impacts, however, the fully lined helmets invariably perform better. Note also that the suspension type helmets were dropped from $92 \mathrm{~cm}$ rather than $183 \mathrm{~cm}$ (one half the impact energy) when impacted on locations other than the top. Even at this reduced impact level, headform accelerations exceeded $500 \mathrm{~g}$. This demonstrates a design limitation of suspension type helmets which allows effective attemation of impacts to the top of the head but minimal attenuation elsewhere. Typical acceleration-time curves are shown in fig. 10 . Considerations in Establishing Impact

Performance Criteria

As indicated earlier, the optimum fire helmet design combines the correct balance of protection, cost, weight and comfort. But, as with any helmet, increased protection is generally obtained by sacrificing comfort, weight and cost. For example, to obtain more impact protection, 
the distance between the shell and head may be increased, permitting more stopping distance between the head and impacting object. But increased size is generally accompanied by increased weight and less comfort. Unlike the motorcyclist who expends little energy while riding and can afford to wear heavy helmets, the firefighter does strenuous work during routine structural firefighting and places a high premium on lightweight equipment. 28/

The impact requirements in the proposed standard (appendix 3) were based on biomedical information, test data obtained from various commercially available fire helmets (appendix 1) and our own assessment of the state-of-the-art in materials and helmet design. In addition, the needs of firefinhters, safety officers and administrators were considered (appendix 2). Helmets that meet these requirements will substantially reduce the effects of blows to the head. Although none of the helmets tested meet the proposed impact requirements (appendix 3), we are convinced that they can be made without significantly compromising cost and comfort. All of the fire helmets in this country have been patterned after crash helmets (interior fully lined with an energy absorbing material such as foamed styrene) or industrial hard hats (sling suspension system)(see figs. 11 thru 17). Yet, the state-of-the-art in helmet design and manufacturing permits production of fire helmets that provide better protection than either the sling suspension or fully lined helmets that are currently available. Some examples of innovative design that might be employed in fire helmets are shown in figs. 18 thru 23. Ail of the helmets shown are football helmets. 


\section{Penetration Resistance}

Protection against injury from penetrating objects can be viewed as a special case of impact protection where the impacting object is pointed. With pointed objects, however, the threat of injury is likely to be scalp (and possibly skull) penetration rather than closed head injury discussed earlier.

The proposed penetration resistance test is similar to the test described in ANSI $Z 9017 /$ and FMVSS $Z 18$ 16/. It requires that a pointed steel cylinder be dropped in guided free fall from a height of $2.5 \mathrm{~m}$ onto a helmet which is mounted on a metal headform. Contact between the penetrator and the headform constitutes failure. Helmets were tested for resistance to penetration by dropping the penetration striker from various heights (appendix 1). Leather, glass reinforced plastic, and polycarbonate all have a good field record in providing protection against penetration by sharp objects. The requirements were set to prevent any lowering of present performance.

\section{Heat Resistance}

Comments from firefighters (appendix 2, letters 4 thru 11 ) indicate widespread dissatisfaction with some present helmets because of low resistance to heat. To substantiate complaints, deformed helmets and photographs of heat damaged helmets (figs. 24 and 25) were presented by fire departments in different geographical locations. In all cases, the helmets involved were thin shelled polycarbonate (approx. $0.190 \mathrm{~cm}$ ). However, it should be noted that in investigating reports of deformed helmets, there were no cases of helmets having contributed to the injury. 
On this basis, one manufacturer $26 /$ argues that the helmet has done its job in protecting the user. Some firefighters 27/ on the other hand, have expressed concern about the suitability of helmets that deform during structural firefighting operations which they do not consider to be extreme or unusual. It is also significant that there was not a single reported case of helmet deformation from departments using the helmets with thicker polycarbonate shells (approx. $0.400 \mathrm{~cm}$ to $0.500 \mathrm{~cm}$ ). Field information, then, suggests that polycarbonate is a marginal material which may or may not be satisfactory, depending on thickness.

In a study by Grumman Aerospace Corporation 28/, temperature measurements were taken at the scene of structural fires. They reported the "typical fire scene temperature" to be in the range of $38-65^{\circ} \mathrm{C}$ $\left(100-150^{\circ} \mathrm{F}\right)$ with a maximum of approximately $230^{\circ} \mathrm{C}\left(450^{\circ} \mathrm{F}\right)$ "for a short interval."

Radiant heat flux measurements made during the same study showed heat intensities ranging from 0.03 to 0.13 watts per square centimeter.

On the basis of data obtained from 72 fire incidents, Burgess 29/ reports that "maximum temperatures in excess of $80^{\circ} \mathrm{C}\left(176^{\circ} \mathrm{F}\right)$ can be expected in on $7 y$ $1 \%$ of all structural fires."

Simms and Hinkley $30 /$ describe several ranges of heat exposure for fire fighters. Under normal conditions the authors estimate temperatures of up to $55 \mathrm{C}\left(137^{\circ} \mathrm{F}\right)$ and a radiation intensity of up to $0.14 \mathrm{~W} / \mathrm{cm}^{2}$; while during rescue operations, the study predicts firefighters might expect to encounter temperatures from 60 to $275^{\circ} \mathrm{C}\left(140-527^{\circ} \mathrm{F}\right)$ and radiant heat loads from $0.15 \mathrm{~W} / \mathrm{cm}^{2}$ to approximately $1.3 \mathrm{~W} / \mathrm{cm}^{2}$. During controlled tests with volunteer firefighters, Dupont $31 /$ reported that one subject withstood $221^{\circ} \mathrm{C}\left(430^{\circ} \mathrm{F}\right)$ for 3 minutes. 


\section{High Temperature Requirements}

Guided by the published reports, comments from the field, and the evidence of heat damaged helmets, three minutes at $250^{\circ} \mathrm{C}$ was established as a reasonable test condition for high temperature performance. Under these conditions, it was possible to duplicate damage that occurred during actual field use. It is important to note that damaged field helmets that were used as a guide were all involved in incidents where the user survived. The only demand placed on the helmet during this test is that it not deform to such an extent that it becomes a hazard iteself. The intent of the high temperature requirement is to ensure that a firefighter can escape or be rescued from an extraordinarily high heat situation without having his helmet curitribute to his injuries. Laboratory tests were conducted with various commercially available helmets (appendix 1). Helmets that deformed in the field failed the test, while helmets with no record of heat damage in the field passed.

A spearate heat load requirement is included as a part of the impact test to insure that a helmet will offer protection against impact at elevated temperatures. Specifically, a radiant heat load of $0.6 \mathrm{~W} / \mathrm{cm}^{\text {? }}$ is applied to the helmet for 3 minutes immediately prior to impact. Based on reports cited earlier, helmets that meet this requirement should perform satisfactorily if impacted while exposed to heat loads that one might normally encouter while fighting active fires. Laboratory tests show that some helmets currently produced will meet the impact requirement after exposure to radiant heat (appendix 1 ). 
Flammability

Simultaneous exposure to direct $\mathrm{fl}$ ames and high radiant heat loads is not unlikely for firefighters. Therefore, the flammability test requires that the helmet and ear protectors be exposed to direct flame and a radiant heat load of $0.6 \mathrm{~W} / \mathrm{cm}^{2}$. The radiant heat load is well above the exposures anticipated for routine firefighting $28 /$ and well above any measurements recorded by Burgess during his study. After reinoving the flame (but not the radiant heat source) the helmet and ear protectors must extinguish themselves within five seconds. Laboratory tests (appendix 1) indicate that most of the fire helmets currently available will meet the proposed flammability requirements.

\section{Chin Strap/Retention System}

The function of the chin strap is simply to keep the helmet on the head. Current motorcycle helmet standards $16 /, 17 / \& 24 /$ require that the chin strap support a $1300 \mathrm{~N}$ (300 1b) static load. It is well within manufacturing capability to produce such a chin strap. However, firefighters expressed concern that neck injuries might result from unyielding straps. Some also favored breakaway devices.

The proposed criteria require that chin straps be capable of supporting a static load of $650 \mathrm{~N}(146 \mathrm{lb})$. This requirement is proposed to prevent helmets from being dislodged during moderate impacts. It also allows manufacturers to design chin straps that will break loose to avoid neck injury. 


\section{Electrical Resistance}

Collapsing ceilings and walls are likely to expose live electric wires creating a serious hazard to firefighters. Helmets are therefore required to pass an electrical resistance test. The proposed requirement for electrical resistance is similar to ANSI 289.1. 23/ Fire helmets that have met this requirement in the past have also performed satisfactorily in actual field use (appendix 3, p. 13).

\section{Visibility}

For both logistical and safety purposes it is important for firefighters' helmets to be highly visible. During the daytime this can best be accomplished by using light colored helmets such as white, yellow, orange, etc. At night, retro-reflective markings on the helmet can greatly increase visibility by reflecting light back toward the source. Proposed values for color and retro-reflectance of fire helmets (appendix 3 , pg. 3) were based on the requirements for firefighters' turnout coats and the state-of-the-art in retro-reflectance.

\section{Summary}

In reviewing the test data and field information it is apparent that additional work is necessary in several areas.

Injury data. A comprehensive system of gathering firefighter injury information is essential. Specific injury data is necessary to determine weaknesses in present protective equipment and to establish a sound basis for development of new, improved protective gear. 
The National Fire Prevention and Control Administration initiated a project during fiscal year 1977 to study firefighter injuries. It is anticipated that this study will help satisfy the need for specific injury information.

New helmet designs. Impact test results show that present helmets provide the user with two choices: (1) sling suspension helmets - excellent attenuation of impacts to the top of the head with minimal impact attenuation elsewhere; (2) fully lined helmets - good attenuation of impacts to front, sides, back and top of the head but considerably less impact attenuation on the top than is offered by the sling suspension helmet. A combination of the sling suspension and padding would incorporate the best features of both designs and provide firefighters with more protection against impact than either of the current choices. This is not a new concept but has been available in football helmets for many years. Yet, it has not been adapted to fire helmets. Other energy and heat absorbing systems should be evaluated to optimize comfort, weight, cost and protection.

New shell materials should be investigated to provide protection at high temperatures at a reasonable cost and weight.

Equipment compatibility. Helmets must be designed to be compatible with other equipment. Face shields sometimes interfere with breathing masks; chin straps on breathing masks interfere with helmet straps, breathing tanks carried on the back interfere with the brim of the helmet.

NASA and NFPCA have jointly sponsored a program to examine the requirements for a total firefighters' ensemble. A major part of this project will be the important problem of equipment compatibility but the solution is three to five years away. 
Eventually, through the combined efforts of government, industry and users, fire helmets and other protective gear will advance to a level which al1 may consider acceptable. In the meantime, test methods and performance criteria must be established to ensure a reasonable level of protection within current technological limits. 


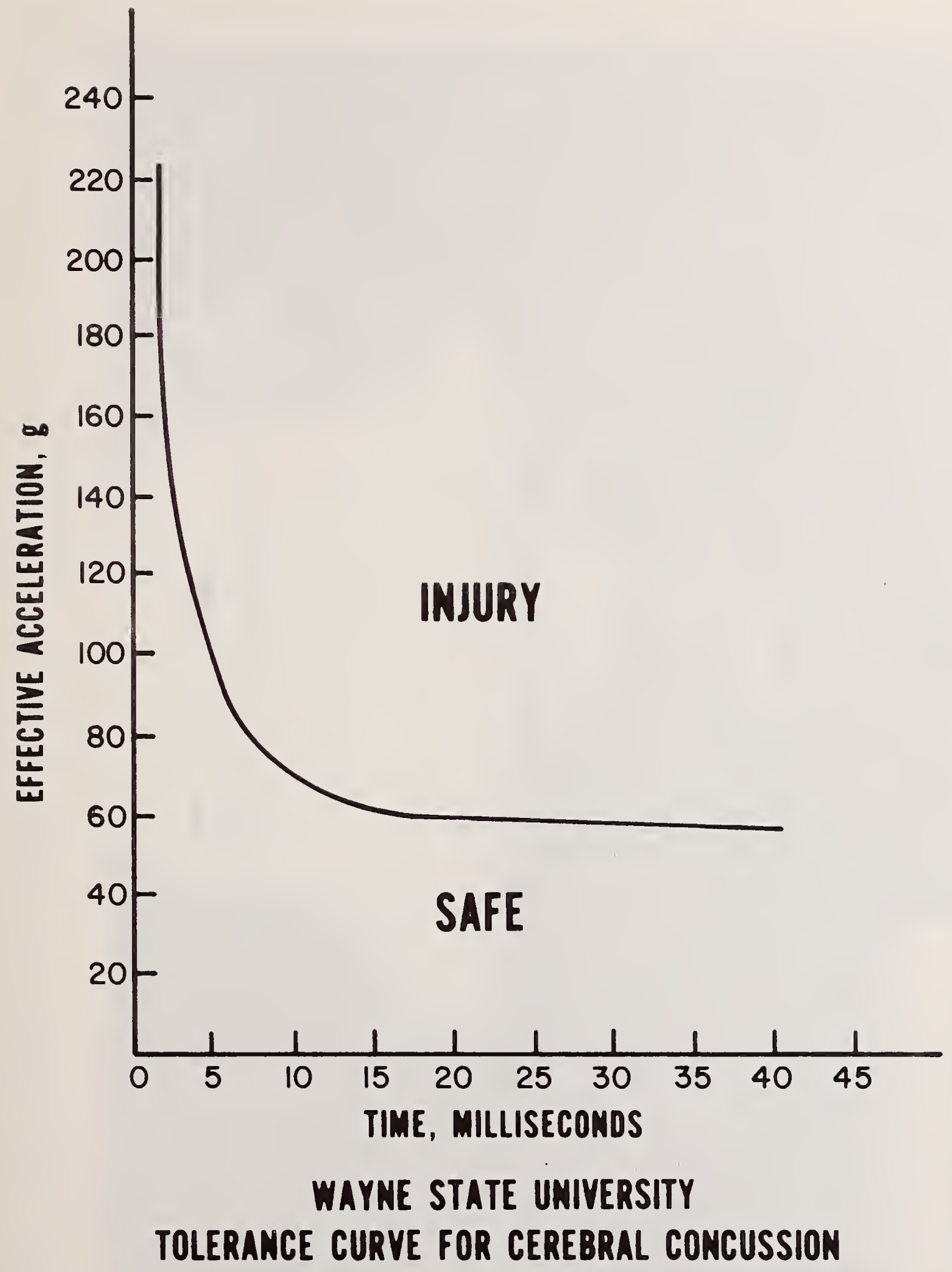

Figure 1. 


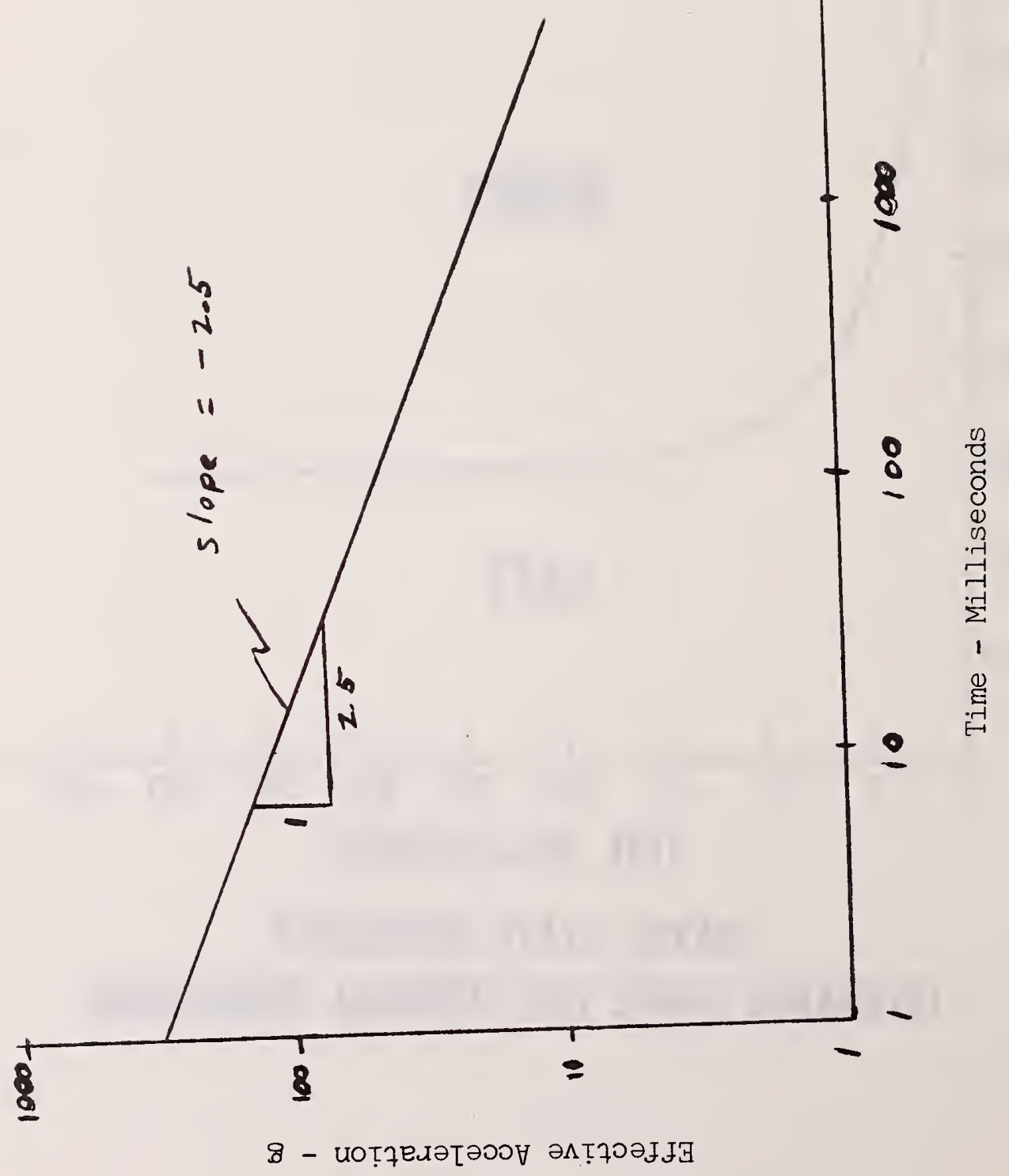

$\sum_{0}^{0}$

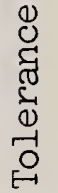

离

崩

$\stackrel{\infty}{2}$

崩

苛

80

1

\begin{tabular}{l}
1 \\
0 \\
0 \\
\hline
\end{tabular}

i

药 


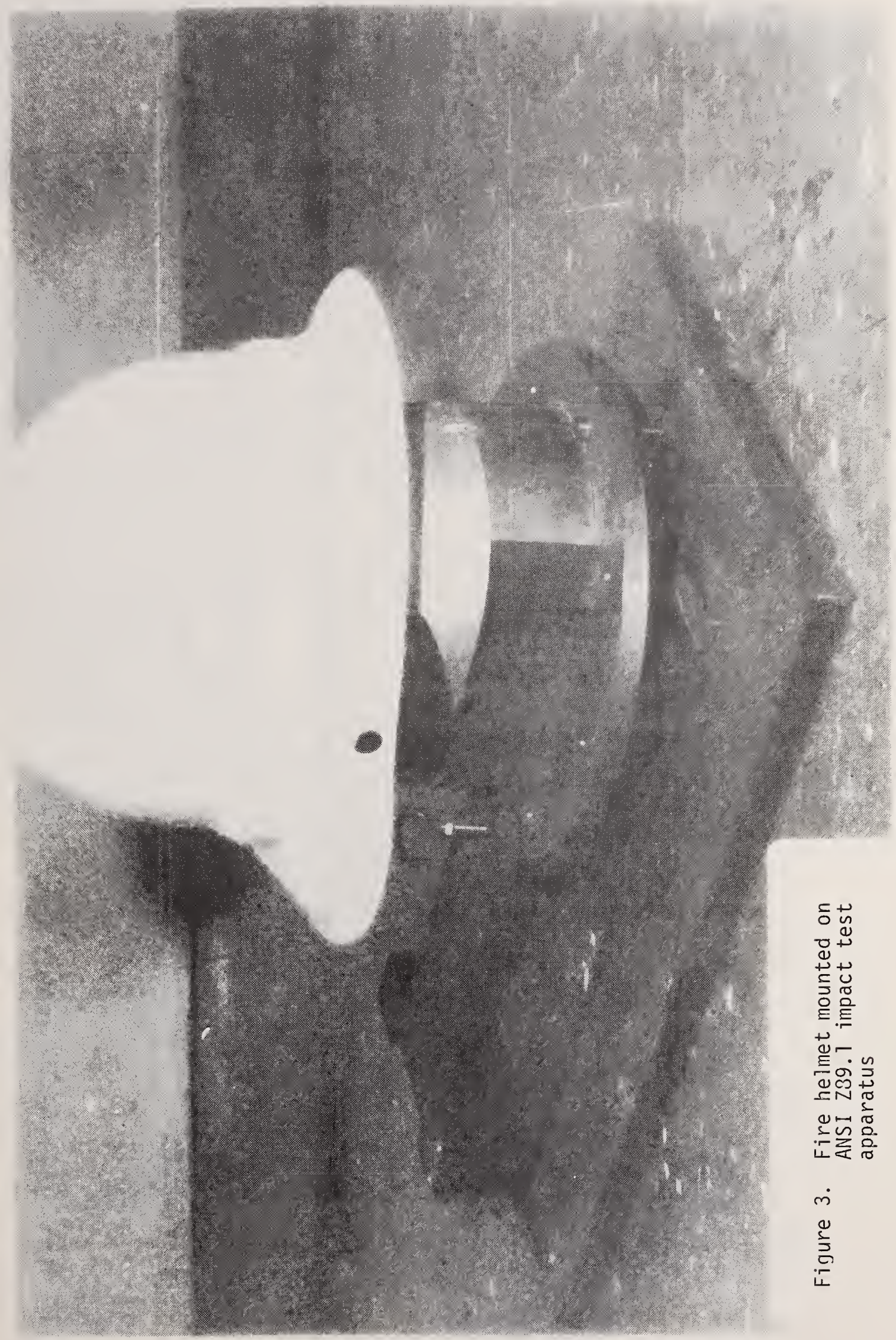




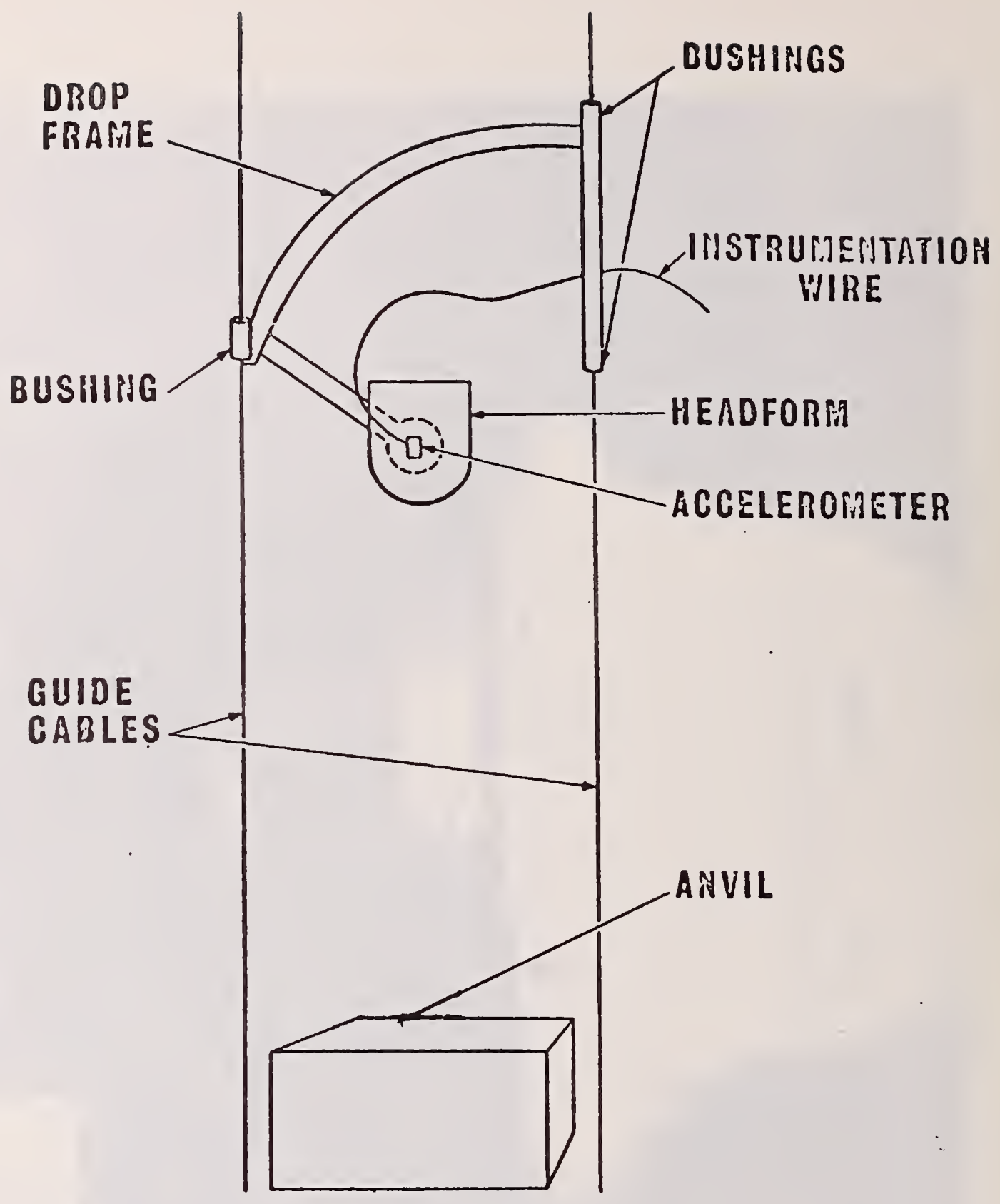

Figure 4. 290.1 test apparatus 


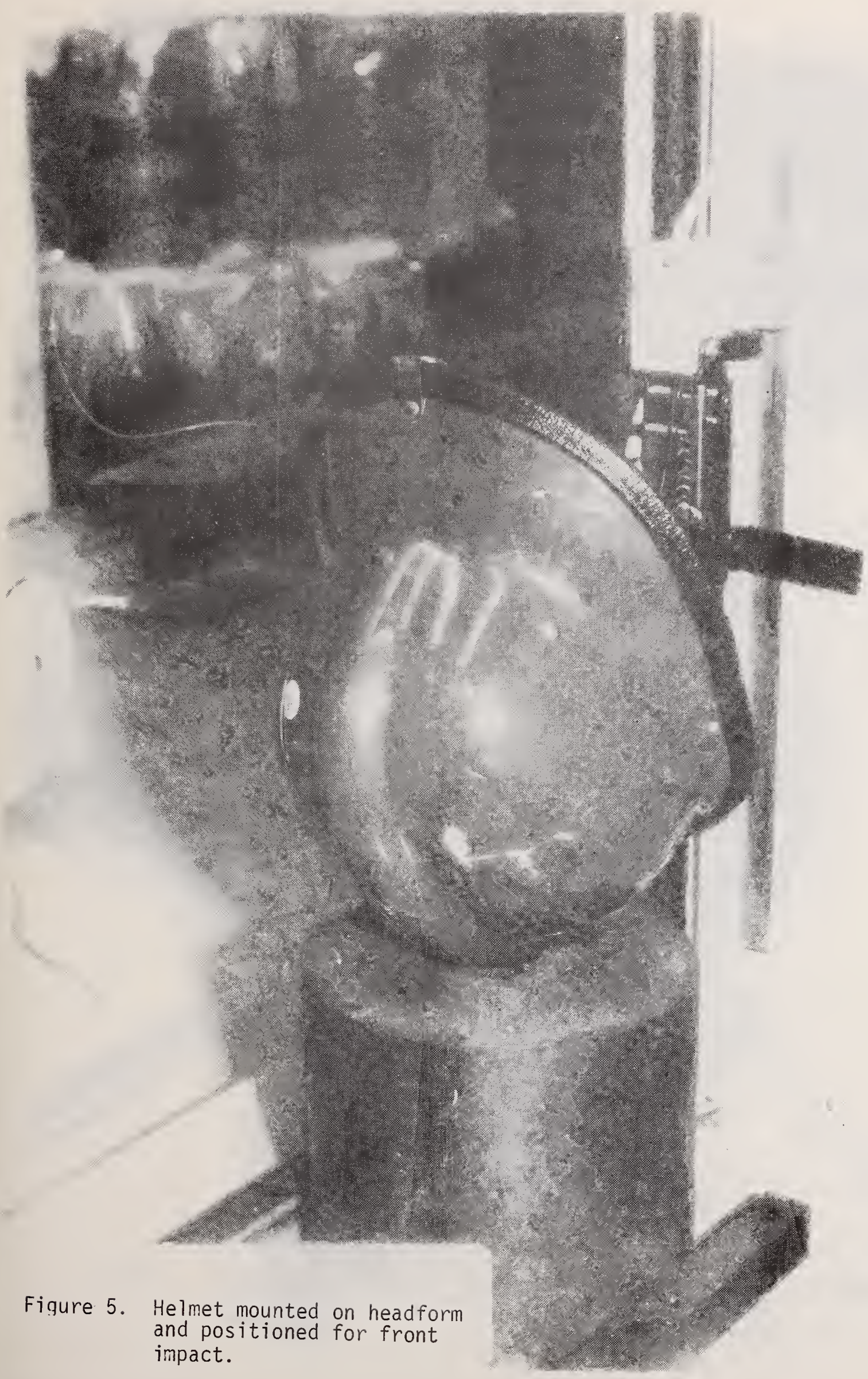




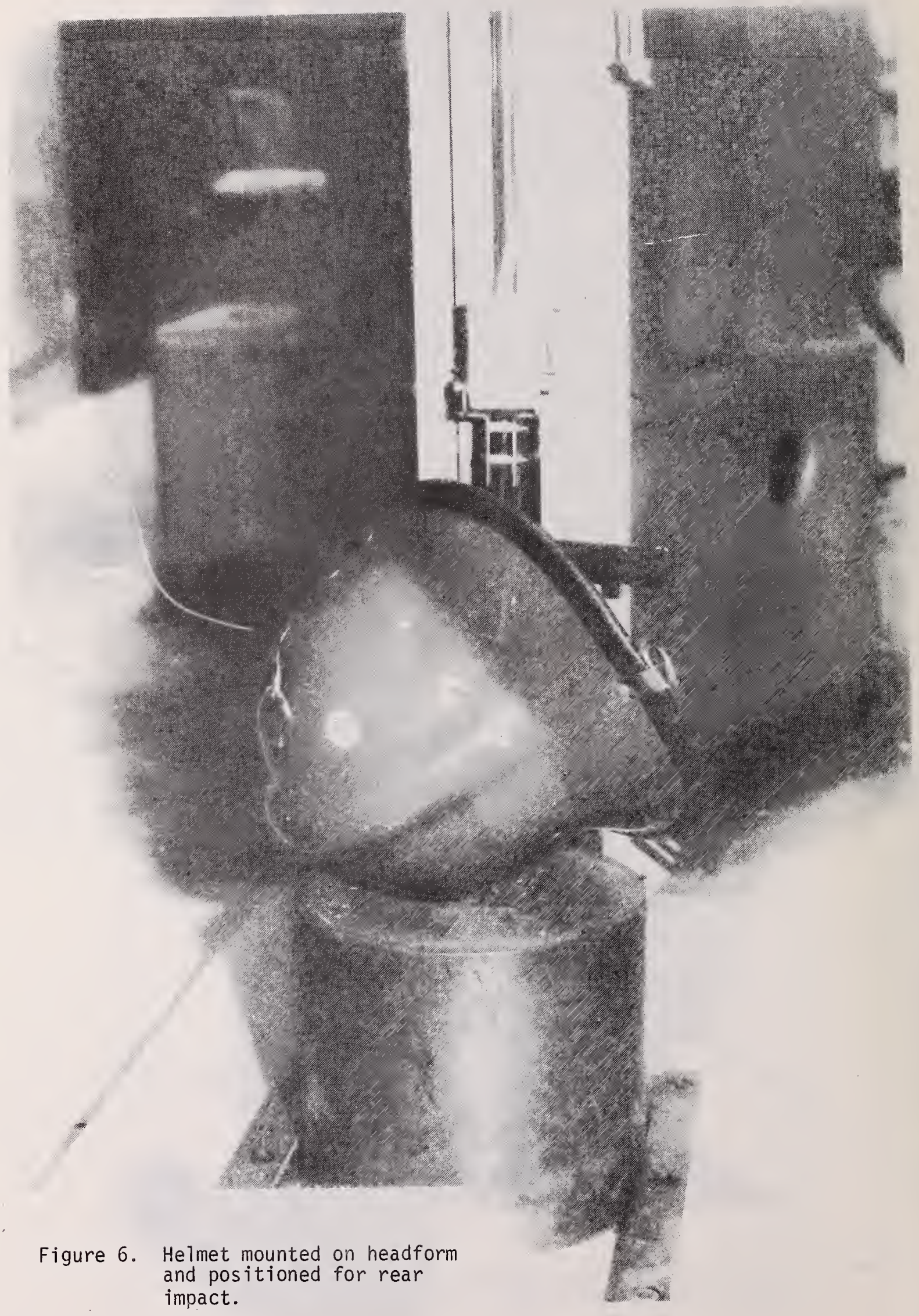




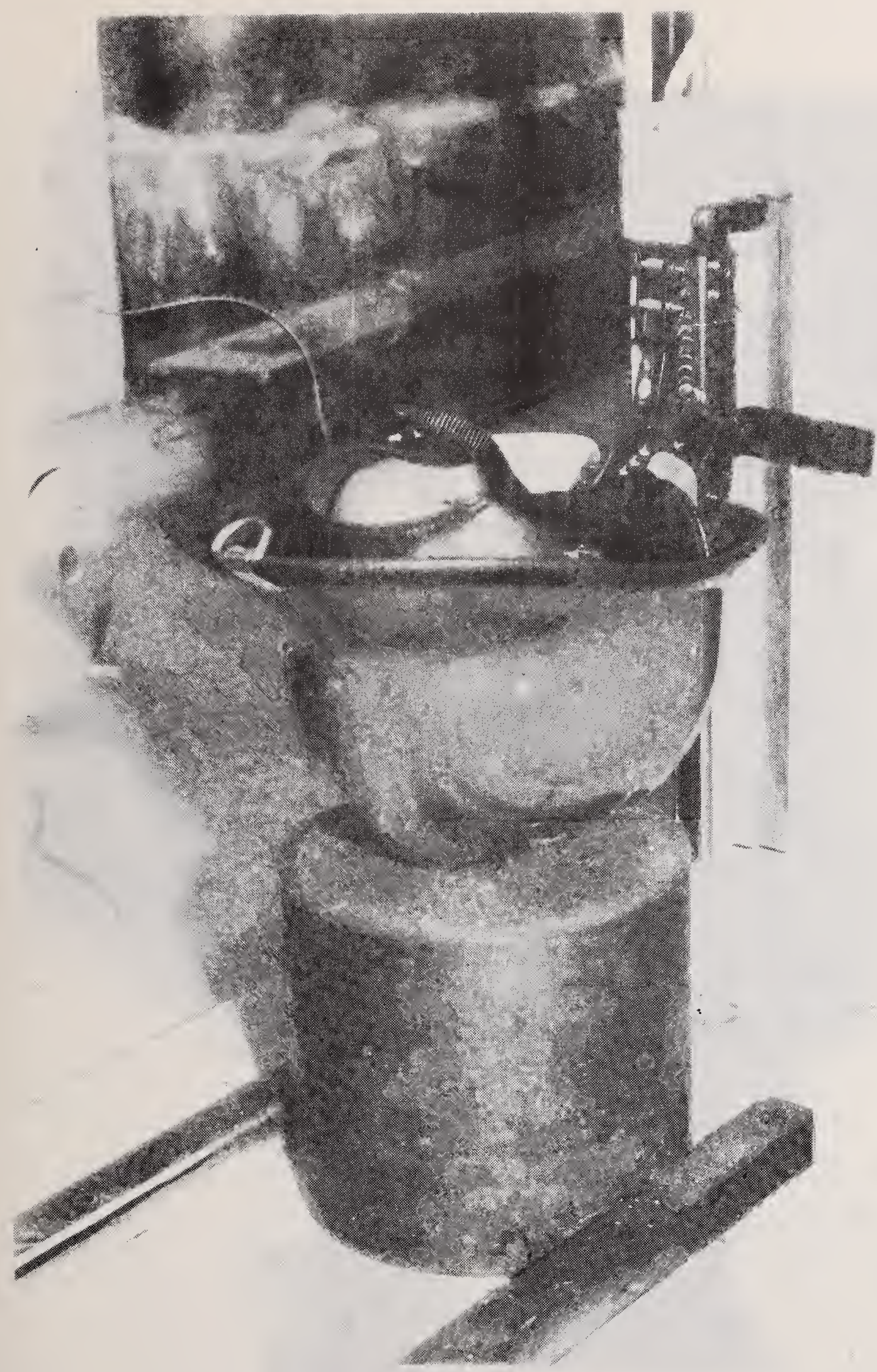

Figure 7. Helmet mounted on headform and positioned for top impact. 


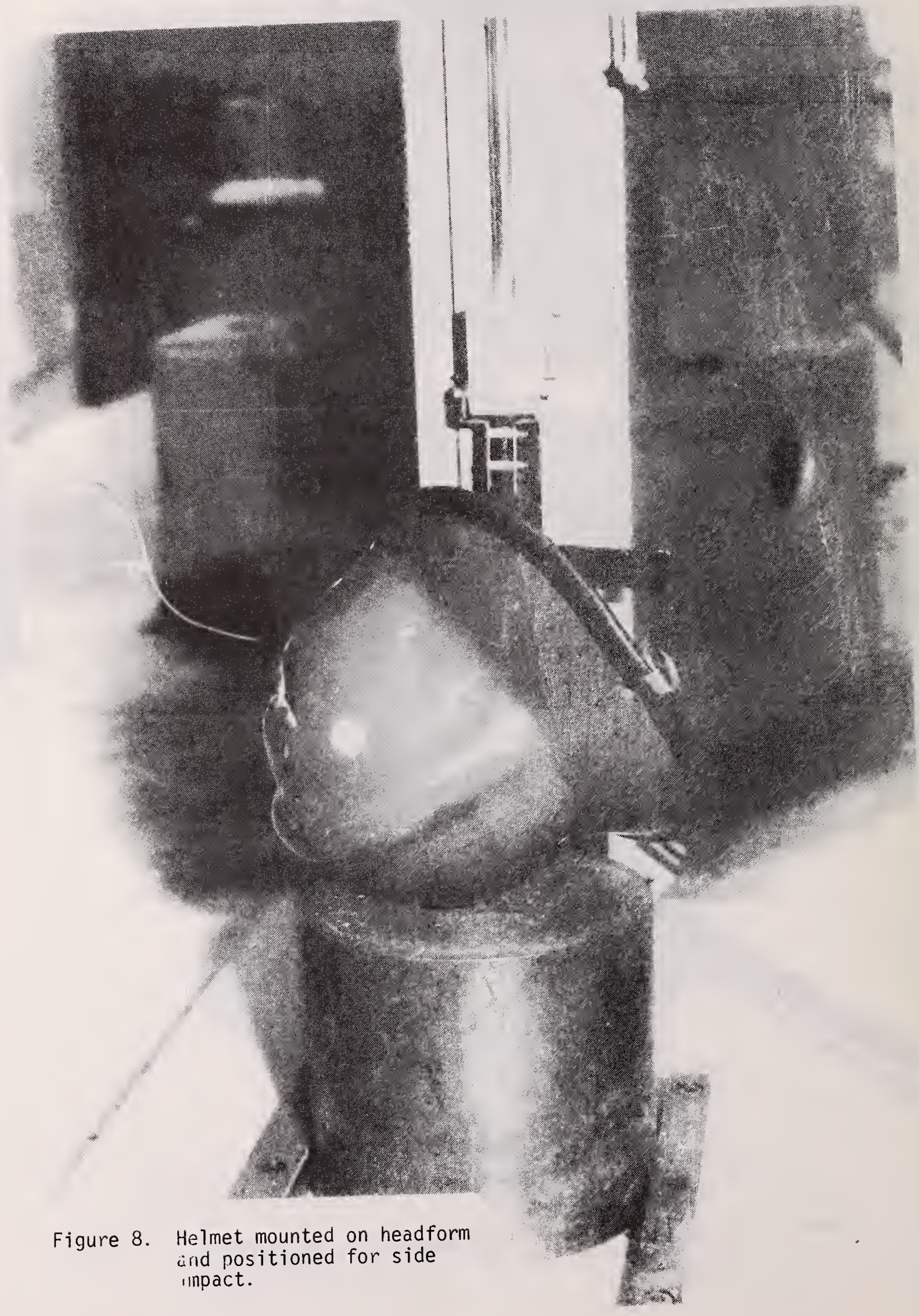




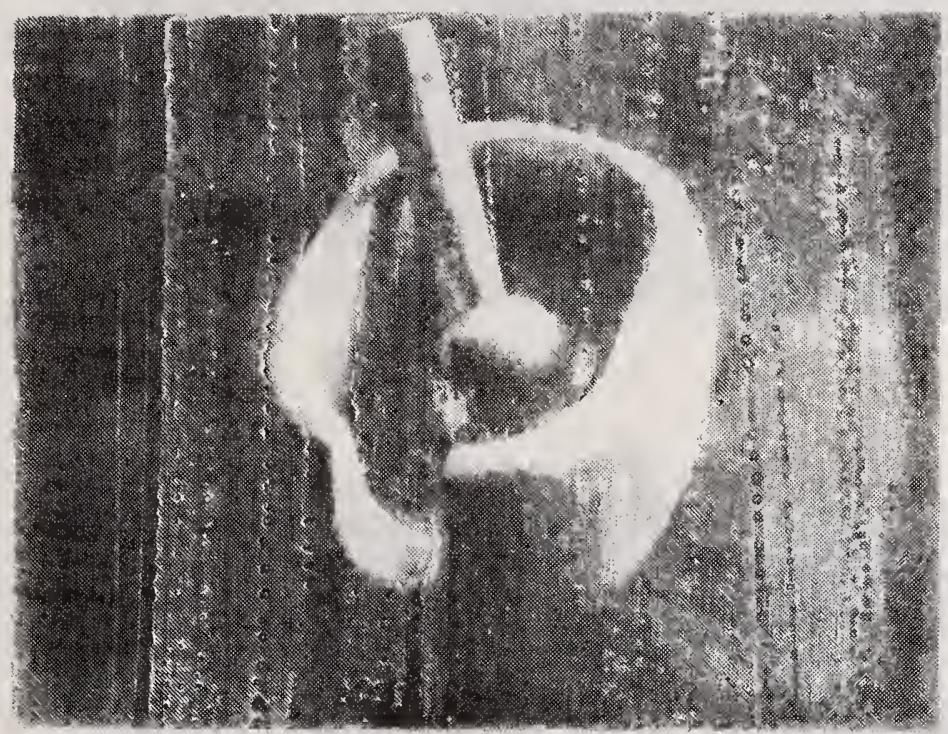

Figure 9. Metal headform (290) with ball and socket. 

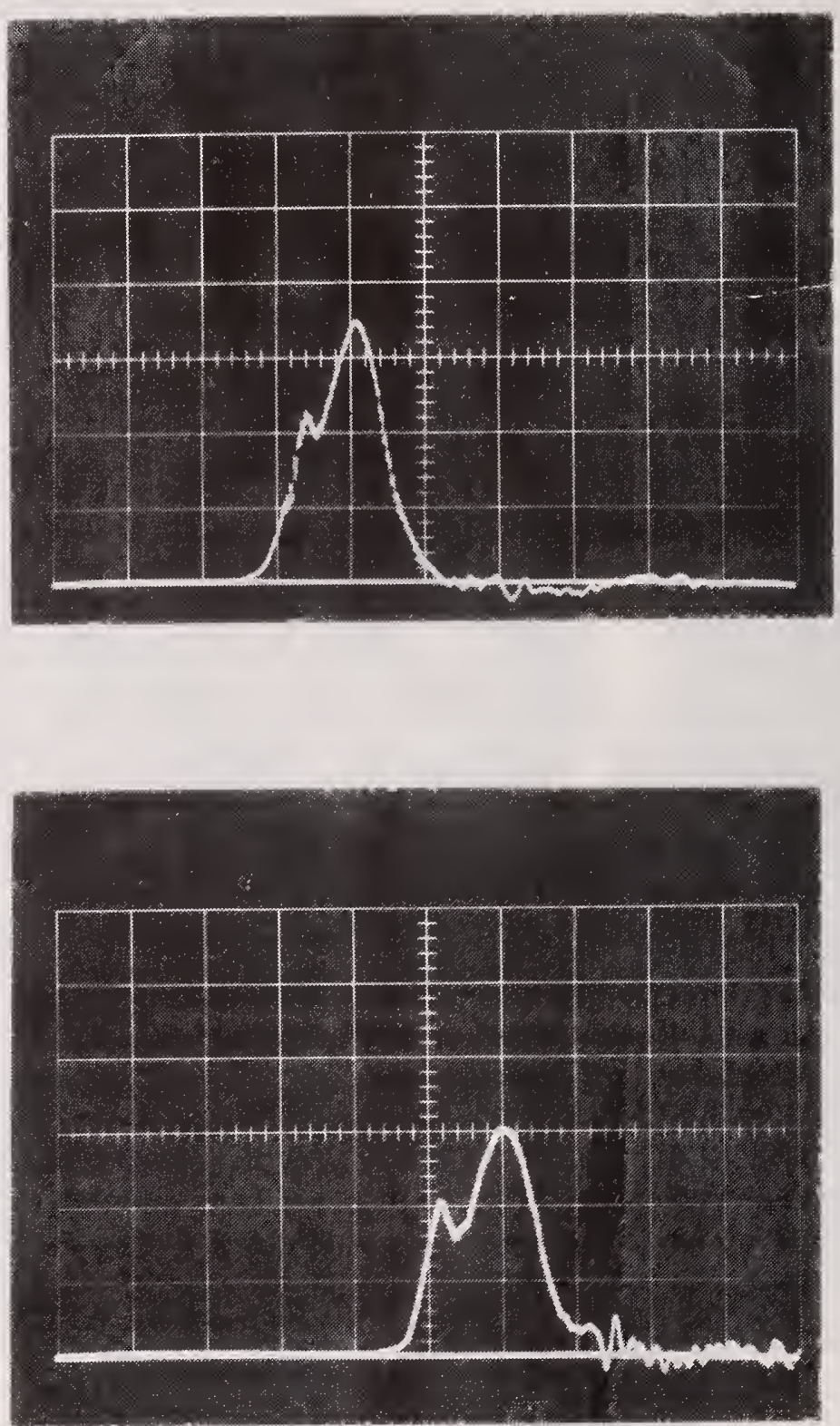

Figure 10. Typical acceleration-time curves ordinate: acceleration:- $100 \mathrm{~g}$ 's/division abcissa: time - i mil?isecond/division 


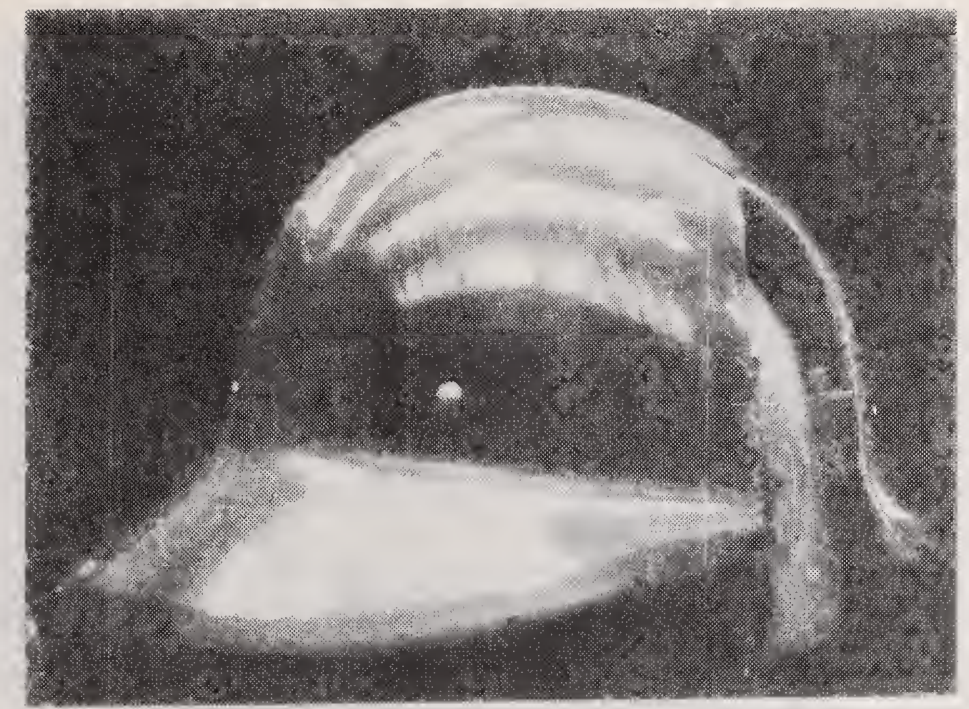

Figure 11. Fully lined fire helmet with glass reinforced plastic shel1.

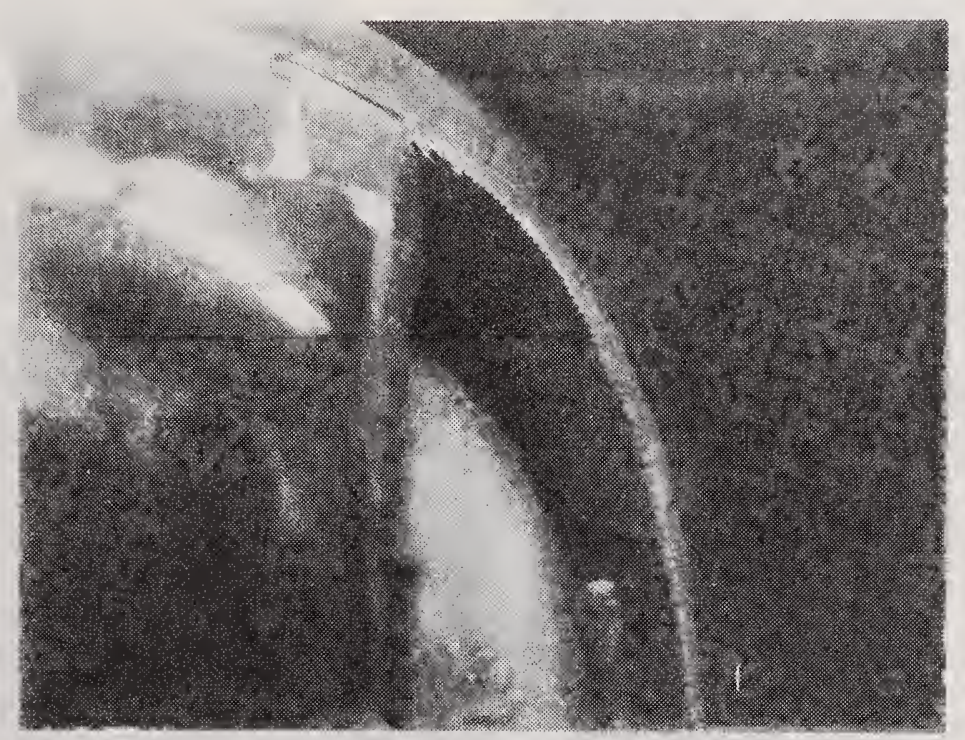

Figure 12. Close-up of cutaway section showing foamed plastic lining. 


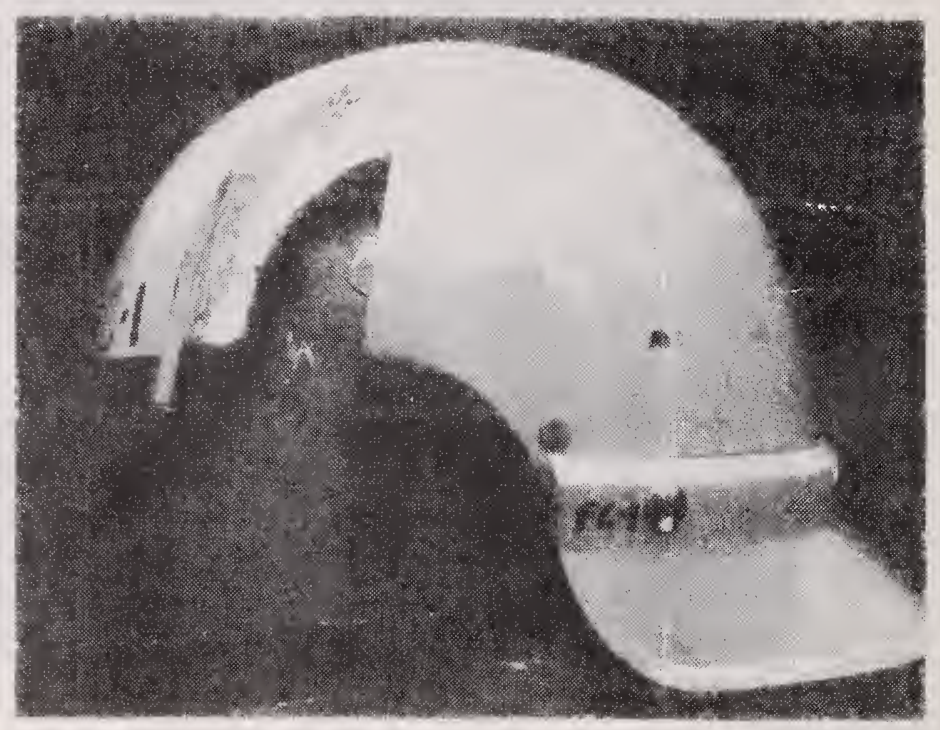

Figure 13. Fully lined fire helmet with polycarbonate shell.

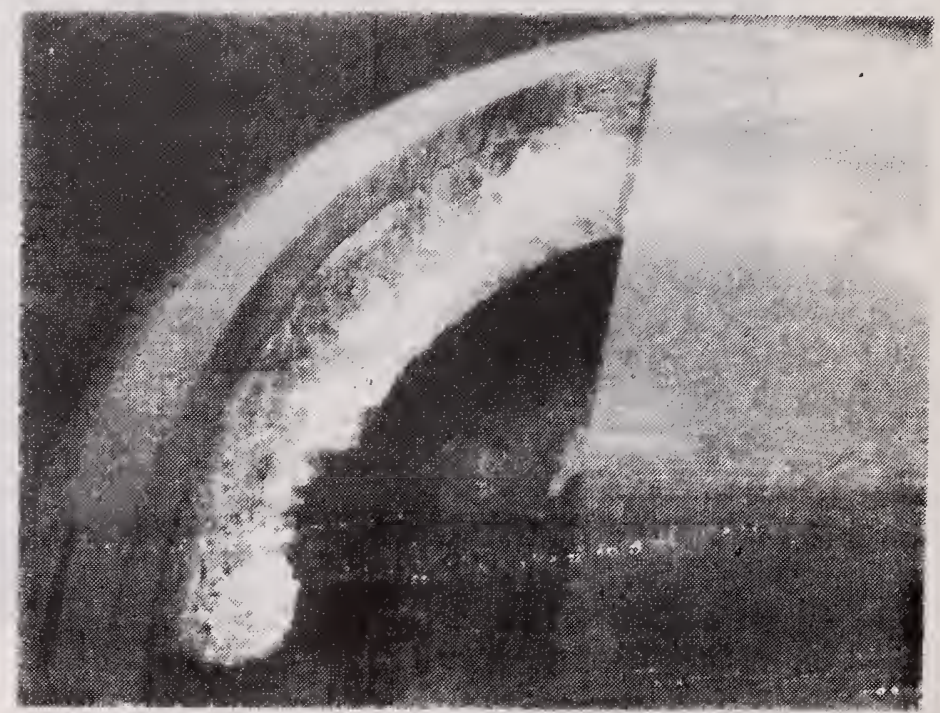

Figure 14. Closeup of cutaway section showing foamed plastic lining. 


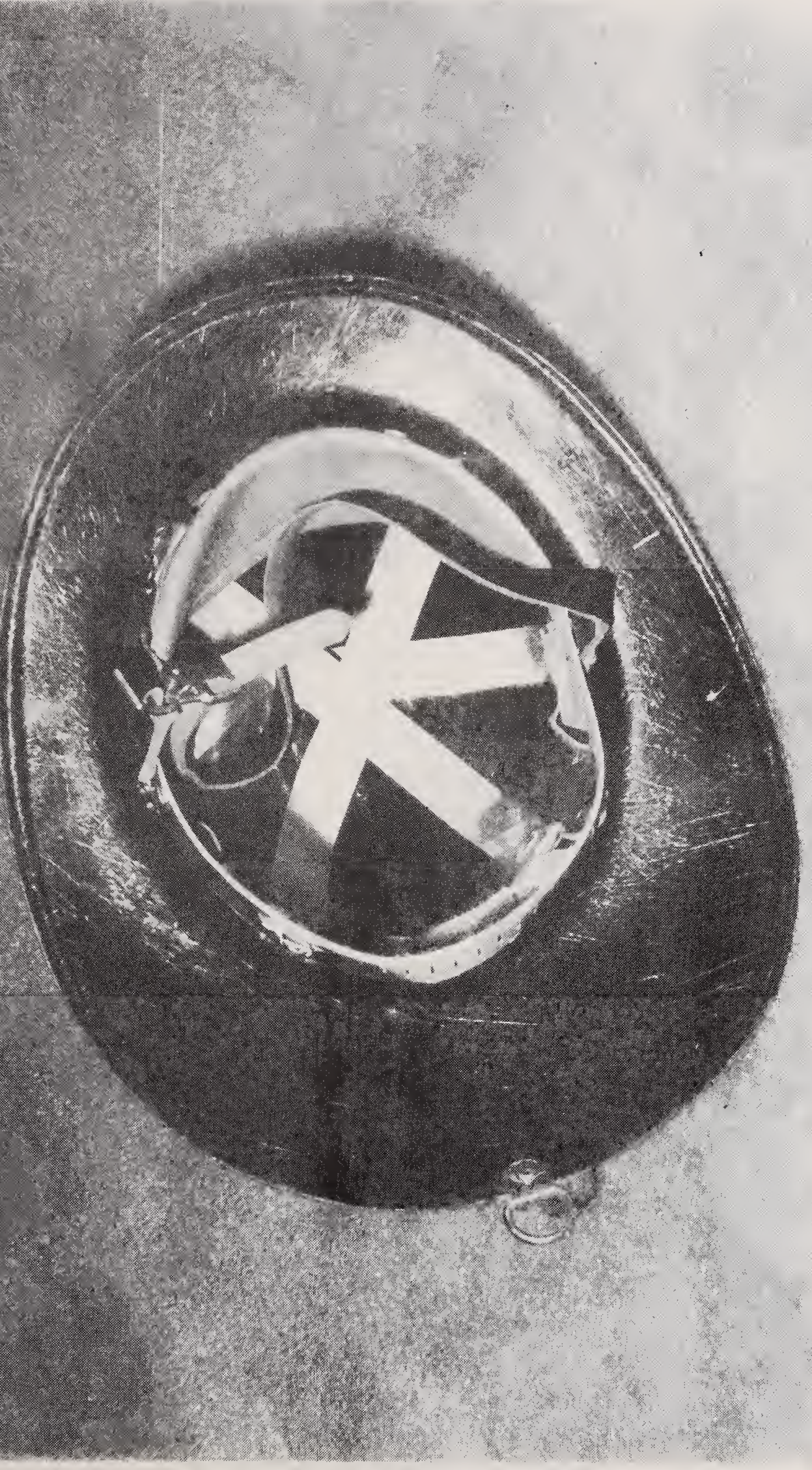

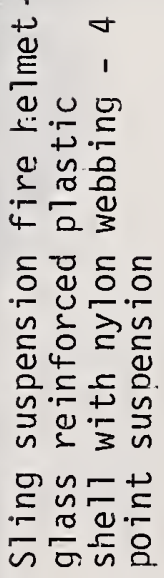

เి

ปั. 


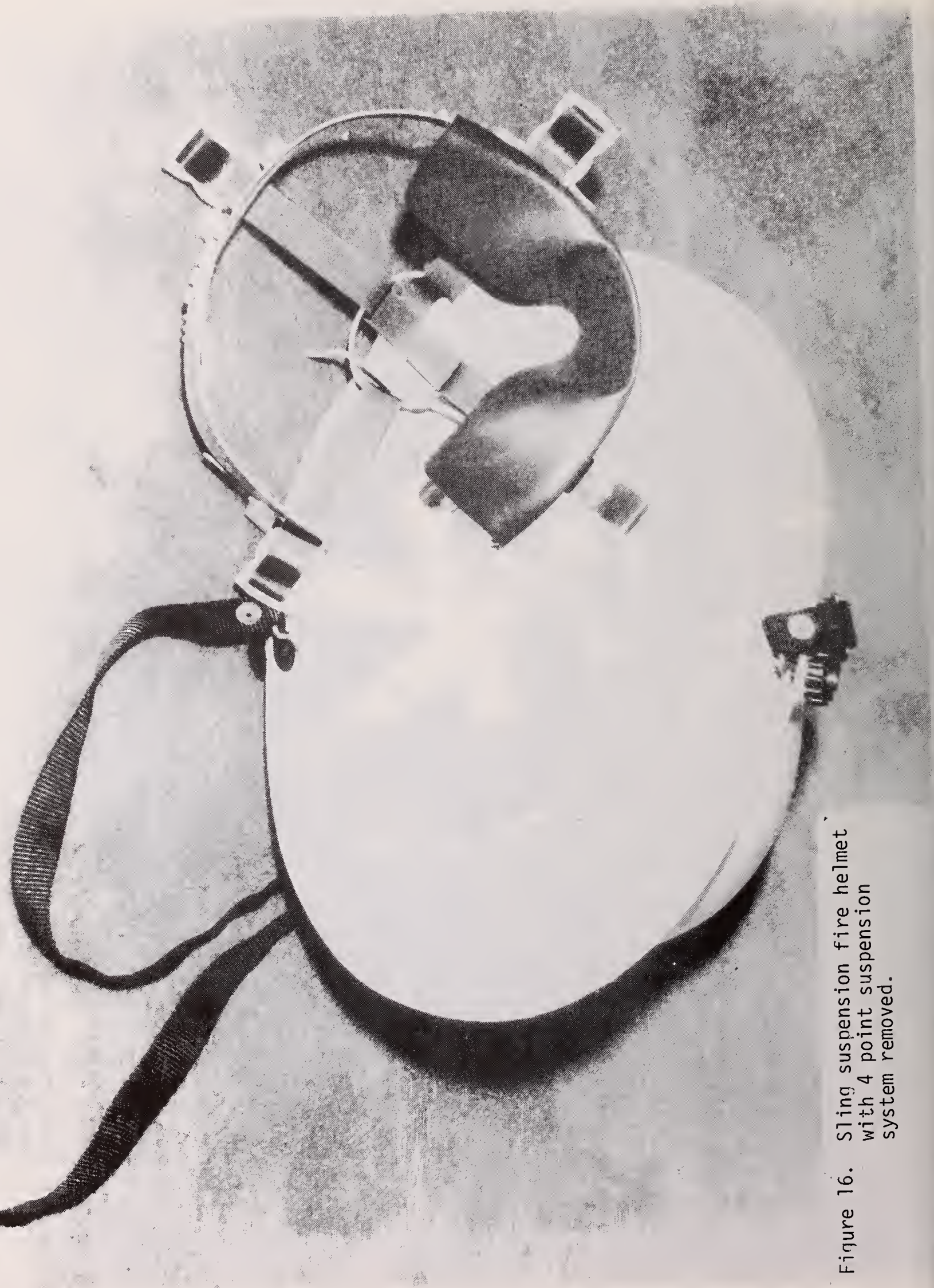





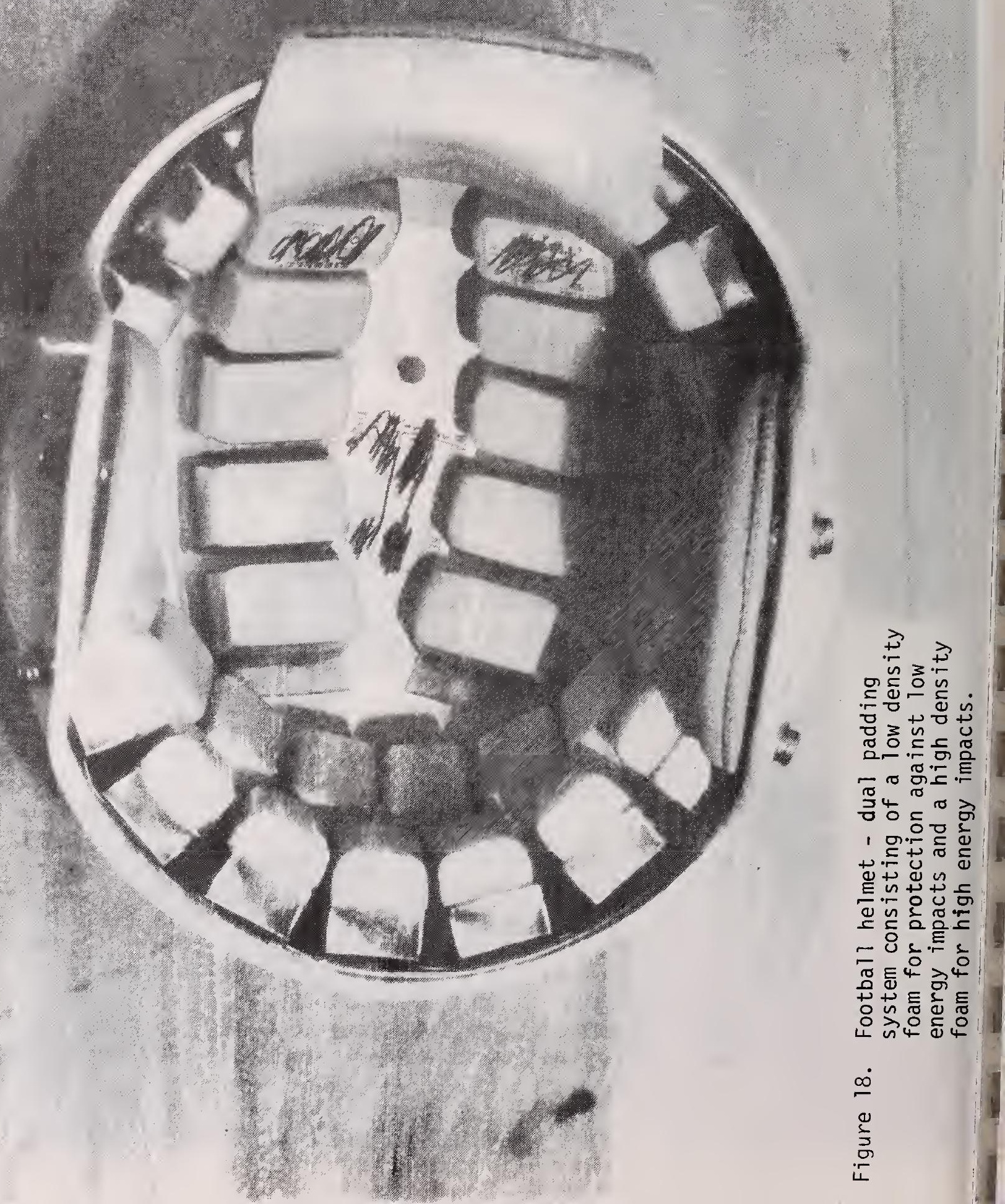




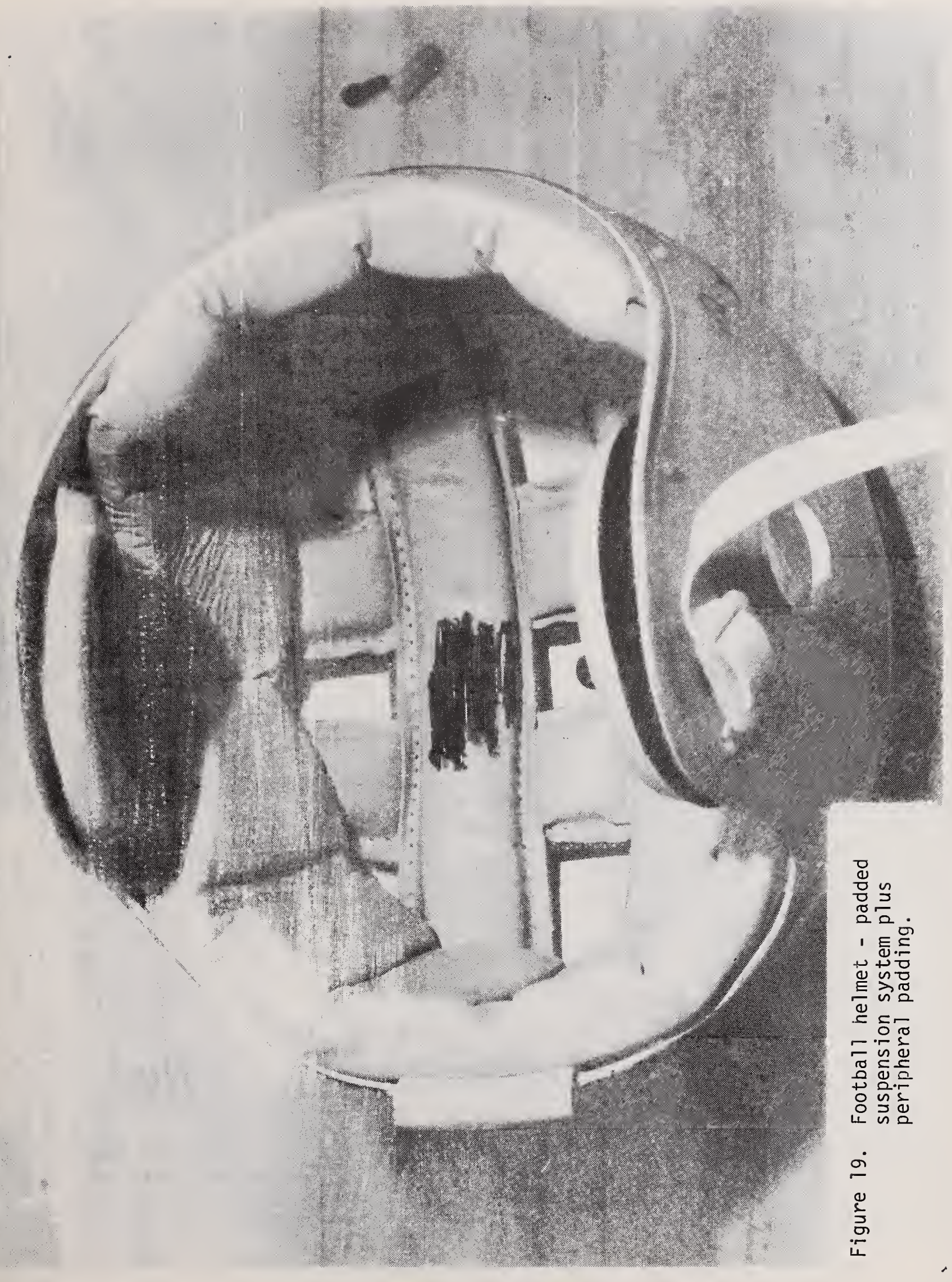




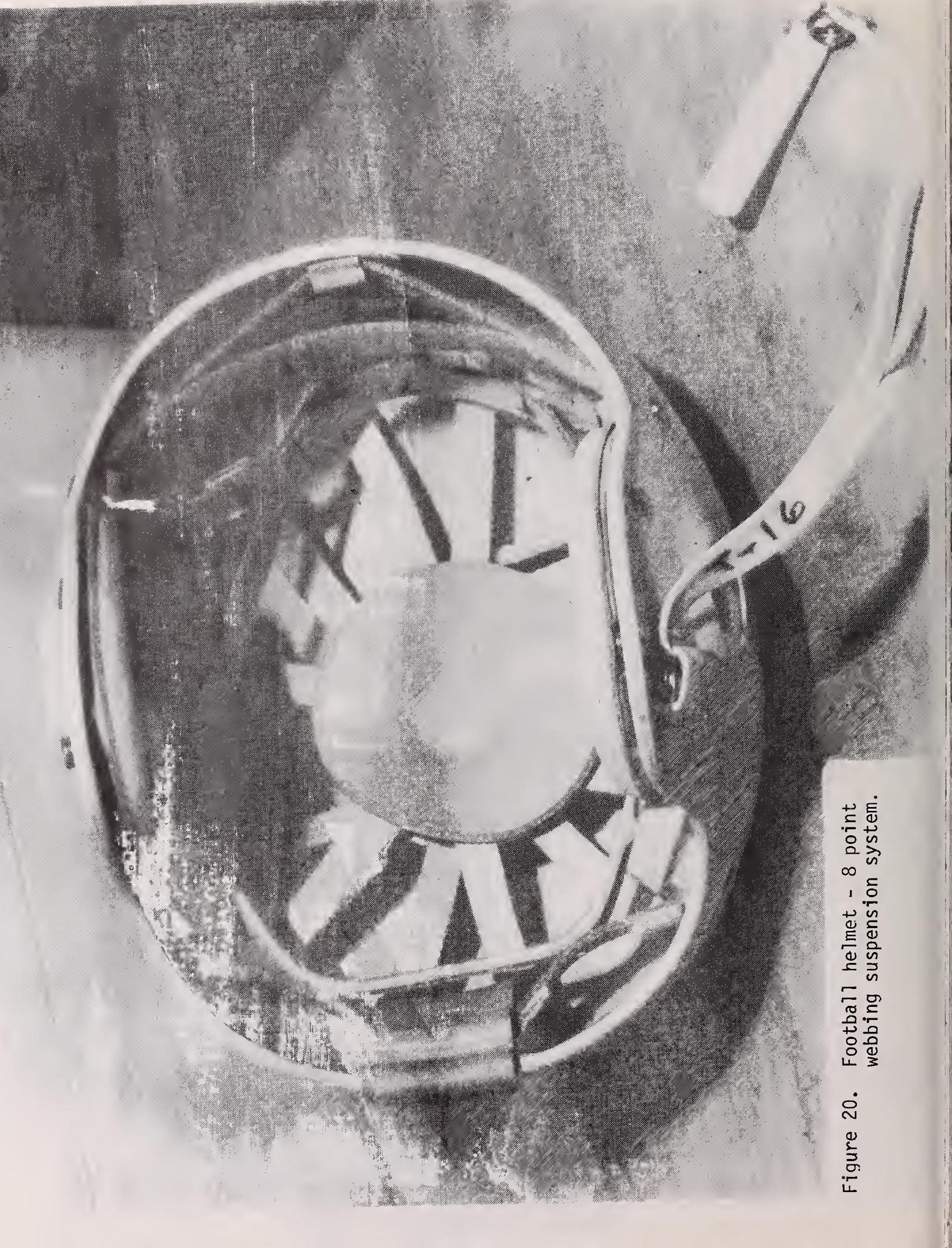




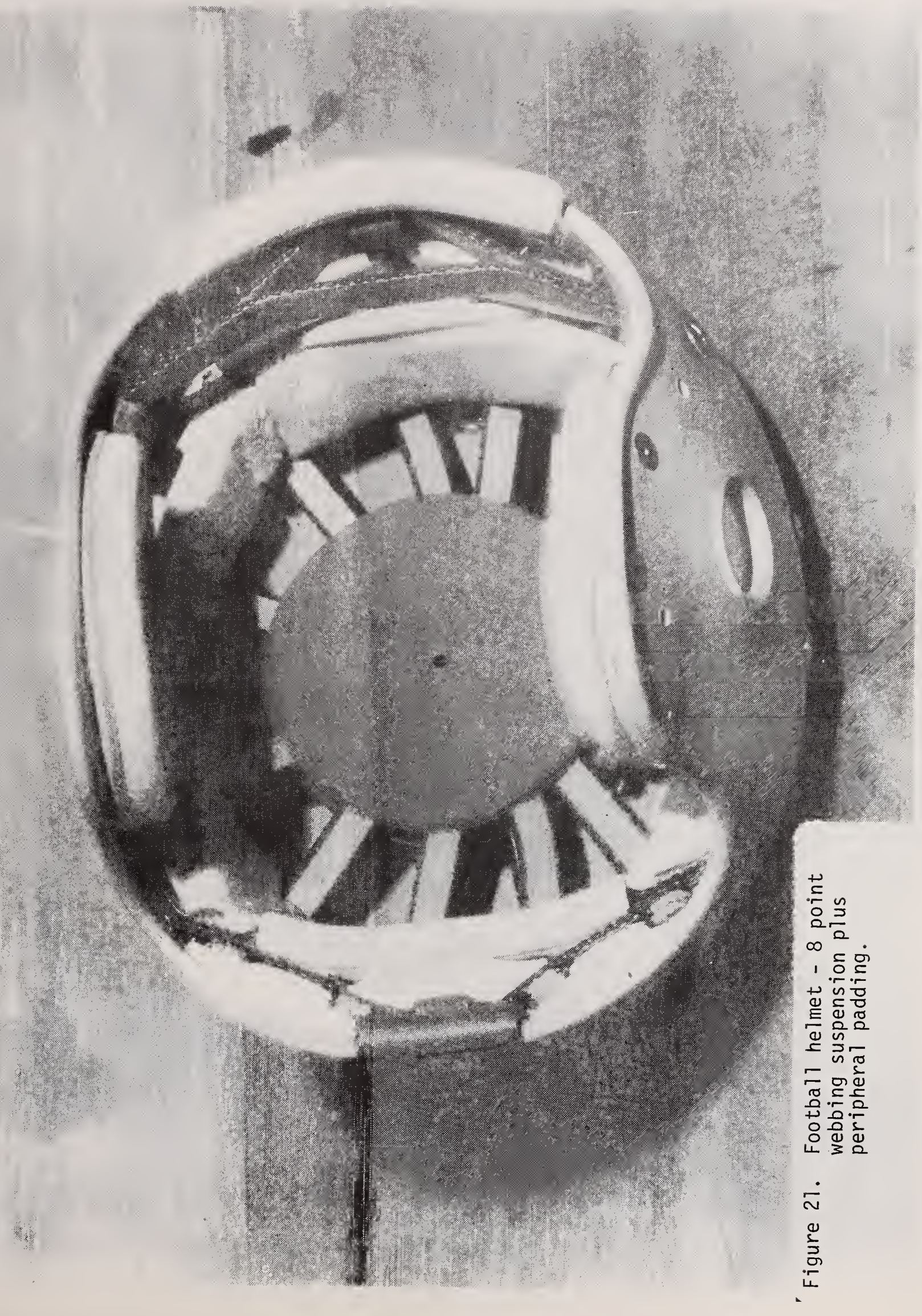




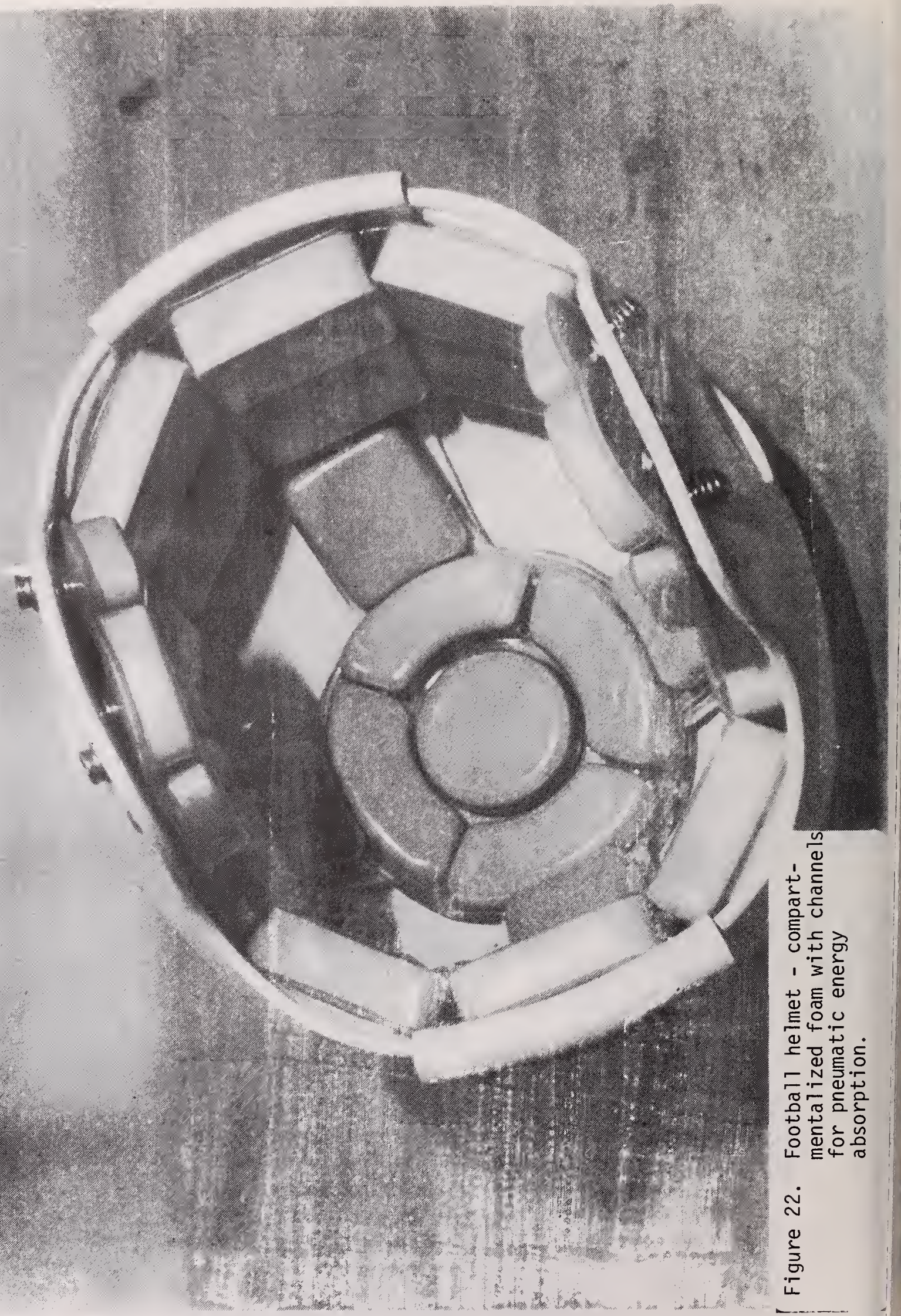




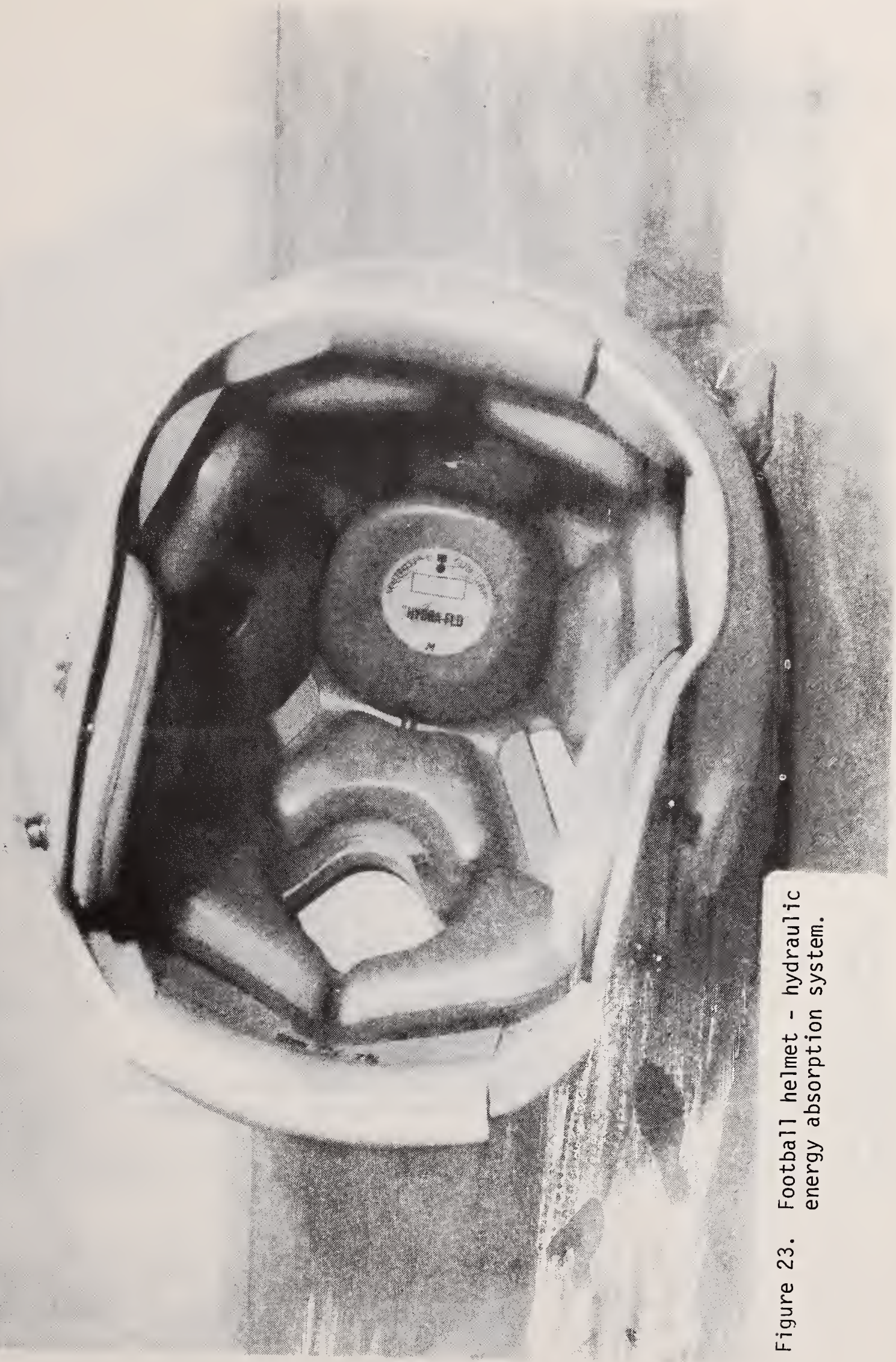




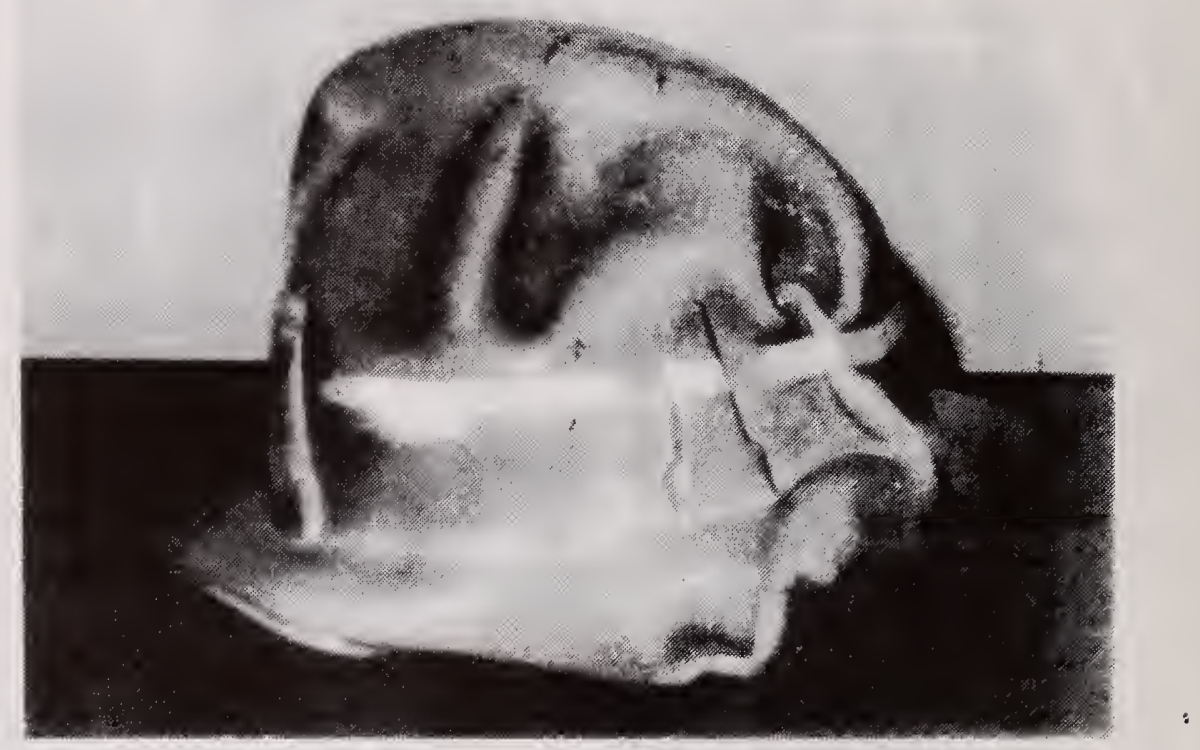

Figure 24. Heat damaged helmet recovered from injured firefighter. 


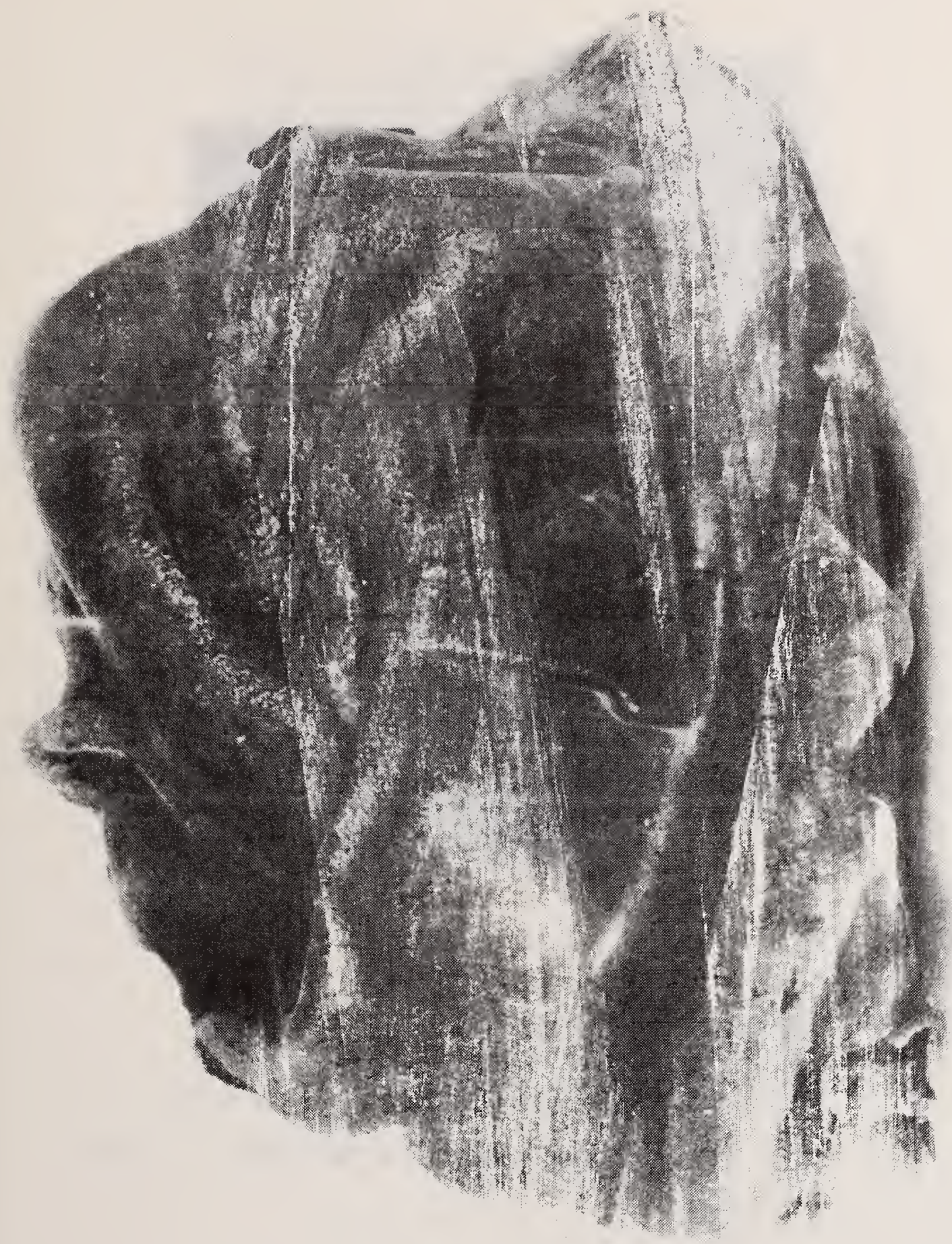

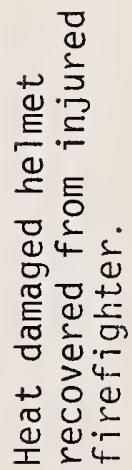

$\stackrel{\circ}{\sim}$

章 


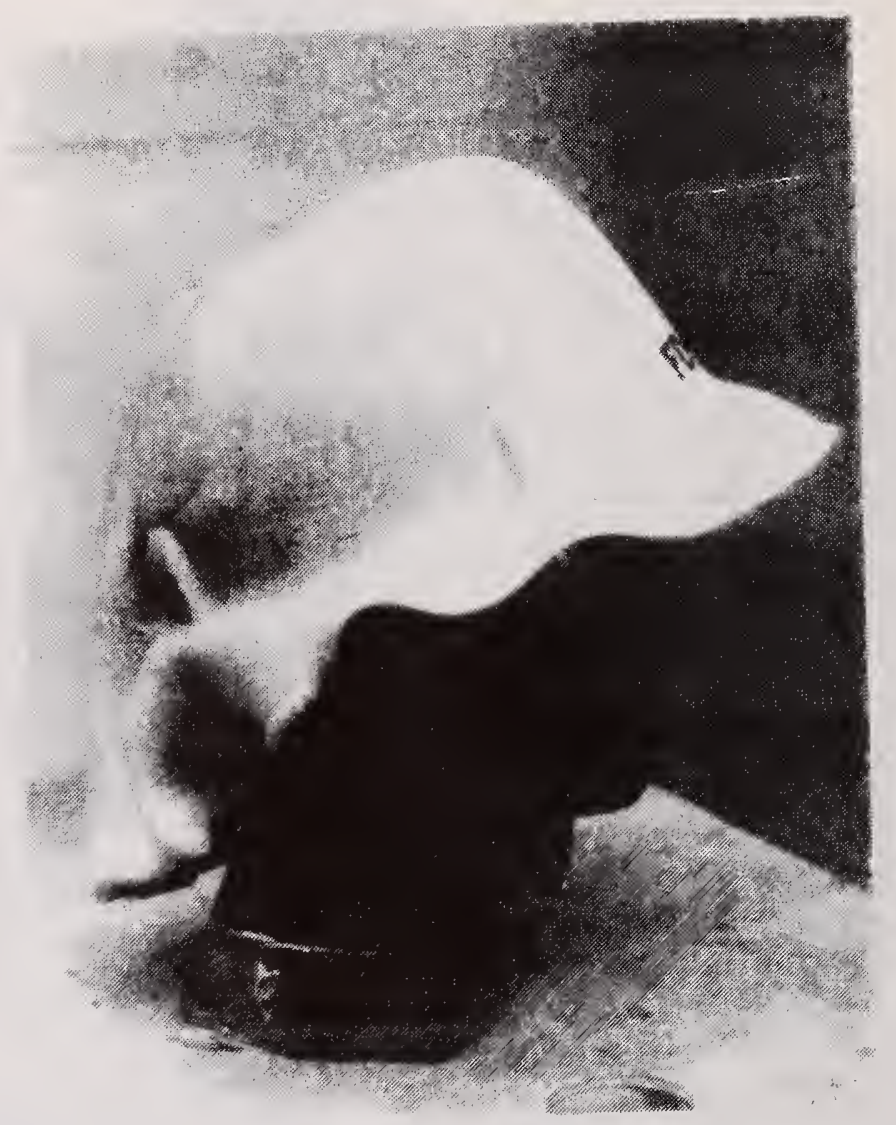

Figure 26. Polycarbonate shell (thin wall)

High Temperature Test (250 C - 3 min.) 


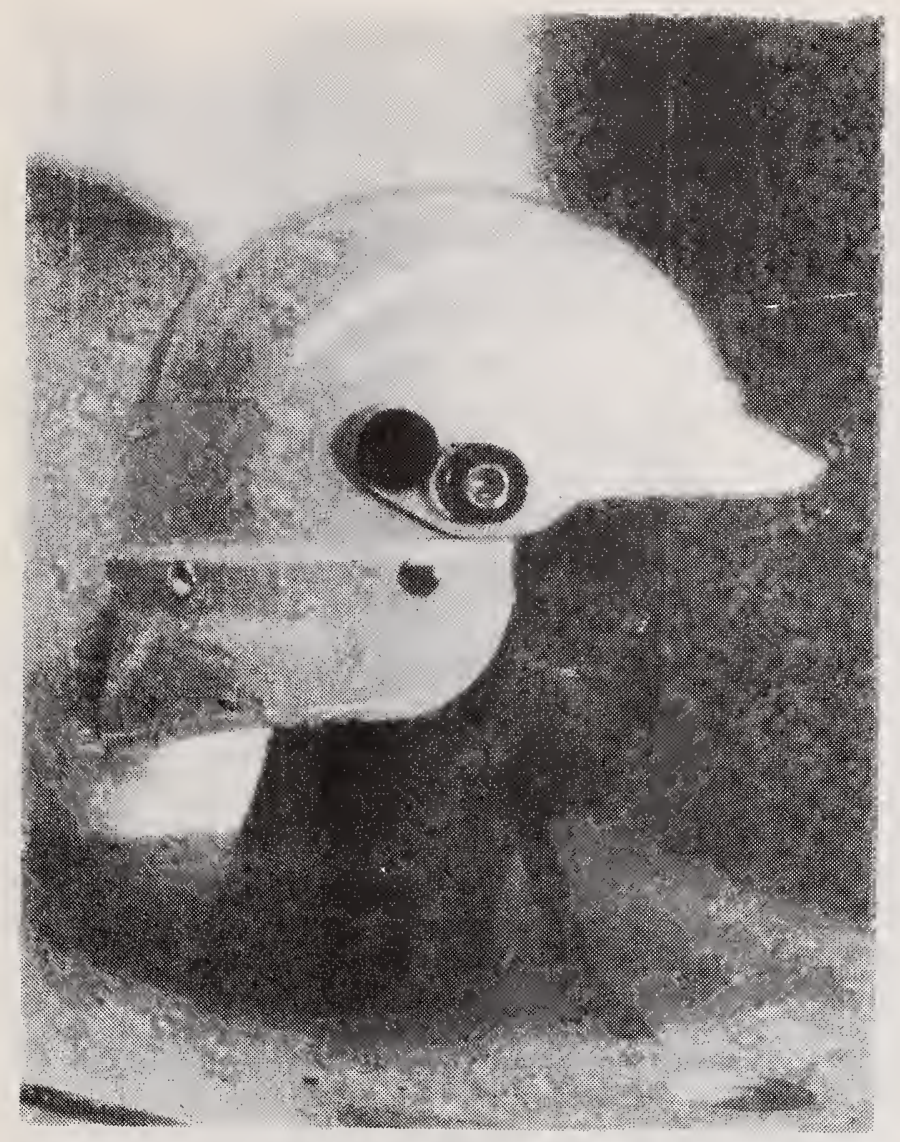

Figure 27. Polycarbonate shell (thick wa11) High temperature test (250 C $-3 \mathrm{~min}$. 


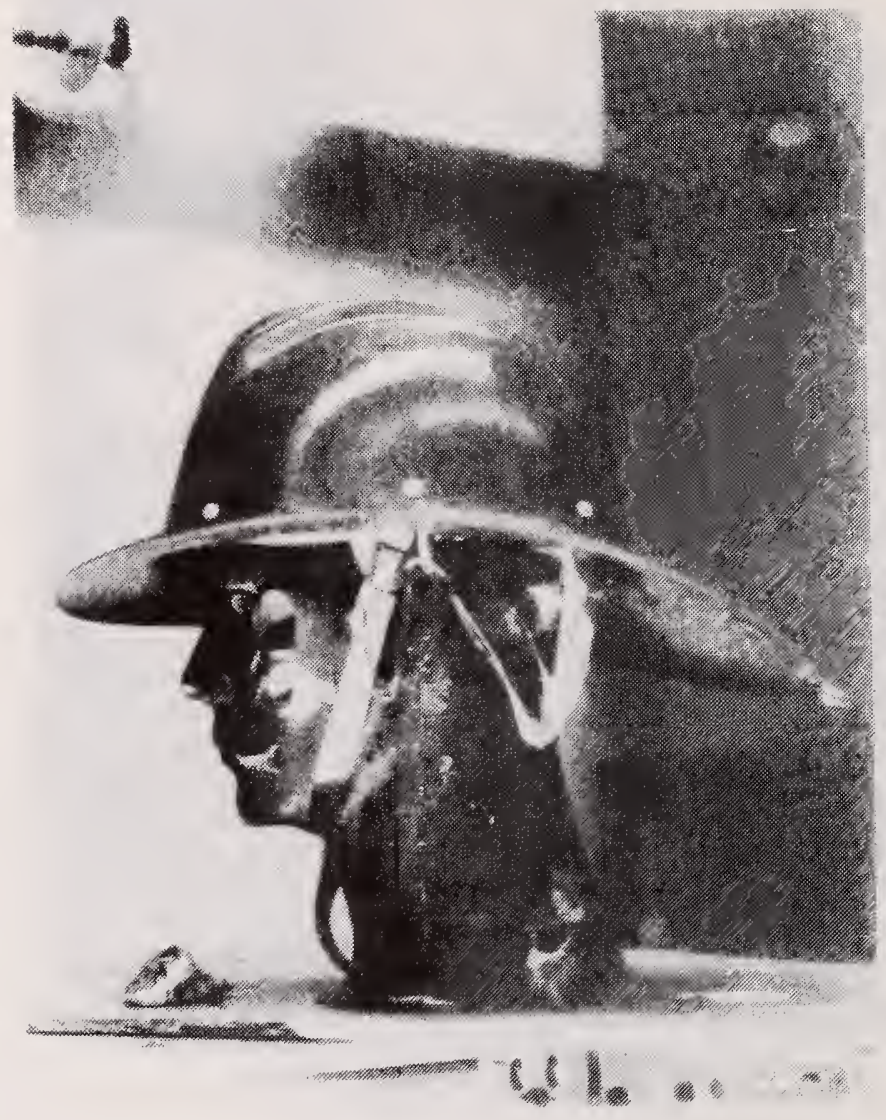

Figure 28. GRP shell

High temperature test (250 C - 3 min.) 


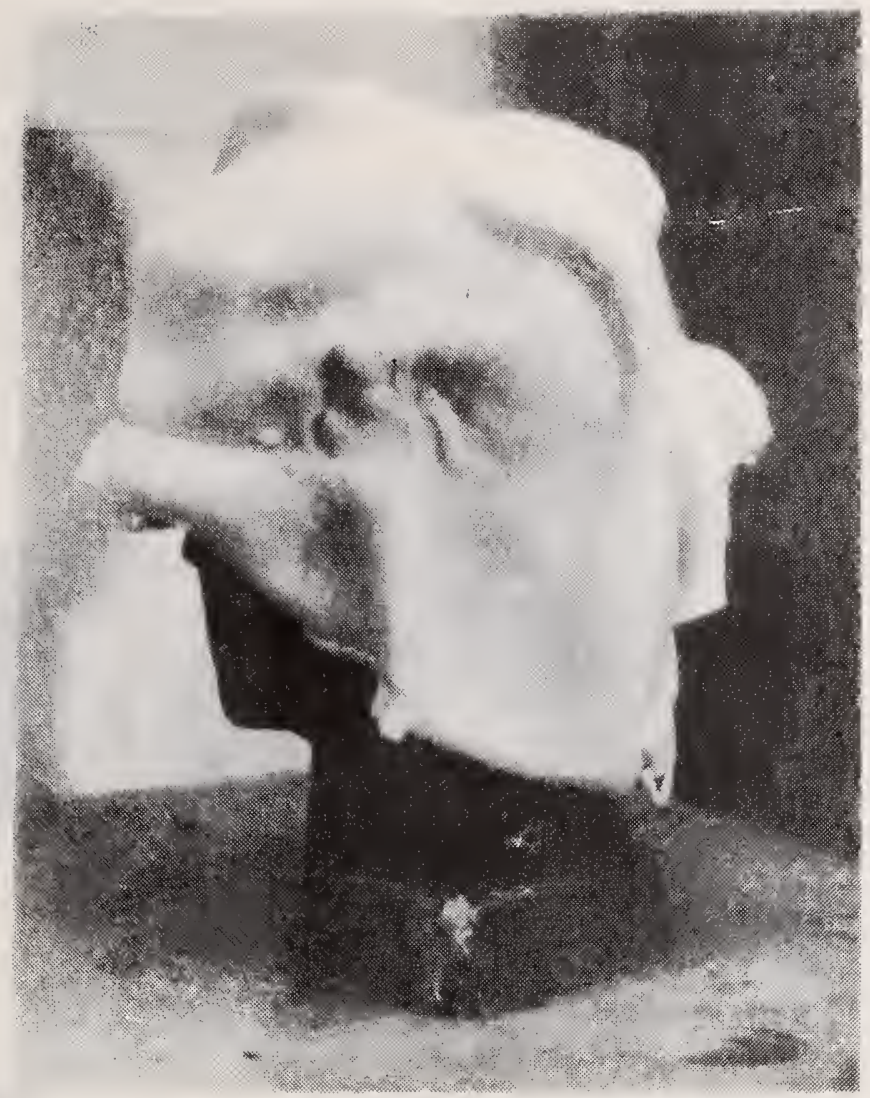

Figure 29. Polycarbonate shell (thin wa11)

High temperature test (250 C $-3 \mathrm{~min}$. 


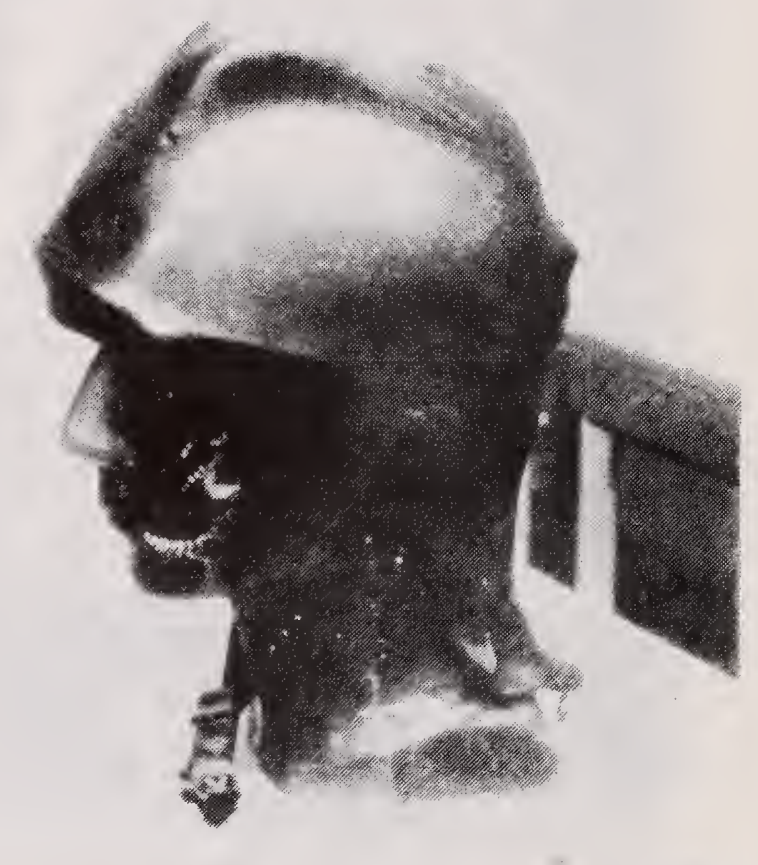

Figure 30. Polyethylene shell (discontinued)

High temperature test (250 C $-3 \mathrm{~min}$.) 


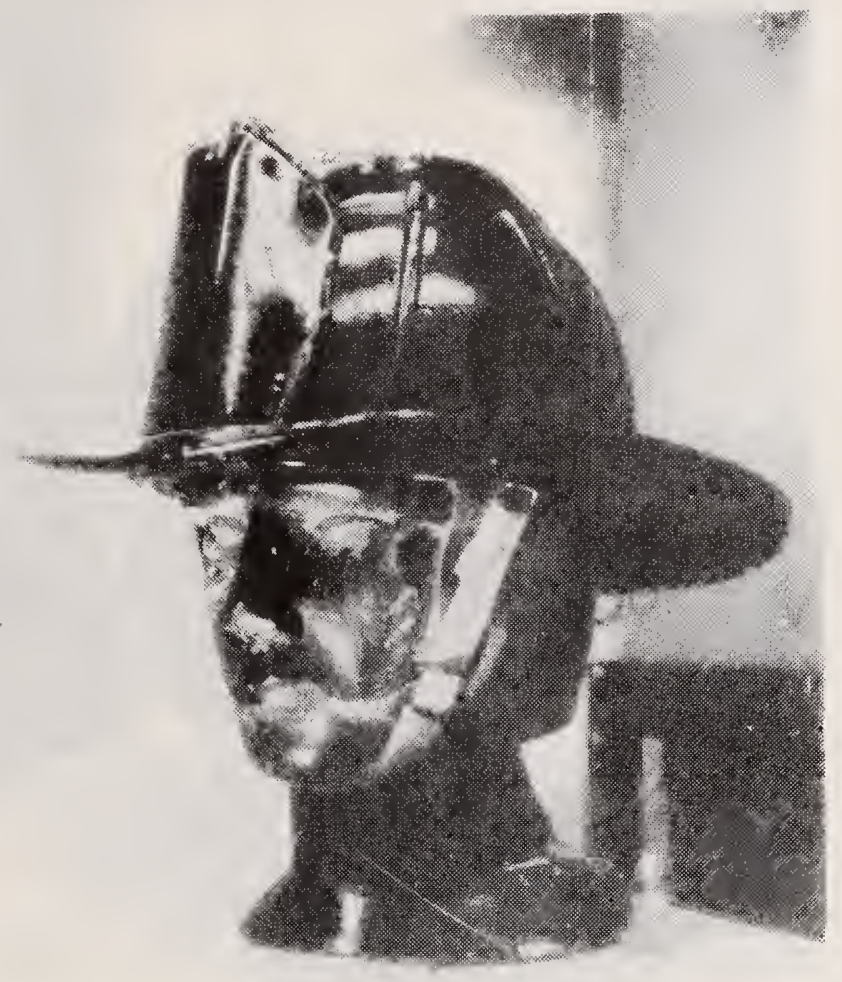

Figure 31. Leather shell

High temperature test (250 C -3 min.) 


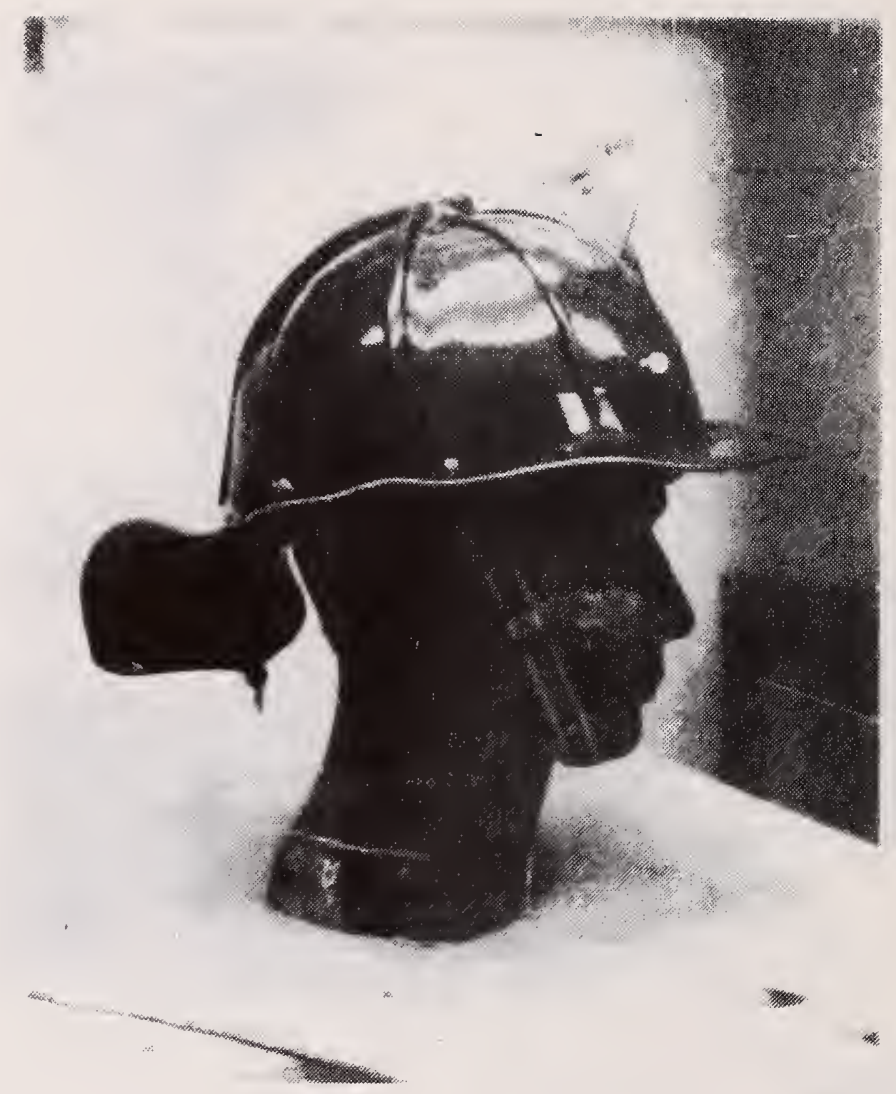

Figure 32. Polycarbonate shell (thick wall) High temperature test ( $250 \mathrm{C} .-3 \mathrm{~min}$. 


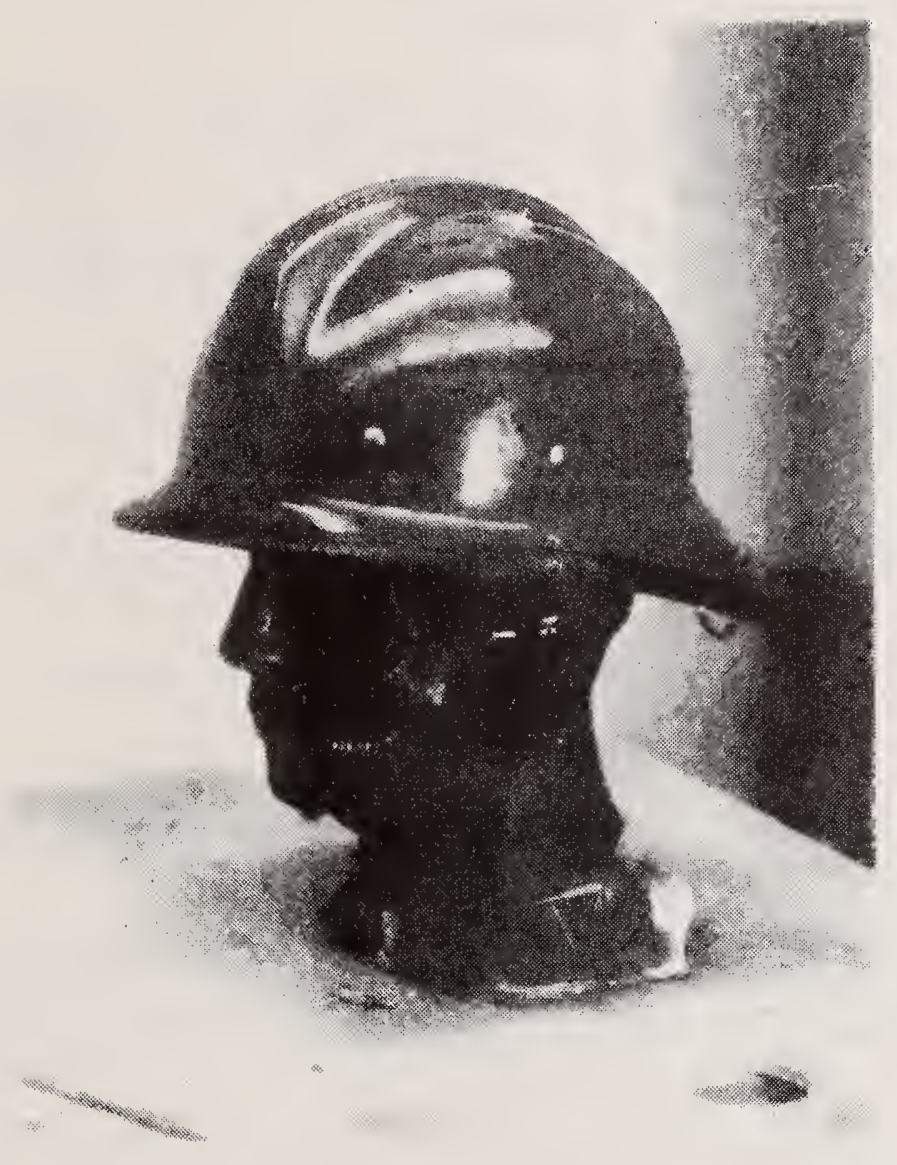

Figure 33. GRP she11

High temperature test (250 C -3 min.) 

1. Alexander, G., Dayton Ohio Fire Department, personal communication.

2. Granados, R., Washington, D.C. Fire Department, personal communication.

3. Douglas, J.M., Nahum, A.M., Roberts, S.B., Applications of Experimental Head Injury Research, 12th Stapp Car Crash Conf.

4. Thomas, L.M., Hodgson, V.R., and Gurdjian, E.S., "Skull Fracture and Management of Open Head Injury," Neurological Surgery, Vol. 2, W.B. Saunders Co., Phila., 1973

5. Gurdjian, E.S., and Schuwan, H.K., "Management of Skull Fracture Involving the Frontal Sinus," Annals of Surgery, Vol. 95, 1932

6. Gurdjian, E.S., Webster, J.T., Experimental and Clinical Studies on the Mechanism of Head Injury, Trauma of the Central Nervous System, Balto., Williams \& Wilkins, 1945, p. 48

7. Hilbourn, A.H.S., Mechanics of Head Injuries, Lancet, 2:438-441, 1943

8. Thomas, L.M., Mechanisms of Head Injury, Impact Injury \& Crash Protection, Springfield, I11., Charles C. Thomas, 1970, pp: 27-62

9. Sellier, K., Untershawcheidt, The Mechanics of the Impact of Violence on the Skull, Third International Congress of Neurological Surgery, Excerpts Medical International Congress Services No. 110. Copenhagen, Excerpts Medical Foundation, p. 87, 1965

10. Hodgson, Impact Injury and Crash Protection, Springfield, I1l., Chas. C. Thomas, 1970

11. Gurdjian, E.S., Lissner, H.R. and Patrick, L.M., "Protection of the Head and Neck in Sports," JAMA, Nov. 3, 1962, Vol. 182, pp. 509-512

12. Gadd, C.W., "Use of a Weighted-Impulse," Proceeding of 10th Stapp Car Crash Conf., Society of Automotive Engineers, New York, 1966, pp. 164-174

13. Versace, J., "A Review of the Severity Index," Proceedings of the 15th Stapp Car Crash Conference, Society of Automotive Engineers, New York, pp. 771-796, 1971

14. Newman, J.A., On the Use of the Head Injury Criterion (HIC) in Protective Headgear Evaluation, Proceedings of the 19th Stapp Car Crash Conference, Society of Automotive Engineers, New York, 1975 
15. Standard Method of Impact Test and Performance Requirements for Football Helmets, National Operating Committee on Standards for Athletic Equipment, Inc., Sept. 1973

16. Motorcycle Helmets, Federal Motor Vehicle Safety Standard FMVSS 218, National Highway Traffic Safety Administration, Federal Register 38 F.R. 22390, Aug. 20, 1973

17. "Specification for Protective Headgear for Vehicular Uses," American National Standards Institute, 290.1-1971

18. Firefighter Mortality Report, International Association of Firefighters, 1750 New York Ave., NW., Wash., D.C. 20006

19. Berger, Robert E., Considerations in Developing Test Methods for Protective Headgear, NBSIR76-1107, August 1976

20. Hodgson, V.R., Mason, M.W., and Thomas L.M., "Head Model for Impact," Proceedings of 16th Stapp Car Crash Conference, P. 45, New York, Society of Automotive Engineers, Inc., 1972

21. Andrews, L.M., Football Helmet Tests: Comparison Using Both NOCSAE and ASTM Recommended Test Methods, National Bureau of Standaids letter report to the Consumer Product Safety Commission, March 3, 1976

22. McManus, Laurance R., Report to ASTM F-8 Committee on Sports Equipment and Facilities

23. Safety Requirements for Industrial Head Protection, ANSI 289.11969, American National Standards Institute, Inc., New York, 1969

24. Standard for Protective Headgear, Snell Memorial Foundation, G.G. Snively, Dir., 761 Laurel Dr., Sacramento, CA, 1975

25. Unpublished report, Mine Safety Appliance Co.

26. Pettican, Richard, Mine Safety Appliance Company, Pittsburgh, PA, personal communication

27. Huffines, Carrol1, Baltimore County Fire Department, personal communication

28. Abeles, DelVecchio, Himel, A Firefighter's Integrated Life Protection System, Phase I Report, Sept. 1974, Fire Dept. of the City of New York, contract No. 219454, May 1973, Gramman Aerospace Corp., Bethpage, NY 11714

29. Burgess, Wm. A., Fourth Summary Progress Report, NFPCA Grant 76010, Aug. 31, 1976 
30. Simms, Hinkley, "Protective Clothing Against Flames and Heat," British Information Services, 45 Rockefeller Plaza, New York, NY

31. Dupont, Harry B., How Much Heat Can Firemen Endure, Fire Engineering, Feb. 1960 , p. 122 

APPENDIX 1. Test Results 



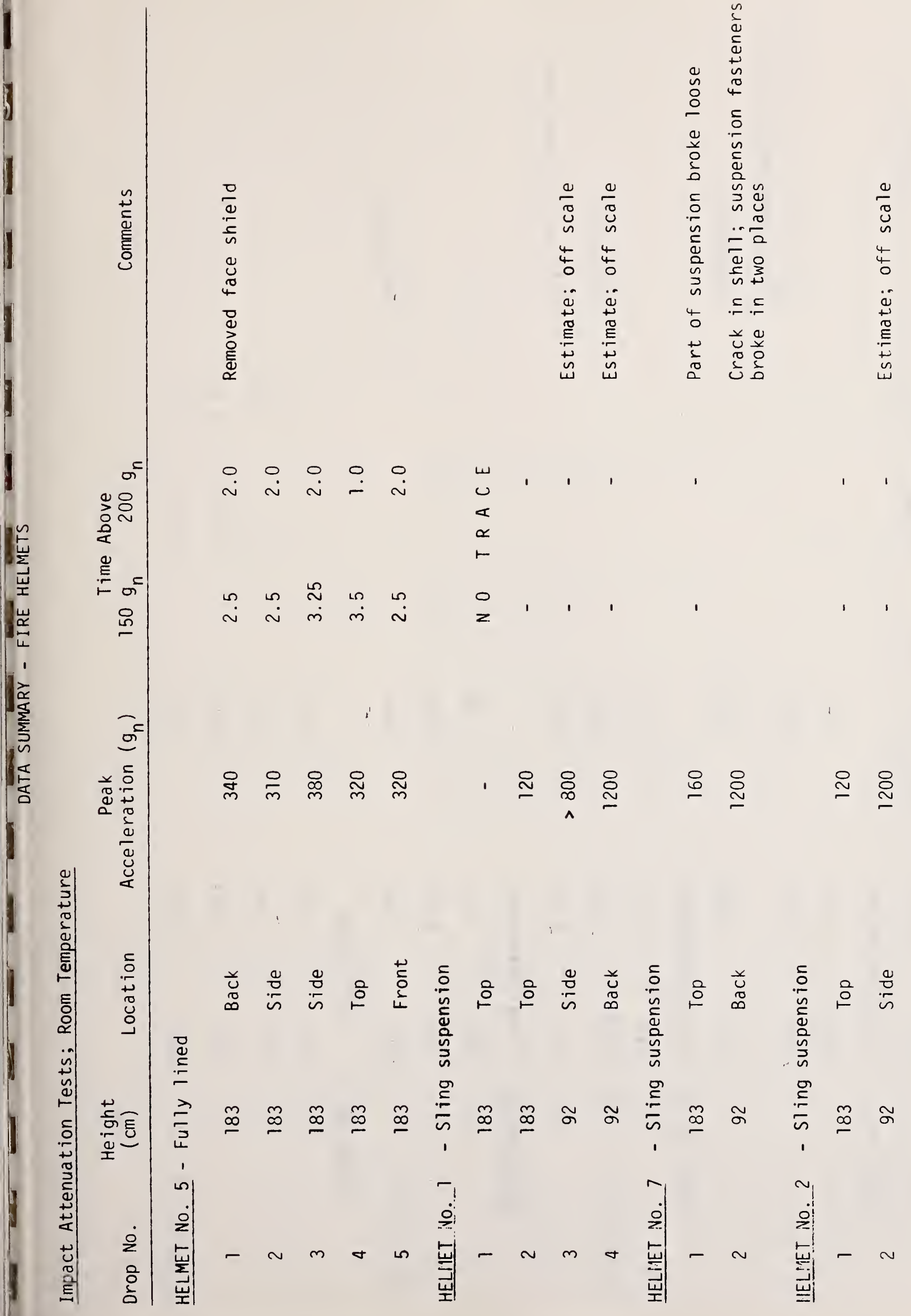




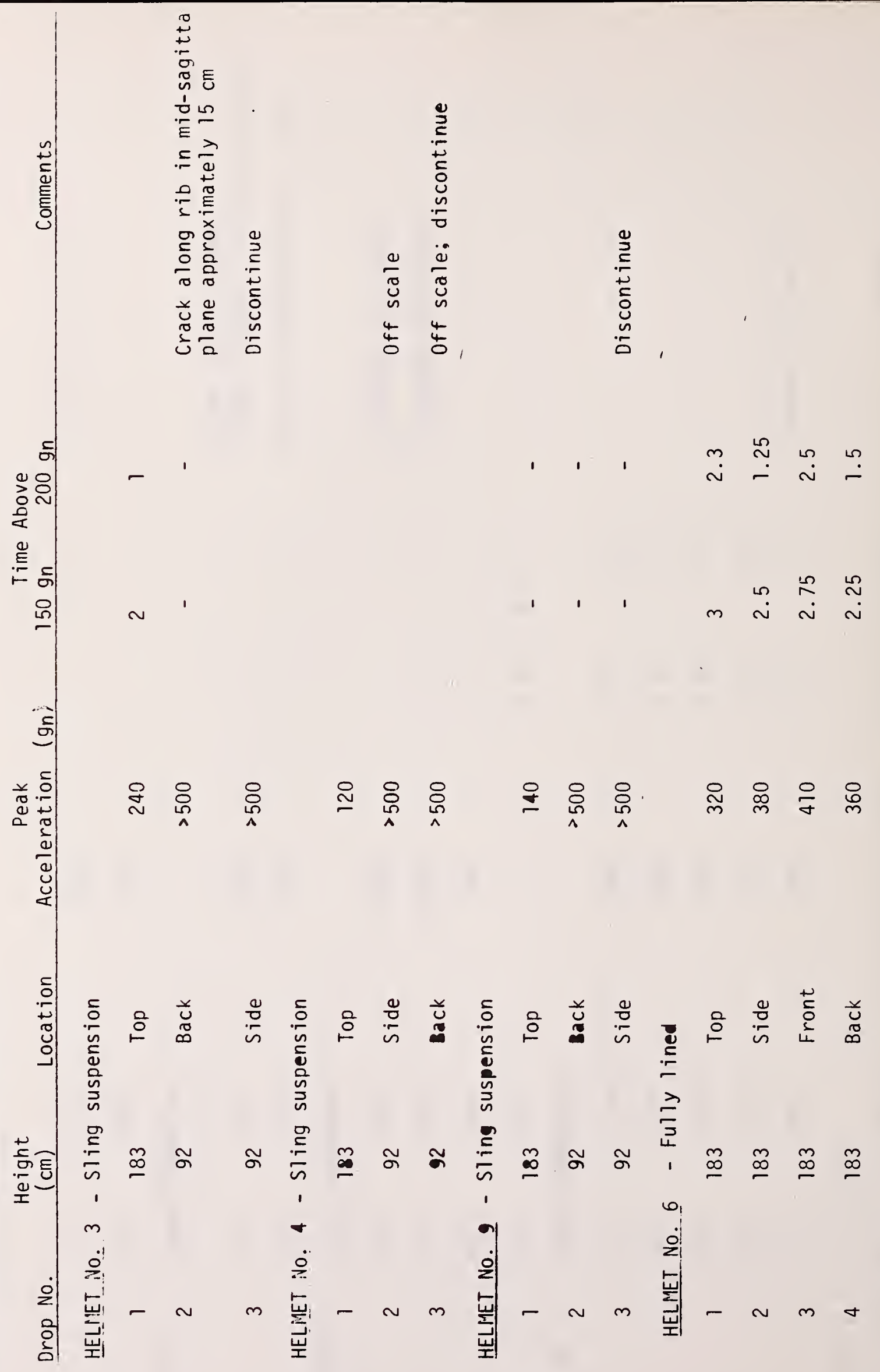


$>8$

$\stackrel{\sim}{\sim} \stackrel{\sim}{\sim}$

$\stackrel{\sim}{\sim} \stackrel{\sim}{\sim} \sim$

운

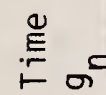

용

$\because \begin{array}{cccc}\sim & 0 & 0 & 0 \\ \sim & \sim & \sim & \sim\end{array}$

$\stackrel{\sim}{\sim} \underset{\sim}{\sim} \stackrel{\infty}{\sim}$

유 요요 율

욜 을 율

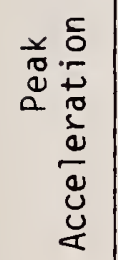

\begin{tabular}{c}
5 \\
0 \\
\pm \\
0 \\
0 \\
\hline
\end{tabular}

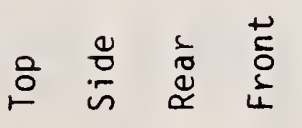

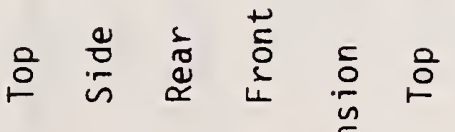

¿

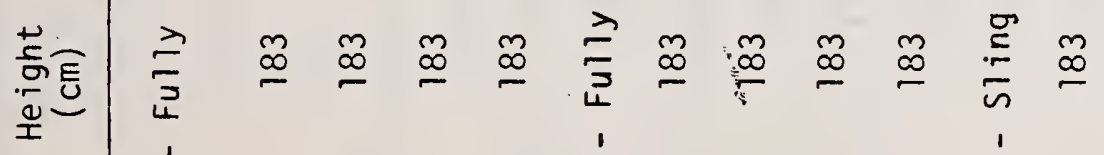

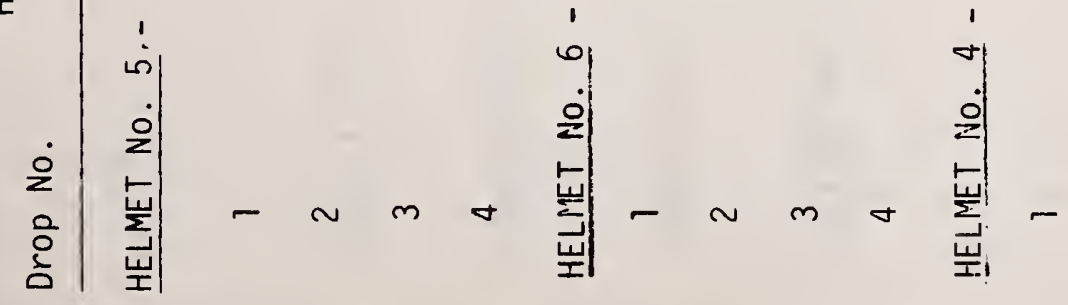


$\frac{0}{0}$

$\begin{array}{lll}\frac{1}{\pi} & 0 & 0 \\ 0 & 0 & 0 \\ 4 & \ddots & 4 \\ 4 & 4 & 4\end{array}$

$\begin{array}{llll}n & 0 & \infty & +\end{array}$

$\begin{array}{lll}\sim & \infty & +\end{array}$

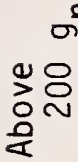

$\stackrel{\mathscr{E}}{:}=$

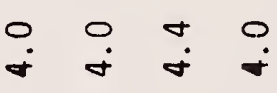

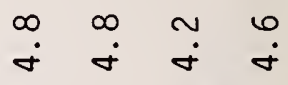

응

요

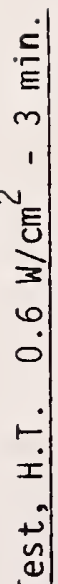

0

$\bigcap_{\wedge}$

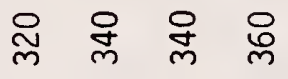

8
เ
1

\&

옷

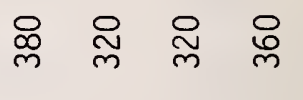

잇

5
$\stackrel{0}{ \pm}$
0
0

다

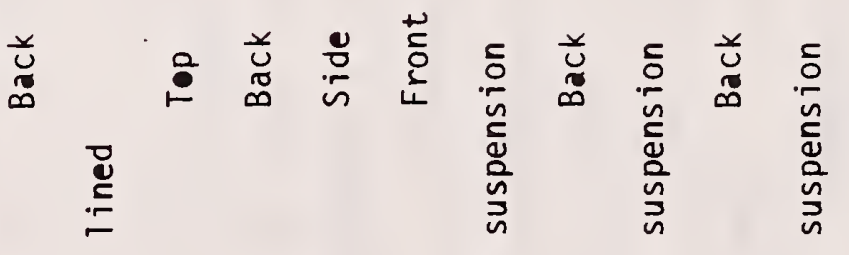

弟

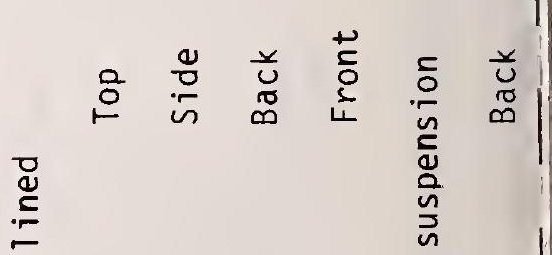

蒙鞄

气̃

n

$\approx \underset{\overline{1}}{2} \infty$

$\infty \cong \infty$

早 
을

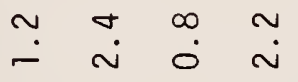

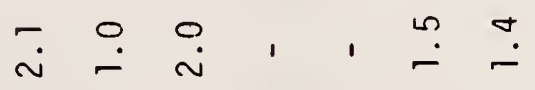

吉

$\stackrel{\oplus}{\sim} \stackrel{\sim}{\sim} \stackrel{m}{\sim}$

$\begin{array}{llllll}\infty & 0 & \dot{N} & \sim & \sim & \sim \\ \sim & \dot{\sim} & \dot{m}\end{array}$

क्षे।

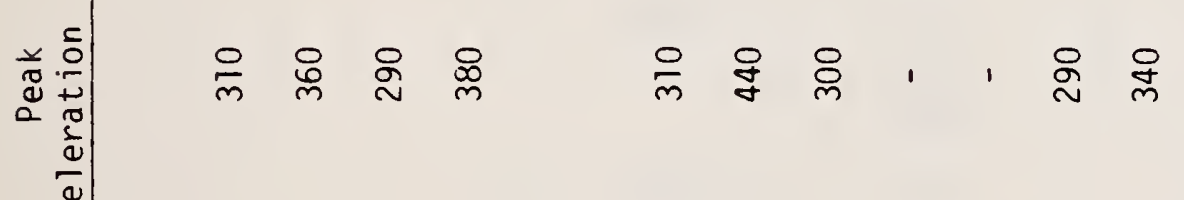

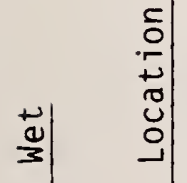

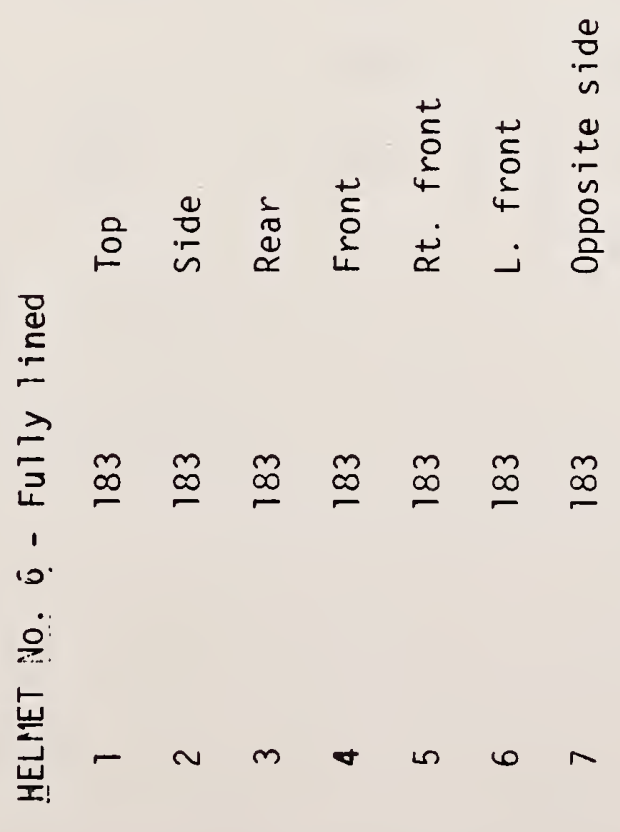



Data Summary - Fire Helmets

Penetration Tests, R.T.

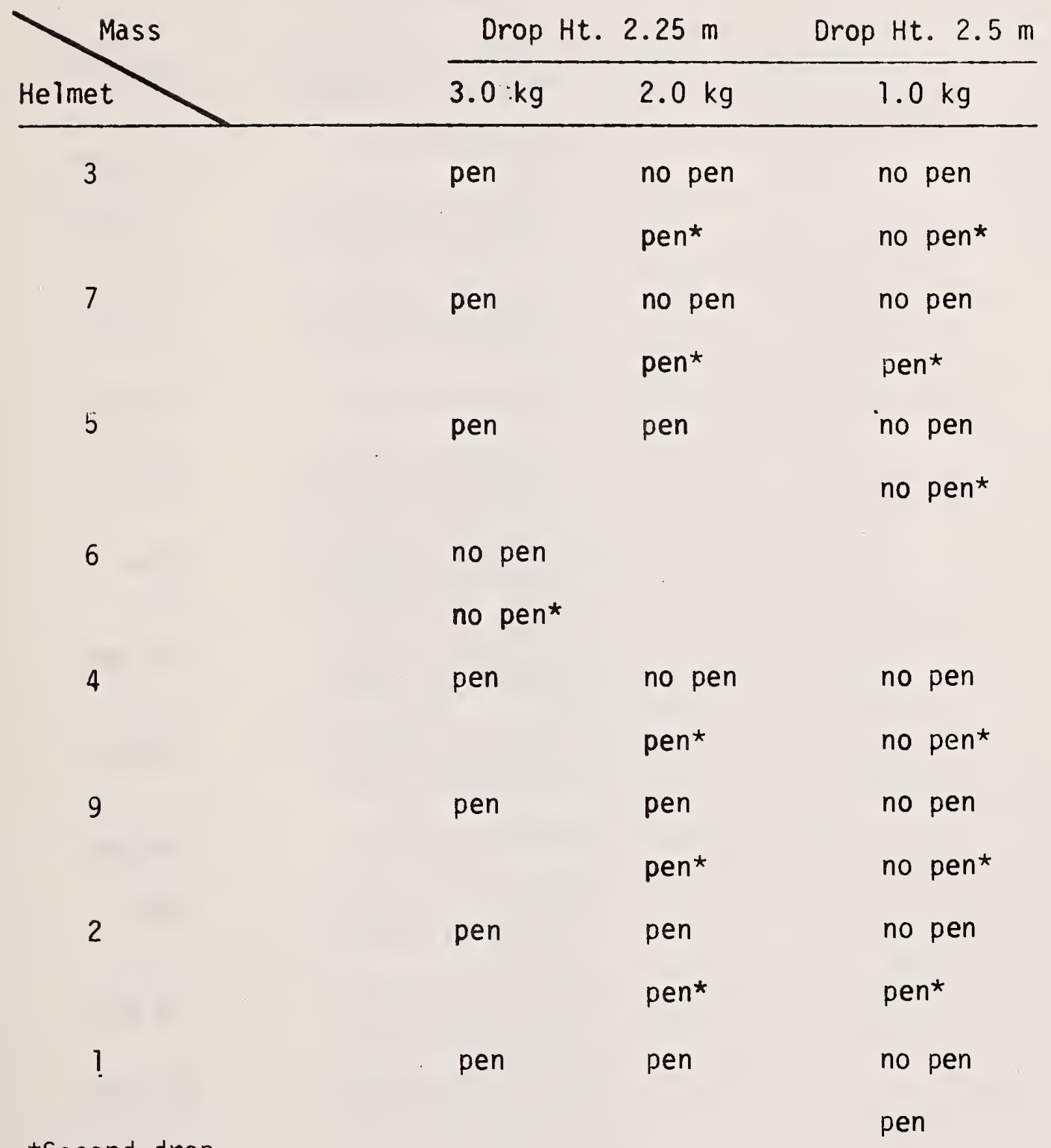

*Second drop 
Penetration Test, $50^{\circ} \mathrm{C}$; Striker mass $1.0 \mathrm{~kg}$, Drop Height $2.5 \mathrm{~m}$

Drop No.

Location

Comments

6

Back, $5 \mathrm{~cm}$ above

No pen reference plane

2

Side, $5 \mathrm{~cm}$ above

No pen reference plane

5

Opposite side

No pen

3

1

Back, $5 \mathrm{~cm}$ above reference plane

No pen

2

Side, $5 \mathrm{~cm}$ above reference plane

No pen

3

Opposite side

No pen

2

Back, $5 \mathrm{~cm}$ above reference plane

Pen

2

Side, $5 \mathrm{~cm}$ above reference plane

4

Back, $5 \mathrm{~cm}$ above reference plane

Pen

2

Side, $5 \mathrm{~cm}$ above reference plane

No pen

3

Opposite side

No pen

7

Back, $5 \mathrm{~cm}$ above

Pen reference plane

Back, $5 \mathrm{~cm}$ above reference plane

No pen

2

Side, $5 \mathrm{~cm}$ above reference plane

No pen

3

Opposite side

No pen

1

Back, $5 \mathrm{~cm}$ above

Pen reference plane 
Penetration Tests; High Temperature $\left(100^{\circ} \mathrm{C}\right)$; Striker

Mass $1 \mathrm{~kg}$, Drop Height $2.5 \mathrm{~m}$

Helmet

Drop No.

Location

Comments

1

1

Top/side

No pen

2

Back/side '

Pen

2

1

Front/side

Pen

3

7

Front/side

No pen

2

Top/side

No pen

4

1

Back/side

No pen

2

Front/side

No pen

5

1

Back/side

No pen

2

Top/side

No pen

6

1

Front/side

No pen

2

Back/side

No pen

7

1

Front/side

Pen 
Flammability Test; radiant flux $0.8 \mathrm{~W} / \mathrm{cm}^{2}$, bunsen flame - $15 \mathrm{~s}$

Helmet Comments

$\begin{array}{ll}1 & \text { No flame } \\ 2 & \text { No flame } \\ 3 & \text { No flame } \\ 4 & \text { Paint burns; extinguishes after } \\ & \text { flame is removed } \\ 5 & \text { No flame } \\ 6 & \text { Paint flames; extinguishes } \\ 7 & \text { after removal of flame } \\ & \text { No flame }\end{array}$


Convective Heat Test: $250^{\circ} \mathrm{C}, 3 \mathrm{~min}$.

(Discontinued)

8

1

3

2

6

5

4

7
Front, sides and back deformed. Back brim flowed onto neck of head form.

Suspension melted onto floor of oven. Brim deformed $9.2 \mathrm{~cm}$ below basic plane.

Brim deformed. Back brim curled toward headform and down $7 \mathrm{~cm}$ below basic plane.

Entire shell softened and deformed. Back brim dropped $8.6 \mathrm{~cm}$ below basic plane.

Edging smoked. No visible distortion. Ear flaps blistered.

Back brim softened and deformed $7.5 \mathrm{~cm}$ below basic plane.

Paint blistered.

No visible distortion in shell. Suspension system melted onto oven floor. 
Helmet No.

1

3

2

6

5

4

7
Polycarbonate shell; nylon webbing/polyethylene suspension

Polycarbonate shell; nylon webbing suspension

Polycarbonate shell; nylon webbing/polyethylene suspension

GRP shell; foamed inner lining

Polycarbonate shell; foamed inner lining

Leather shell; nylon webbing suspension

GRP shell; polyethylene/nylon webbing suspension 
APPENDIX 2. Correspondence from firefighters 
SUBJECT: Firoft chtor Holmet:

\section{Sir:}

Tho following is related to the above subject.

$T_{a}$ king a position of no price compror:se on safety to our personnel, the leather helmet is the best head protective cear availablo at the present tire.

Porsonal injury experience of (2) line officers demostrated the effectimess of the leather helmet.

1. A sash wisteht dropned from a undetermined heignt on the warers helmet nroduced a concussion and nrovented a nossible fractured skull.

2. A hosa clamp's sudden release crushed the side of the vearors helmet and althouch the woarer suffered lacerations, the s!ull was unharmed due to excellent coronaI plans protection of the rib designed halnot.

The criteria for testing helmets is excellent and we find no fault or recomnend any changes at this timo. 

On permanent disabllity bicause of a hecmet apllure. The hecmer actually cullasped (caucd in) when struck BV. THE WHIPPIAE $Z Y_{2}=$ NOZZLE.

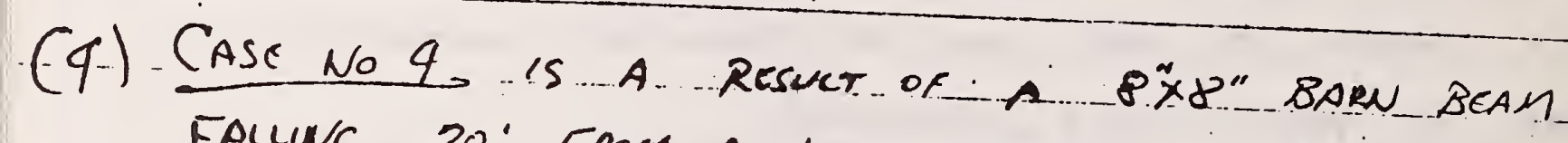

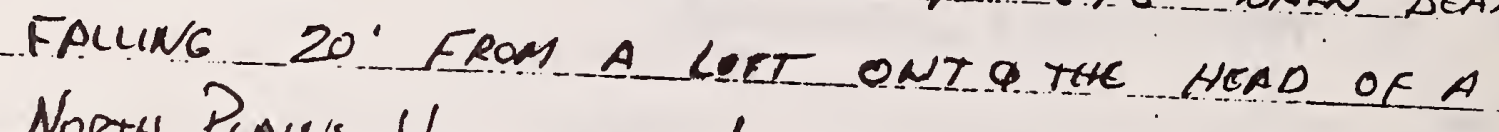
North Puans Voluntare lu this case ithis fire figuter

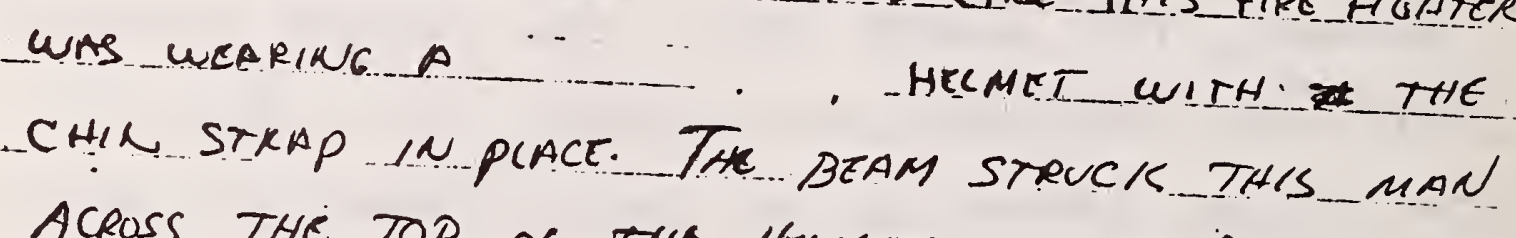
ACROSS THE TOP OF THE HELMTT TO THE RIGAT OR

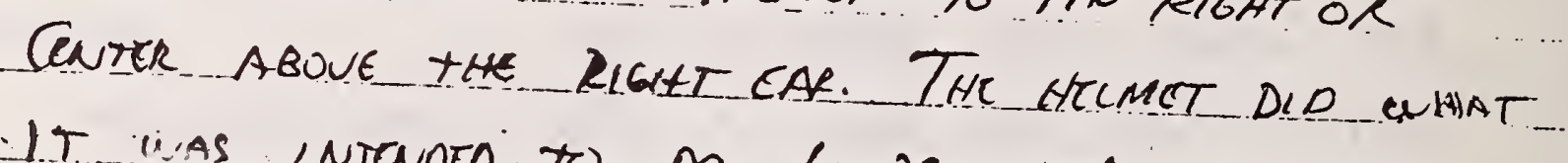
IT WIAS INTCWDA TO DOL IT PRTUEUTED AMY HEAD

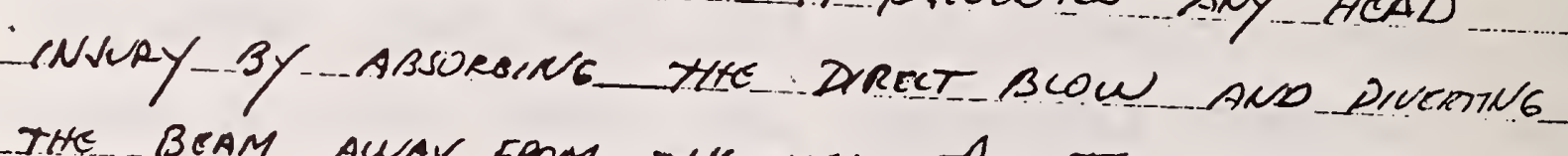
THe BCAM AWAY FROM TLH MAN . FHE IMPACT WAS ABSORBCD BY THE INNER CINCK, HOWFUE, THS MPN WAS DRLVON DOWN TO HES KNUES RER A moneat. From ztels iNe Recerver no Invury.

-(5) In heis case an Assestant Chief or the torts Grove Fire Deppatmint was - STRuck by A

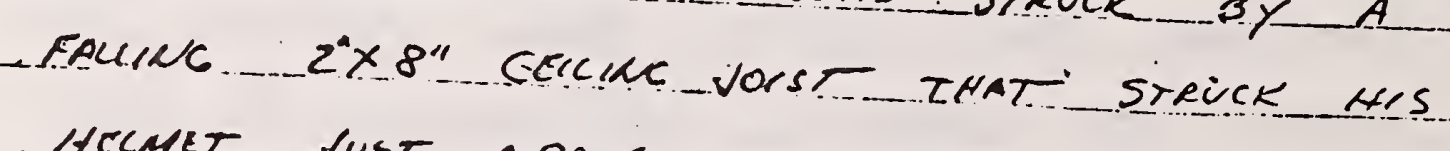

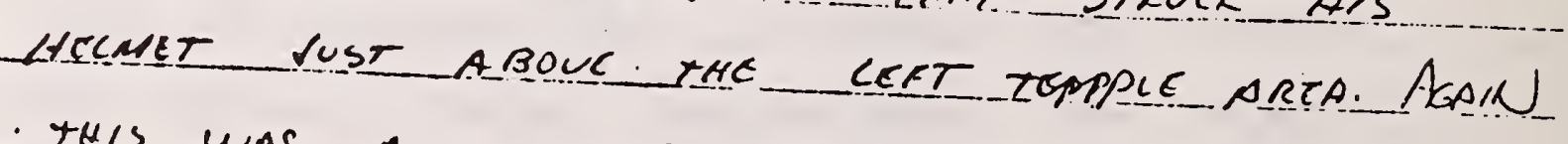

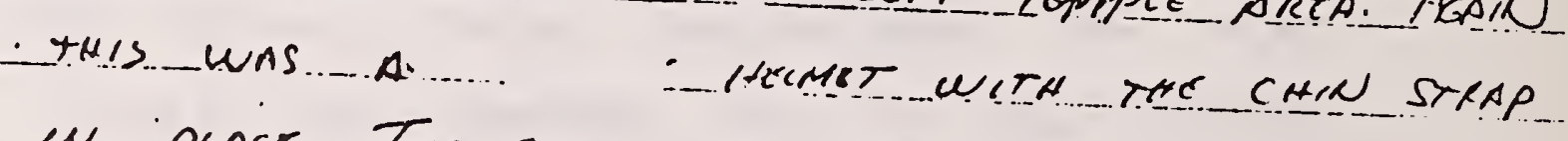
in place. THe Bcow tore rre Face surero SWIUAC FROM the Hesmet AND THE IMPACT 
KNOCKED .. THE MAN TO THE FLOOR IN A DAZED CONDition. THE MAN suffered No inJury, However, THE INNER LINER OF THE ACMES DID SHOW THE

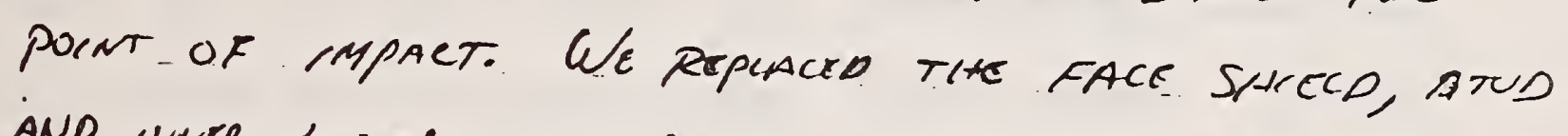
AND INNER LINER AND PLACED THE HELMET BACK INSERUICE.

(6) IN THIS CASE IT WAS TO OUR FIRE FGGTCR

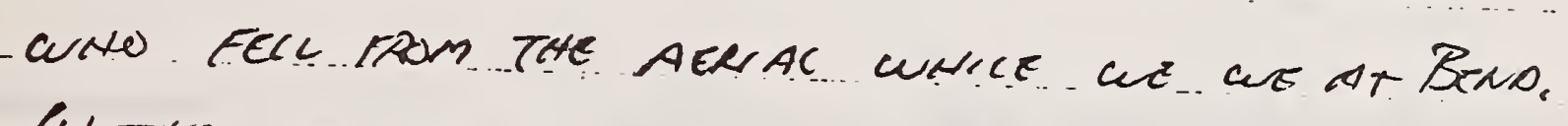
LATHS INCIDENT THE FACT THAT HIS HELMET STAYED ON H() HEAD SAVED HIM FOR INJURY TO HES HEAD. THAT MEDIACY SWORD HAVE CAUSED DEATH. THC FACT THAT THIS .... HELMET ONCE AGAIN DID SUST wat IT UAS apPOSE TO OO THAT WAS STAY ON AND pROTECT TIFE MANS HEAD. THE FACE

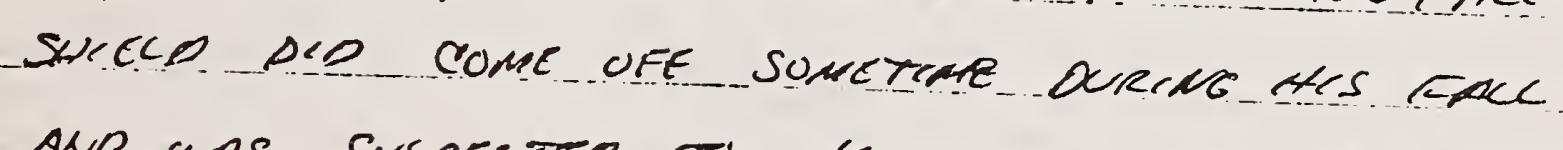

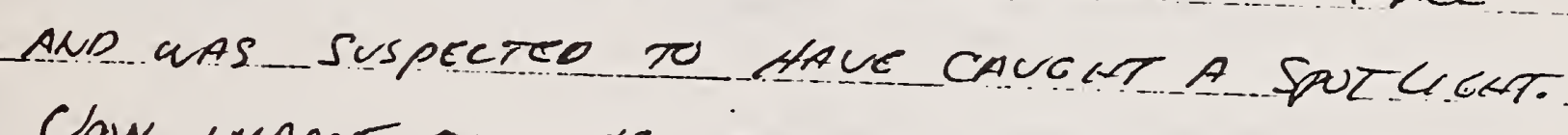
UPON IMPACT ON THE GROVeS THE NECK SHEA SPLIT AND PIPPEN ore ON OWE STDE ABSURBIVG. A Goode Andvari or the IMpact AgRuest tHe GroUND. SCRTACE.

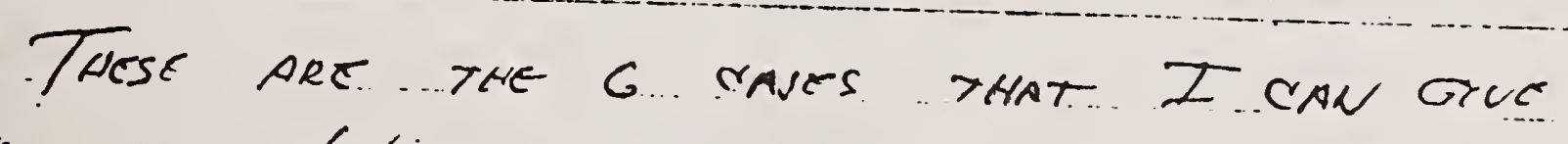

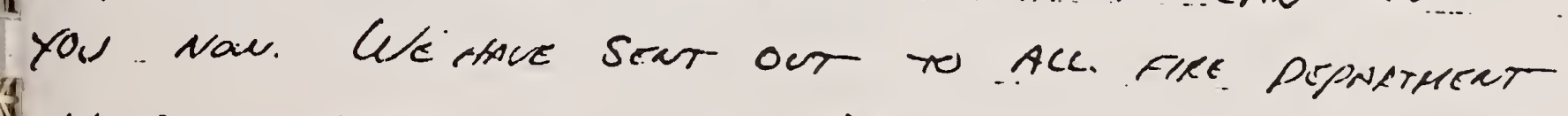

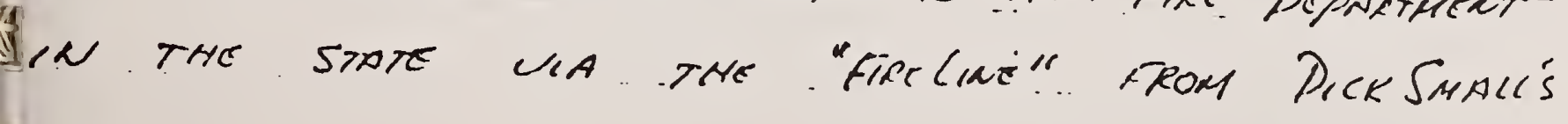




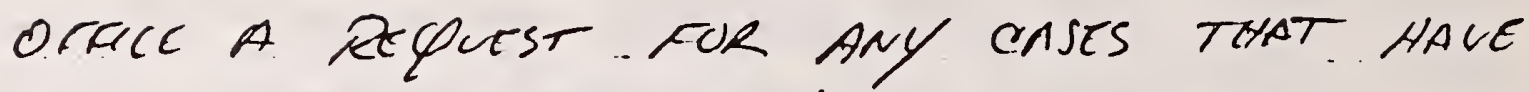
OCCUrRED REGARDING. ANY HEMET FAURE OR GOOD SAFETY FEATRRS. THAT HAVE PREvented FAIluRES. THIS INFORMATION WILE LE SENT CITHER TO ME OR. Directly to you.

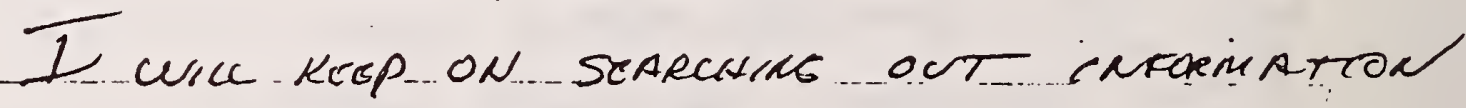
on TItis, HePefucly an time to Do you some Goon. I will Br Goring BACK to yo sod 
l'ational Bureau of Standards

\section{A255 Polymer Building}

Washington, D.C. 20234

\section{Dear Sir:}

The tyne of helmet wich the Iit+leton Fire Dept. Gives us to wear is the

fire helmet. There are a number of had noints rinted to this helmet. The main one is its inability to abso b hlows and impacts from the side. This defect is caured, I believe, by the sling, type harness which these helmets have. The sling harness also causes the helmet to fly off or iecome lislodged after any blow received from above, the side or the hack.

If the fire-ighter who is wearing this helmet in a fire is well protected from the heat the helmet will start to deform and melt while on his head. This has hannened twlce, in the oast four years, to different fire-fighters on this department, which has only 60 menbers.

helmet doesnot previde any protection to the ears or neck of the wearer. When the Helmet is adjusted to fit the fire-fighters hear rithout a mask it covers his head fairj, well; however when a mask is put on, the helmet sits way un on the top or his head, where it can be easily knocked off even with the chin strap innlace.

The type of holmet which I have ordered for myself, even-though it is against the denartments tried and true method, is the new

But this helmet still lacks some inno'ations which wculd ailow it to be even safer and easier to use. One ruld be to brild into the helmet a radio and a lipht. In other words, build a helmet which would te like the one worn by the fizhter vilots of W.:. II. Another idea :Nold be to build into the helmet the face-niece of the mack.

I helieve that no matter what color, type or style of helnet is used by a de"artment for which a per: on is working, he should be allover to inar a safer, better, and more-compatible-with-masks, helmet if it is intro "uced onto the market, even $i$ " the firerighter has to purchase it with his own money. 
Mr. Nicholas Calvano

National Hureau of Standards

A 25' Polymer Euilding

Washington, D.C. 20234

Dear Sir:

The following is information regarding the helmets that are worn by the

firefighters.

One hundred fifty-five helmets of the enclosure were purchased and placed in service by the Department.

Our men are satisfied with them with the excention of three problems.

1. The eyeshield fittings are not structurally adequate for the fire service.

2. The liner is not removable for washing.

3. The ear and neck protection is not long enough.

One of the relmots was worm by a ladder truck operator when involved in an accident in which cur 851 Seagrave Ladder truck was hit on the front wheel at an intersection and forced into a ccncrete pillar at $25^{\prime} \mathrm{mph}$. The truck drivers head hit the windshield with enough force to break the glass with no head injury resulting.

This helmet desinn affords more lateral protection than the which the $"$ replaced.

\section{The features we are looking for in a helmet are:}

1. Lateral as well as vertical protection.

2. Light weight.

3. Neck and ear protection from heat and cold.

4. Ease of cleaning - in and out.

Attached are the specifications for the 1000 series helmets that were purchased for our department.

Please advise if we can be of any further service. 
Nir. Walter Lambert

Director, Rssearch Department

IAFF Headquarters

$1 ? 50$ New Pork Ave., N.T'.

Viashington, D.C. 20006

Dear Sir and Brother;

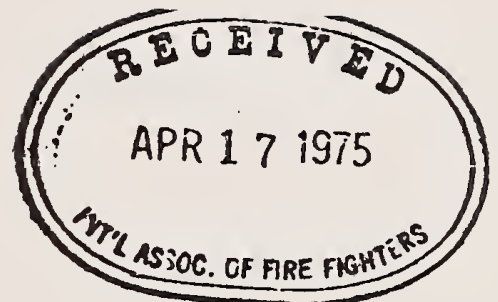

This letter is in reply to your request for information concerning our complaints with our protective helmets. Our department supplies us with biack helmets. A survey of our members brought the following complaints:

1. It is too bulky, ycu can't get through narrow places with heir.et on.

2. Helmet doesn't fit over $\mathrm{MSA}$ seli-contained air mask and if you attenpt to use your helmet with a mask on, the helmet keeps falling off.

3. Heimet offers very little protection upon impact of even small folling objects.

4. Helmet melts at temperatures commly encountered in interior fires.

5. "Plectron" shields on our helinets ir3p smoike between your face and tre shie?d.

6. Bracket on the shield breaks the helrot under very little stress.

7. "lectron" snitids are not easily scenated and when they are not dorm in front of your faze, they ame bulky anc make it difficult to get into and out of epns r tus.

8. Black helnets ale not visicie at right unless reflective tape is put on helret

Generally, I would say that tradition has lient our helmets the same in design wilie materials and research has advanced. We need a close fitting helmet design to protect the firofighter and not tha tradition of the firefighter. 
November 5, 1974

Nicholas Calvano

National Bureau of Standards

A255 Polymer Building

Washington, D.C. 20234

Dear Sir:

In response to your article in Fire Engineering magazine, we also have a complaint.

We had helmets buckle on us at a fire. Neither man was burned. Both men were performing tasks near the fire.

I fcel equipment should withstand more heat than an individual.

Wishing you success in your undertaking, 
Mr. Nick Calvano

National Bureau of Standards

Rt. 705 Quince Orchard Road

Gaithersburg, Maryland 20760

Dear Nick:

I am sending, under separate cover, helmet that melted on a man while he was fighting a fire at the school. AIso, I am sending a film on the explosion and fire that occurred in Houston in a train derailment.

Sincerely yours, 
January 28,19

Mr. Nicholas Calvano

National Bureau of Standards

A255 Polymer Building

Wa shington, D.C. 20234

Dear Sir,

Enclosed are 3 pictures of my fire helmet. It is a

helmet. I was wearing this helmet in the early morning hours on June 7 , 1974 when in the attempt to rescue a man from a burning room I was caught in the room and had to be pulled out myself. It was a very brief period and did not last longer than a minute. Even in the intense heat in the room I do not believe that this could happen. I am now very dismayed at these results. So are a number of my fellow firemen. I spent 33 days in a burn unit with about $40 \%$ burns on my body and was off work for 4 months. This helmet is said to meet the present federal standards and if this is so, then I belleve something should be done to make the standards much higher.

Respectfully, 
Mr. Nicholas Calvano

National Bureau of Standards

A255 Polymer Building

Washington, D.C. 20234

Dear Sir:

The September 1974 issue of "Fire Chief" magazine contains an article requesting information and comments regarding firefighter's helmets. I would like to comment.

We have received many comments from fire-fighters in the State of Michigan voicing their disapproval of many helmets approved by OSHA. They distort upon the application of low heat (less than $150^{\circ} \mathrm{F}$ ), they will ignite, etc. This office has tried to find documentation of any incident of a firefighter being injuried or killed while wearing a metal helmet or one with metal rivets, whereby the headpiece contributed to the accident. We can find none. Considering the numbers of fire-fighters who have worn this style headgear and the length of time each wore it, the record is outstanding in favor of the helinets worn in the past.

The leather helmet has a record even better than the metal. This style is worn by the fire-fighters in communities where the number of fires are the greatest; Chicago, Boston, New York, Kansas City, etc. The only reason other cities did not use them was the cost.

I believe that a fire-fighter's helmet should be designed for use by a fire-fighter and not for use by a police officer, construction worker, truck driver or any other occupation. Thus, helmets worn by others are not designed to be worn by fire-fighters. The hazards of fire-fighting are similar in many ways, but different in the matter of water, heat and smoke. I firmly believe fire-fighters should be consulted when helmets are tested and designed.

Electricity should not be a significant factor in considering tests to be conducted. Generally, one of the first functions of the fire chief at the scene of a fire is to get the current disrupted so electricity is not a hazard.

Impact tests are important, but not to the point where a helmet must withstand a great weight with not consideration given to a person's neck. It would seem that it is better to test the helmet for "deflection" of either the falling object or the wearer's head, keeping in mind a brim is needed for the channeling of water.

I believe "change" is good if it benefits, but to "change" for the sake of changing can be disasterous. Let's look at what we have; perhaps those who designed the helmets used good logic and materials and if changes must be made, they can be minimal.

We shall notify those in the fire service in Michigan of your requests and urge them to assist you.

Sincerely, 
Mr. Nicholas Calvano

National Bureau of Standards

A 225 Polymer Building

Washington, D.C. 20234

Dear Mr. Calvano,

1 hope the following comments and observations will be of some use in your investigation of fire helmet performance.

We have available a wide variety of fire helmets, primarily as teaching aids in our protective equipment class, but also for use by cur instructors. Most of our experiences have been with the following helmets:

- are the most common helmets in this area, due in great part to their low initial cost. The major problems with this type appear to be light weight, melting, and shattering.

The helnet is easily dislodged from the wearer's head, particularly during response to fires where wind will lift the helmet.

The suspension will not always keep the helmet on during routine firefighting activities, particularly while wearing breathing apparatus.

The helmet will melt or soften when exposed to high heat levels encountered in some fire situations.

One local department has had this type shatter when dropped, although this did not occur during routine use.

appears to offer the best level of protection, perhaps for this reason and the radical design as $f a r$ as fire helmets are concerned, it has had a good deal of use.

Wearers complain of the weight of the helmet, it is the heaviest of those in our inventory. This weight does impart a feeling of security.

My personal feelings are that a fire helmet should offer protection Irom top and side inpacts; provide ear and neck protection from radiant heat, steam and embers; provide face protection from fiying objects (embers, plaster chips, etc.); and be compatible with breathing apparatus (i.e.fit over face piece and no brim interferance with B/A back pack tanks.)

Best of luck on yrur project. 
APPENDIX 3. Model Performance Criteria 



\subsection{Impact Attenuation}

When tested in accordance with paragraph 2.1 , all helmets tested shall meet the requirements below:

\begin{tabular}{|c|cc|}
\hline $\begin{array}{c}\text { Impact } \\
\text { Location }\end{array}$ & \multicolumn{2}{|c|}{$\begin{array}{c}\text { Maximum } \\
\text { Acceleration }\end{array}$} \\
\cline { 2 - 3 } & $g_{\mathrm{n}}{ }^{*}$ & $\left(\mathrm{~m} / \mathrm{s}^{2}\right)$ \\
\hline Top & 150 & 1472 \\
Front & 400 & 3924 \\
Side & 400 & 3924 \\
Back & 400 & 3924 \\
\hline
\end{tabular}

Accelerations above $200 \mathrm{~g}_{\mathrm{n}}$ shall not exceed three milliseconds in duration; accelerations above $150 \mathrm{~g}_{\mathrm{n}}$ shall not exceed five milliseconds.

\subsection{Penetration Resistance}

There shall be no demonstrable electrical contact between the penetration test striker and the headform when the helmet is tested for penetration resistance as described in paragraph 2.2 .

\subsection{Chin Strap/Retention System}

The static strength of the chin strap/retention system shall be tested in accordance with paragraph 2.3 without any break occurring and without any resulting slip or stretch of more than $25 \mathrm{~mm}(1.0 \mathrm{in})$. The width of the chin strap shall be at least $12 \mathrm{~mm}(1 / 2 \mathrm{in})$.

\footnotetext{
${ }^{*} g_{n}$ is the standard acceleration of free fall and is defined as 9.80665 melers per second per second.
} 


\subsection{Ear Flaps}

Ear flaps shall extend at least $25 \mathrm{~mm}$ ( 1 in) in front of the coronal plane and at least $60 \mathrm{~mm}$ (2.4 in) below the basic plane. (See fig. 2)

Ear flaps shall resist ignition when tested in accordance with paragraph 2.4 .

\subsection{Configuration}

The helmet shall be designed to divert falling liquids away from the face and neck.

The helmet shall have no slits, holes or other openings above the reference plane. (See fig. 2) No part of the helmet shall extend more than $15 \mathrm{~cm}(5.9 \mathrm{in})$ from the mid-sagittal plane (see fig. 1) nor more than $20 \mathrm{~cm}$ (7.9 in) from the coronal plane. (See fig. 2) Distances are measured perpendicular to the planes.

\section{$1.6 \quad$ Flame Resistance}

Helmet shells shall resist ignition when tested in accordance with paragraph 2.4.

\subsection{Heat Resistance}

When tested in accordance with paragraph 2.5:

a) there shall be no visible distortion of the helmet suspension/retention system, chin strap, or ear flaps

b) no part of the helmet shell shall touch the headform

c) any shell distortion in the back of the headform shall not extend more than $8 \mathrm{~cm}(3.1 \mathrm{in})$ below the basic plane, and

d) any shell distortion in the front and sides of the headform shall not extend more than $4 \mathrm{~cm}(1.6 \mathrm{in})$ below the reference plane. 


\subsection{Electrical Insulation}

Electrical leakage shall not exceed 3 milliamperes when the helmet is tested as described in paragraph 2.6.

\subsection{Visibility and Reflectivity}

1. For maximum visibility the helmet should be a light color such as white, yellow, light orange, light red, etc. For this document maximum visibility is defined as Munsell Value $7 /(43.06 \%)$ for CIE source "C" (6774K) or lighter when tested in accordance with "Standard Method of Specifying Color by the Munse11 System" or ASTM E308-66, "Standard Recommended Practice for Spectro-photometry and Description of Color in CIE 1931 System."

2. The helmet shall have retro-reflective markings on each of four locations: front, back, right side and left side. The area covered in each location shall be at least $40 \mathrm{~cm}^{2}\left(6.2 \mathrm{in}^{2}\right)$. When tested as described in paragraph 2.7 , the retro-reflective material shall meet the requirements given in the table below:

\begin{tabular}{|c|c|c|c|}
\hline & \multicolumn{3}{|c|}{$\begin{array}{l}\text { Minimum Candlepower per } \\
\text { Foot Candle per sq. ft. }\end{array}$} \\
\hline \multirow[t]{2}{*}{ Observation Angle } & \multicolumn{3}{|c|}{ Entrance Angle (degrees) } \\
\hline & -4 & +30 & +50 \\
\hline 0.2 & 70 & 30 & 3.5 \\
\hline 0.5 & 30 & 15 & 3.0 \\
\hline
\end{tabular}




\section{Associated Test Methods}

\subsection{Impact Attenuation Test}

Four helmets (for large purchases, suitable quality control procedures and sampling plans should be arranged. Mil Std. 105 "Sampling Procedures and Tables for Inspection by Attributes" is recommended as a guide) are required for the environmental conditioning as described in paragraph 2.1.2. A schematic diagram of an impact attenuation test set-up is shown in figure 3.

\subsubsection{Test Equipment}

\subsubsection{Test Headform}

The test headform, which is size $71 / 4$, shall conform to the dimensions in figures 2 and 4 . It shall exhibit no resonance frequencies below $3000 \mathrm{~Hz}$; it may be made of any low resonance magnesium alloy such as magnesium $K-1 A$.

\subsubsection{Drop Assembly}

The drop assembly consists of the test headform, the accelerometer, and the supporting crossarm assembly and shall have a total mass of $5.2 \pm 0.2 \mathrm{~kg}(11.4 \pm 0.4 \mathrm{lb})$. The center of mass of the assembly shall 1 ie within a cone of 10 degrees included angle about the vertical, with apex at the point of impact.

\subsubsection{Test Anvil}

The test anvil shall be steel and have a flat striking surface. The anvil shall be firmly mounted on a steel plate $250 \times 250 \times 25 \mathrm{~mm}$ ( $10 \times 10 \times 1$ in) minimum, backed with a solid mass of at least $140 \mathrm{~kg}$ (309 1b). 


\subsubsection{Acceleration Measurement System}

An accelerometer is used to measure the acceleration imparted to the helmeted headform upon striking the anvil and should be able to withstand shocks up to $2000 \mathrm{~g}_{\mathrm{n}}$. The acceleration data channel, including all instrumentation which may alter the frequency content of the test data and all recording and analysis procedures, shall comply with SAE Recommended Practice $\mathrm{J} 211 \mathrm{~b}$ requirements for channel class 1000 . The time duration of acceleration shall be measured to within \pm 0.1 millisecond.

\subsubsection{Reference Anvil}

The reference anvil is substituted for the test anvil to check the acceleration measurement system. When the bare headform is dropped from an appropriate height, it shall produce a peak acceleration of $400 \mathrm{~g}_{\mathrm{n}}$ $\pm 20 g_{n}$ and accelerations above $200 g_{n}$ of at least one millisecond duration. The reference anvil may be of any material which will reproducibly yield these results. A reference anvil found to be suitable is a oneinch Open Blue Modular Elastomer Programmer available from MTS Systems Corp., P.0. Box 24012, Minneapolis, Minn. 55424.

\subsubsection{Conditioning for Testing}

\subsubsection{Room Temperature}

Condition one helmet at a temperature of $20-28 \mathrm{C}(68-82 \mathrm{~F})$ for at least 4 hours. Test as in paragraph 2.1.3.

\subsubsection{Radiant Heat}

Condition a second helmet by exposing the helmet area to be impacted to an infra-red lamp. The area to be impacted is defined as the circle with $6 \mathrm{~cm}(23 / 8 \mathrm{in})$ radius with its center at the impact point of the 
helmet. Mount the helmet on the test headform in the appropriate drop position and raise the drop assembly to the prescribed drop height. Measure the radiant flux by temporarily removing the helmet from the headform and placing a radiometer in the impact area. Adjust the distance of the heat source until a constant radiant flux of 0.6 Watts per square centimeter is achieved. Remove the radiometer, reposition the helmet on the headform, and subject the impact area to the radiant flux for three minutes.

The heat source should be mounted so that it can be easily swung away to allow helmet impact immediately after the application of heat. Test according to paragraph 2.1.3. If the helmet is not impacted within 10 seconds after removal of the heat source, reapply the heat load for an additional 3 minutes.

\subsubsection{Water}

Condition a third helmet by immersing it in water at a temperature of $25 \pm 5 \mathrm{C}(77 \pm 9 \mathrm{~F})$ for not less than 4 hours nor more than 24 hours. Test according to paragraph 2.1 .3 within 10 minutes after removal from the water.

\subsubsection{Low Temperature}

Condition a fourth helmet by exposing it to a temperature of $-15+0-2 C(5+0-4 F)$ for not less than 4 hours. Test according to paragraph 2.1.3. If the test is not completed within one minute after removal from the cold temperature environment, recondition the helmet 10 minutes for each minute out of the chamber. 


\subsubsection{Test Procedure}

Mount the accelerometer at the center of mass of the drop assembly with the sensitive axis aligned to within 5 degrees of the true vertical when the headform is in the impact position.

Prior to testing, allow all electronic equipment to warm up for 30 minutes or until stability is achieved. Throughout calibration and testing, the ambient temperature shall be $20-28 \mathrm{C}(68-82 \mathrm{~F})$ and the relative humidity 30 to 70 percent.

Check all instrumentation before and after each continuous sequence of tests by impacting a bare instrumented headform on the reference anvil. Record a minimum of three such impacts before and after a test sequency and make them part of the test record. Should the acceleration-time history not meet the required tolerance $(2.1 .1 .5)$ prior to testing, adjust the equipment as necessary. Should the post-test average differ from the pretest average by more than $40 \mathrm{~g}_{\mathrm{n}}$, discard the entire test series.

Position the helmet squarely on the headform and secure it to the headform-crossarm assembly by its chin strap or other means which will not interfere with the test, so as to maintain this position during guided fall.

Adjust the drop height so that the velocity at impact is $6.0 \pm 0.2$ meters per second $(19.6 \pm 0.7 \mathrm{ft} / \mathrm{sec})$.

Impact each helmet once at each of the four sites described below: 


\begin{tabular}{ll}
\hline Orop Site & \multicolumn{1}{c}{ Impact Area } \\
\hline Top & No more than $75 \mathrm{~mm}$ ( $3 \mathrm{in}$ ) from the point \\
& described by the intersection of the helmet \\
& shell, the mid-sagittal plane and the \\
& coronal plane (see fig. 2 ). \\
& No more than $75 \mathrm{~mm}$ ( $3 \mathrm{in}$ ) from the line \\
Side & described by the intersection of the coronal \\
& plane and the helmet surface, above the \\
& reference plane and below the top impact area. \\
Front & At least $25 \mathrm{~mm}$ ( 1.0 in) above the reference \\
& plane, below the top impact area and in front \\
& of the side impact area. \\
& Above the reference plane, below the top \\
Back & impact area and to the rear of the side \\
& impact area.
\end{tabular}

The mass of the test helmet is not included in calculating the impact energy.

\subsection{Penetration Resistance Test}

Two of the helmets used in the impact attenuation test may be used for this test.

A diagram of the penetration resistance test set-up is shown in figure 5 .

\subsubsection{Test Equipment}




\subsubsection{Test Headform}

The test headform, which is size $71 / 4$, shall conform to the dimensions in figures 2 and 4 . Above the reference plane, it shall have an electrically conductive surface which is electrically connected to the contact indicator (2.2.1.3).

\subsubsection{Penetration Striker}

The penetration striker shall have a mass of $1.0 \mathrm{~kg}+25 \mathrm{~g}-0.0 \mathrm{~g}$ $(2.21 b+0.051 b-0.01 b)$. The point of the striker shall be a cone with an included angle of $60 \pm 0.5$ degrees, a height of $38 \mathrm{~mm}(1.5 \mathrm{in})$ and a tip radius of $0.5 \pm 0.1 \mathrm{~mm}(0.020 \pm 0.004 \mathrm{in})$. The hardness of the striking tip shall be Rockwell scale - C 60 , minimum. The penetration striker shall be electrically connected to the contact indicator (2.2.1.3).

\subsubsection{Contact Indicator}

The contact indicator shall indicate when electrical contact of 1 millisecond duration or longer has been made between the penetration striker and the conductive surface of the test headform.

\subsubsection{Conditioning for Testing}

\subsubsection{Room Temperature}

Condition one helmet at a temperature of $20-28 \mathrm{C}(68-82 \mathrm{~F})$ for at least 4 hours.

\subsubsection{High Temperature}

Condition one helmet in a circulating air oven controlled at $100+3 \mathrm{C}$ $(212 \pm 5 \mathrm{~F})$ for not less than 4 hours nor more than 24 hours. 


\subsubsection{Test Procedure}

Place the conditioned, complete helmet on the rigidly mounted test headform and secure it by its chin strap or by other means which will not interfere with the test. Adjust the helmet in the same manner as a person would adjust it to his head. Drop the penetration striker in guided free fall onto the outer surface of the helmet anywhere above the ference plane and at least $75 \mathrm{~mm}(3.0 \mathrm{in})$ from the center of a previous impact site or penetration site. Drop the striker from a height of $2.50+0.01-0$ meters $(98.5+0.5-0$ in) as measured from the striker point to the point of impact on the outer surface of the helmet. Apply a minimum of two penetration blows at different locations to each of the two helmets. The long axis of the striker should be perpendicular to the plane tangent to the impact area. If the test is not completed within 3 minutes after high temperature conditioning, recondition and repeat.

\subsection{Chin Strap/Retention System Test}

The same test helmets used in the impact attenuation test may be used for this test. A diagram of the test set-up is shown in figure 6 .

\subsubsection{Test Headform}

The test headform shall be size $71 / 4$ and capable of supporting the helmet when a load of 890 newtons ( 200 pounds force) is applied to the retention system.

\subsubsection{Conditioning for Testing}

\subsubsection{Room Temperature}

Condition one helmet at a temperature of $20-28 \mathrm{C}(68-82 \mathrm{~F})$ for at least 4 hours. 


\subsubsection{High Temperature}

Condition a second helmet by exposing it in a circulating air oven to a temperature of $100 \pm 3 C(212 \pm 5 \mathrm{~F})$ for not less than 1 hour nor more than 3 hours.

\subsubsection{Test Procedure}

Place the conditioned, complete helmet on the rigidly mounted test headform and fasten the chin strap to the loading device, as shown in figure 6 . Adjust the helmet on the headform so that the points of attachment of the chin strap to the helmet will be subjected to the same stress as the chin strap. Support the helmet so that it will not move during the application of the test loads.

Apply the test loads perpendicular to the basic plane of the headform and symmetrically with respect to the helmet retention system.

Statically load the chin strap system with 100 newtons (22 pounds force) for at least 30 seconds but no more than 1 minute and then measure the maximum distance between the chin strap and the apex of the helmet. Do not remove the load.

Apply an additional 550 newtons (124 pounds force) for at least 3 minutes and again measure the maximum distance between the chin strap and the apex of the helmet.

Record any break in the chin strap/retention system. Record any slip or stretch as the difference between the two distance measurements.

If the test is not completed within 5 minutes after high temperature conditioning, recondition and repeat. 


\subsection{Flame Resistance Test}

\subsubsection{Shell}

Place the helmet in front of a radiant heat source such as the type described in ASTM El62 so that the basic plane of the helmet is parallel to the radiant heat source. Position the helmet so that the crown receives a radiant flux of $0.6 \mathrm{w} / \mathrm{cm}^{2}$. After 60 seconds exposure to the radiant flux, and without removing the helmet from the heat source, place the cone tip of a methane flame against the helmet crown so that the cone makes an angle of 45 with the plane tangent to the crown (see figure 7). After 15 seconds remove the flame and observe whether the helmet shell resists ignition. (No visible flame or afterglow 5, seconds after removal of methane flame.) If part of the shell is constructed of a different material than the crown, test each material in an equivalent manner.

\subsubsection{Ear Flaps}

The flame resistance test for ear flaps is the same as 2.4.1 with the following exceptions:

1. The mid-sagittal plane of the helmet is parallel to the heat source.

2. The ear $f l a p$ receives a radiant heat flux of $0.6 \mathrm{w} / \mathrm{cm}^{2}$.

3. The cone of the flame is applied at an angle of 45 degrees with the ear flap.

\subsection{Heat Resistance Test}

Mount the helmet with ear flaps down on an epoxy headform conforming to the dimensions in figures 2 and 4 , and fasten the chin strap securely. Place the headform, with helmet attached, into a circulating air oven 
which has been preheated to $250 \pm 3 \mathrm{C}(482 \pm 5 \mathrm{~F})$. After three minutes remove the helmet and headform and measure the shell distortion, relative to the basic and reference planes, at the front, sides and back of the helmet. Then remove the helmet from the headform and examine the chin strap, ear flaps, and retention system for distortion.

\subsection{Electrical Insulation Test}

Support the helmet in an inverted position with a wire frame and place it in a vessel containing tap water (see fig. 8). Submerge the helmet until the water is within $13 \mathrm{~mm}(1 / 2 \mathrm{in})$ of the reference plane. Fill the inside of the helmet to within $13 \mathrm{~mm}(1 / 2 \mathrm{in})$ of the reference plane with tap water. Attach one terminal of a suitable* transformer to the wire frame. The second terminal is connected to an electrode and immersed in the water in the helmet. Starting at zero, apply a 60 hertz, alternating current voltage and increase it to 2200 volts root mean square. Maintain the voltage at $2200 \pm 2 \%$ for 3 minutes. Caution should be exercised in conducting this test because of the high voltages required.

\subsection{Visibility Test - Reflectivity}

The retroreflective material shall be tested in accordance with Federal Specification LS-300B paragraph 4.3.7 (available from: Federal Supply Services, General Services Administration, Washington, D.C. 20407).

\section{Glossary of Terms}

\subsection{Basic Plane}

The plane through the centers of the external ear openings and the lower edges of the eye sockets (see figure 1).

*The transformer should have an output voltage which is essentially sinusoidal with a crest factor of $1.41 \pm 0.07$ (crest factor $=$ peak voltage/ true rms voltage). 


\subsection{Coronal Plane}

The plane, perpendicular to the basic and mid-sagittal planes, which passes through the centers of the external ear openings as modeled on a headform (see figures 1 and 2).

\section{3 Edging}

The edge, rim, or rim trim around a helmet.

\subsection{Headform}

A test device which conforms to the configuration of the human head (see figures 2 and 4 ).

\subsection{Mid-Sagittal Plane}

The plane, perpendicular to the basic and coronal planes, which symmetrically bisects the head (see figure 1).

\subsection{Reference Plane}

The plane $60 \pm 1 \mathrm{~mm}(2.36 \pm 0.04 \mathrm{in})$ * above and parallel to the basic plane.

\subsection{Retention System}

The complete assembly by which the helmet is retained in position on the head.

\subsection{Retro-Reflective Material}

A material which reflects and returns a relatively high proportion of light in a direction close to the direction from which it came.

*Measures in parentheses are approximate. 


\section{Model Product Labeling}

Each helmet shall be durably and legibly labelled in a manner such that the label can be easily read without removing padding or any other permanent part. The label shall be affixed so that it is not easily removable and shall retain its integrity throughout the Associated Test Methods (Section 2). Each label shal1 include the following information:

a) name or designation of manufacturer

b) mode1 designation

c) size and weight*

d) month and year of manufacture (uncoded)

e) $10 t$ number

f) recommended cleaning agents, paints, etc., which can be applied to the helmet without damage

g) helmets which can be damaged by cleaning with common solvents shall include a warning that some common solvents may damage the she11

h) helmets with compressible 1 inings shall include a warning that after a severe blow the helmet may no longer protect the head and should be replaced or repaired by the manufacturer.

*Weight refers to the helmet, without accessories, as offered for sale. 

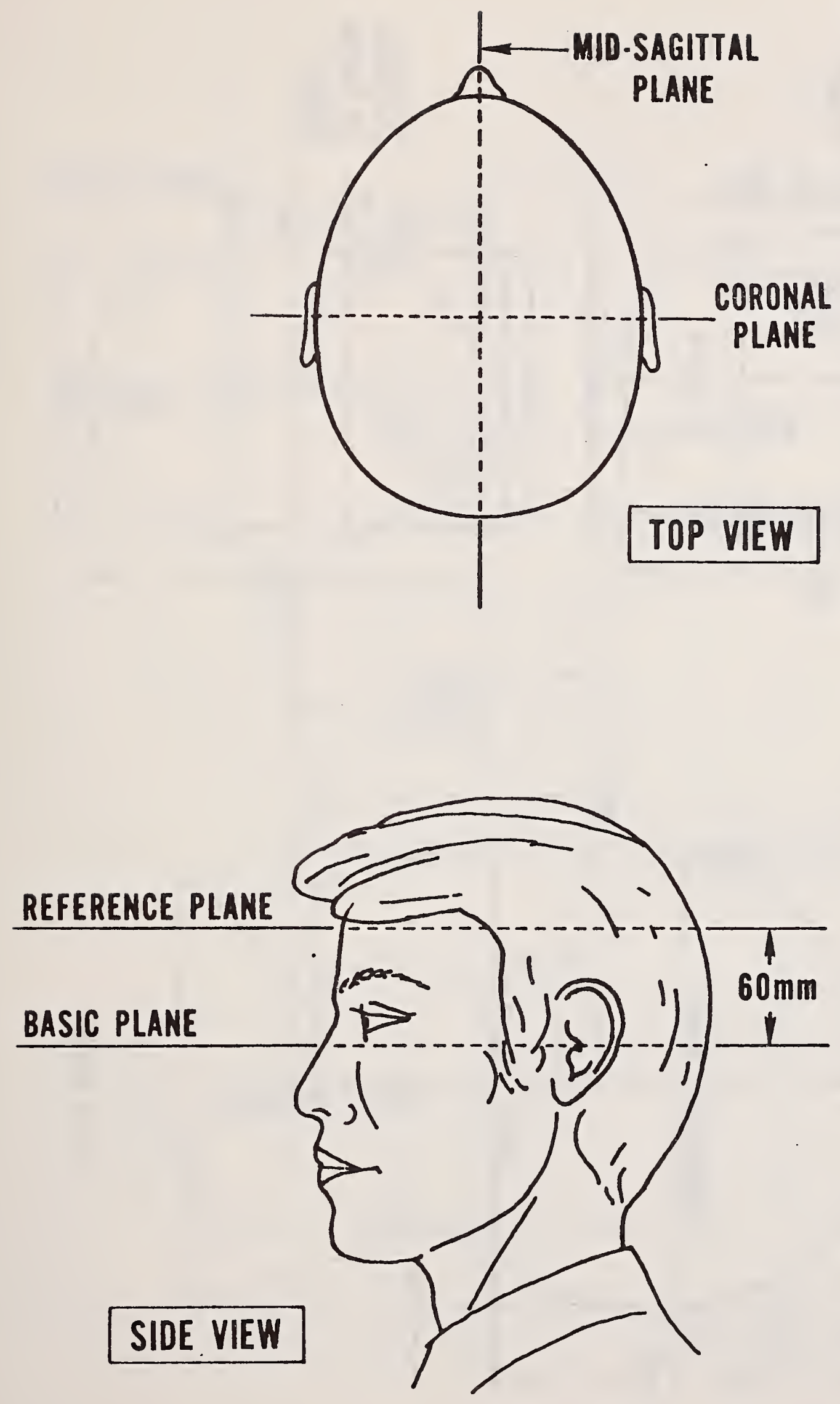

Figure 1. Locations of basic, coronal, mid-sagittal and reference planes. 


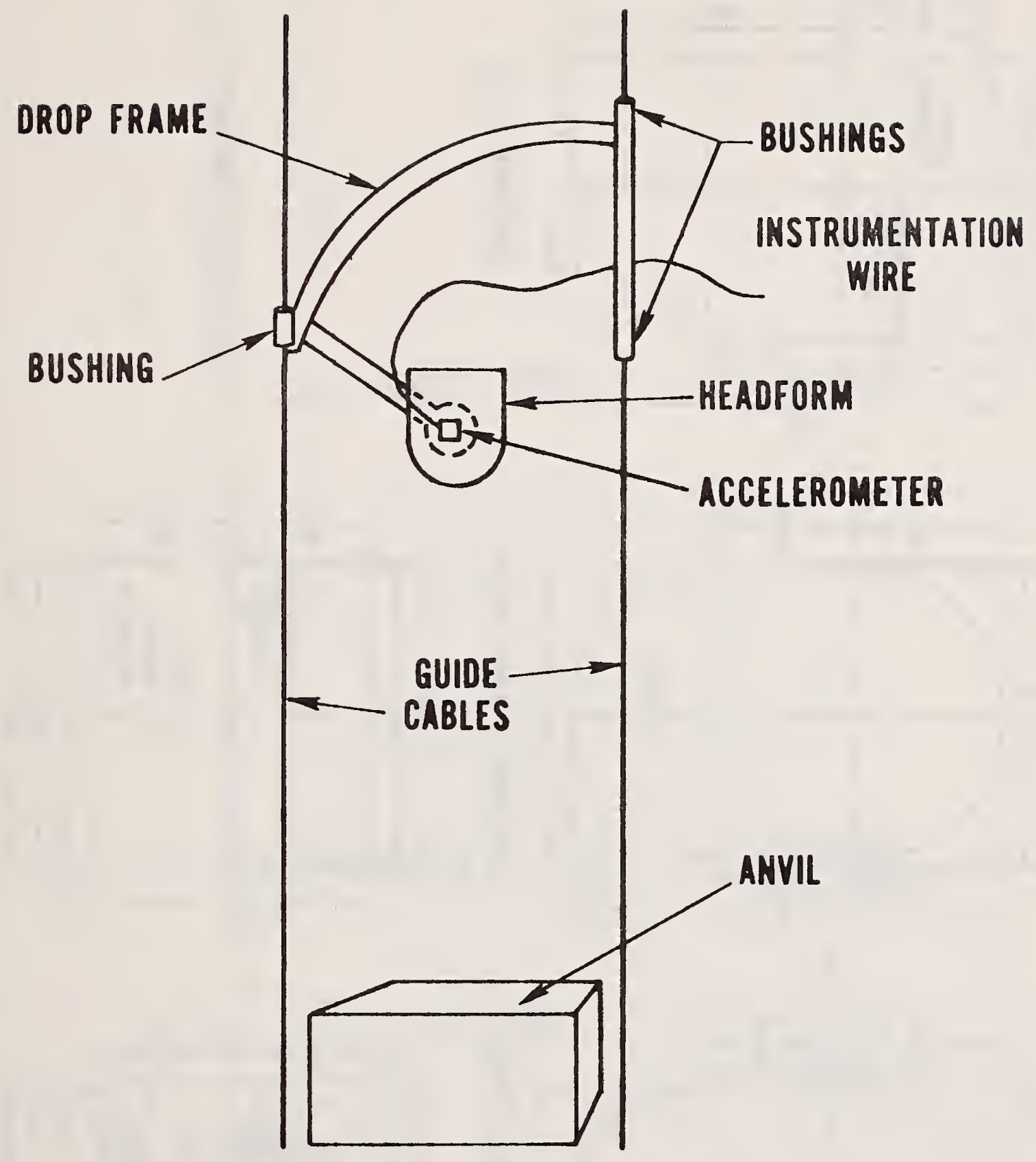

Figure 3. Impact attenuation test setup. 

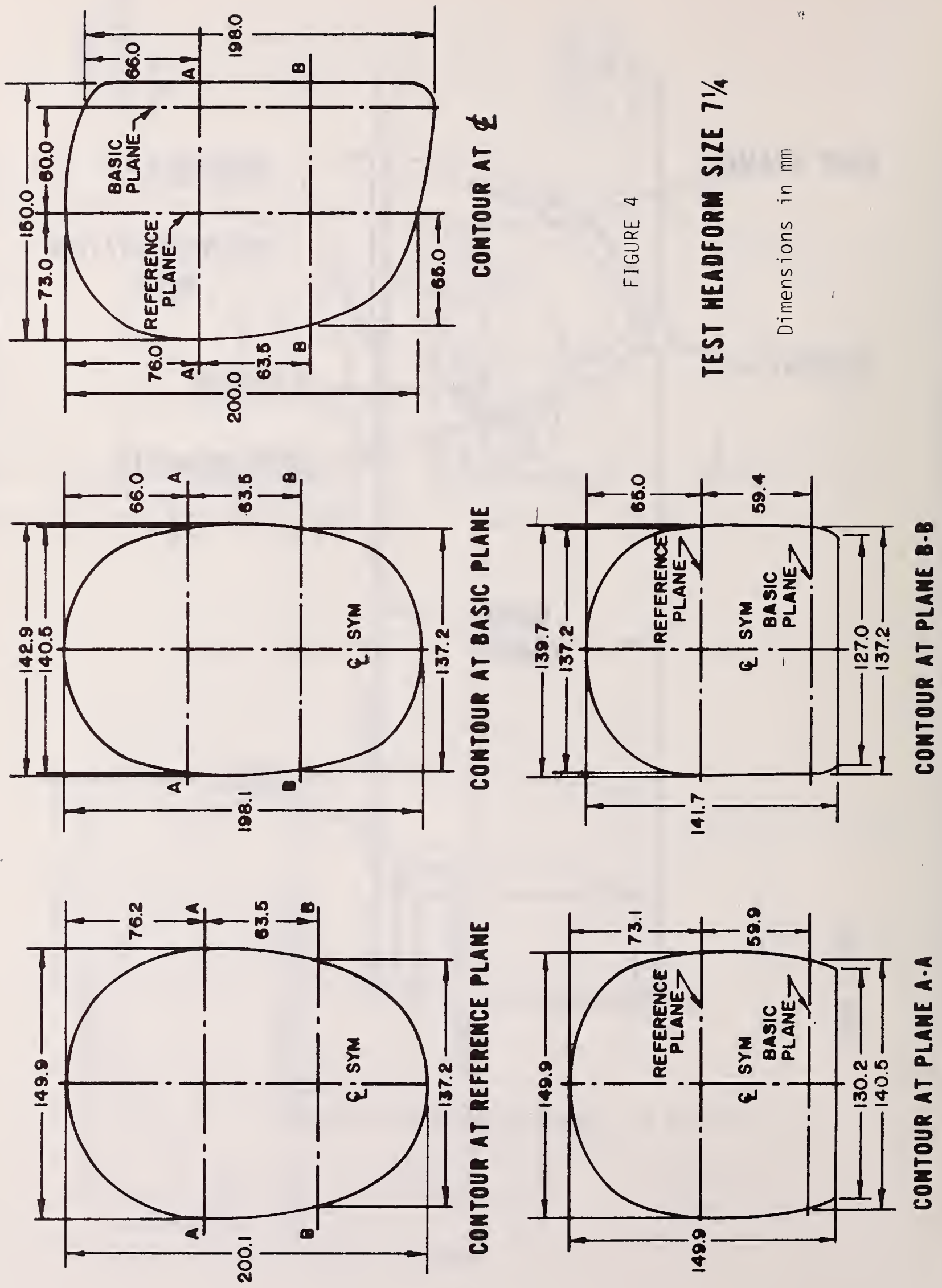


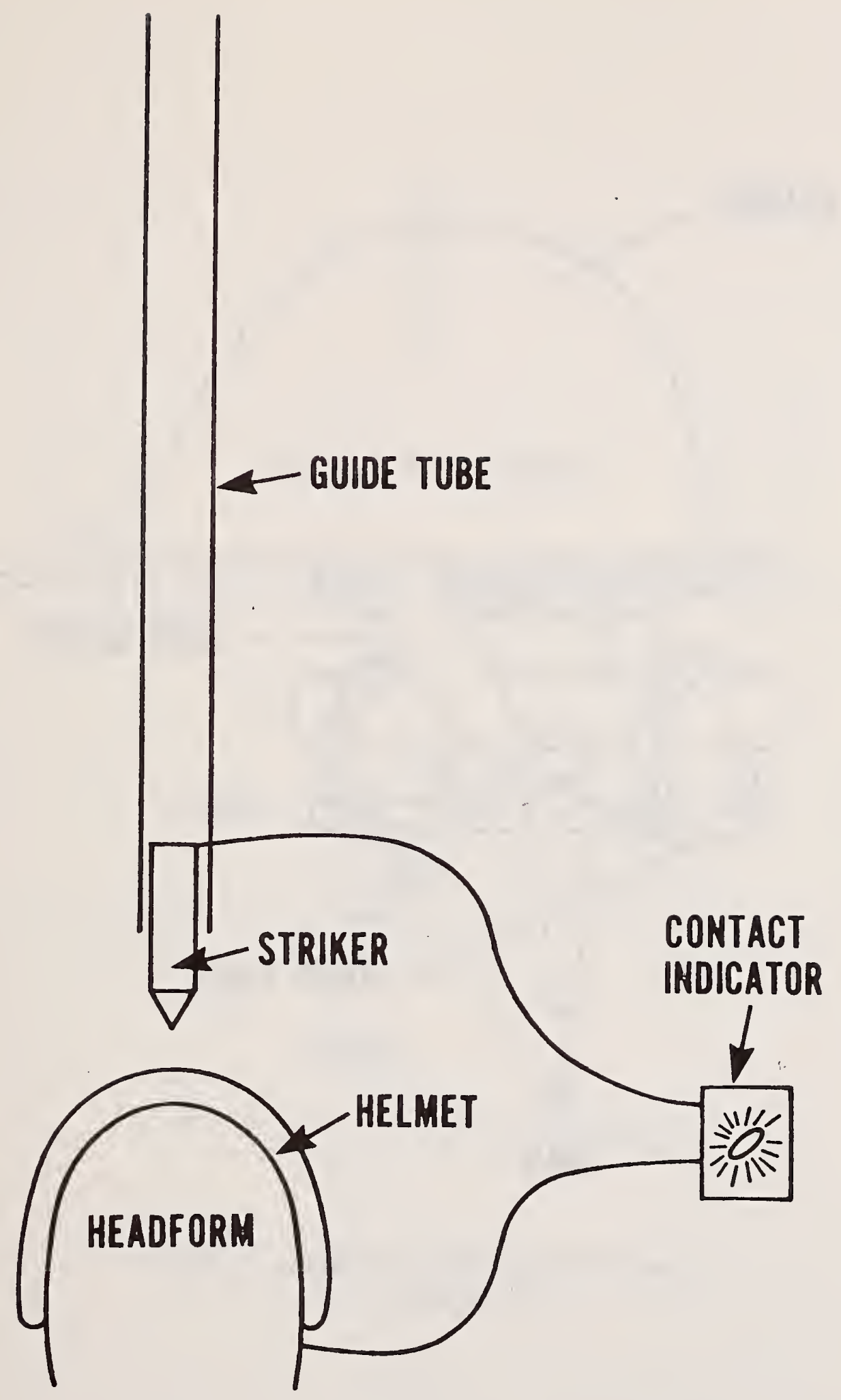

Figure 5. Penetration resistance test setup. 


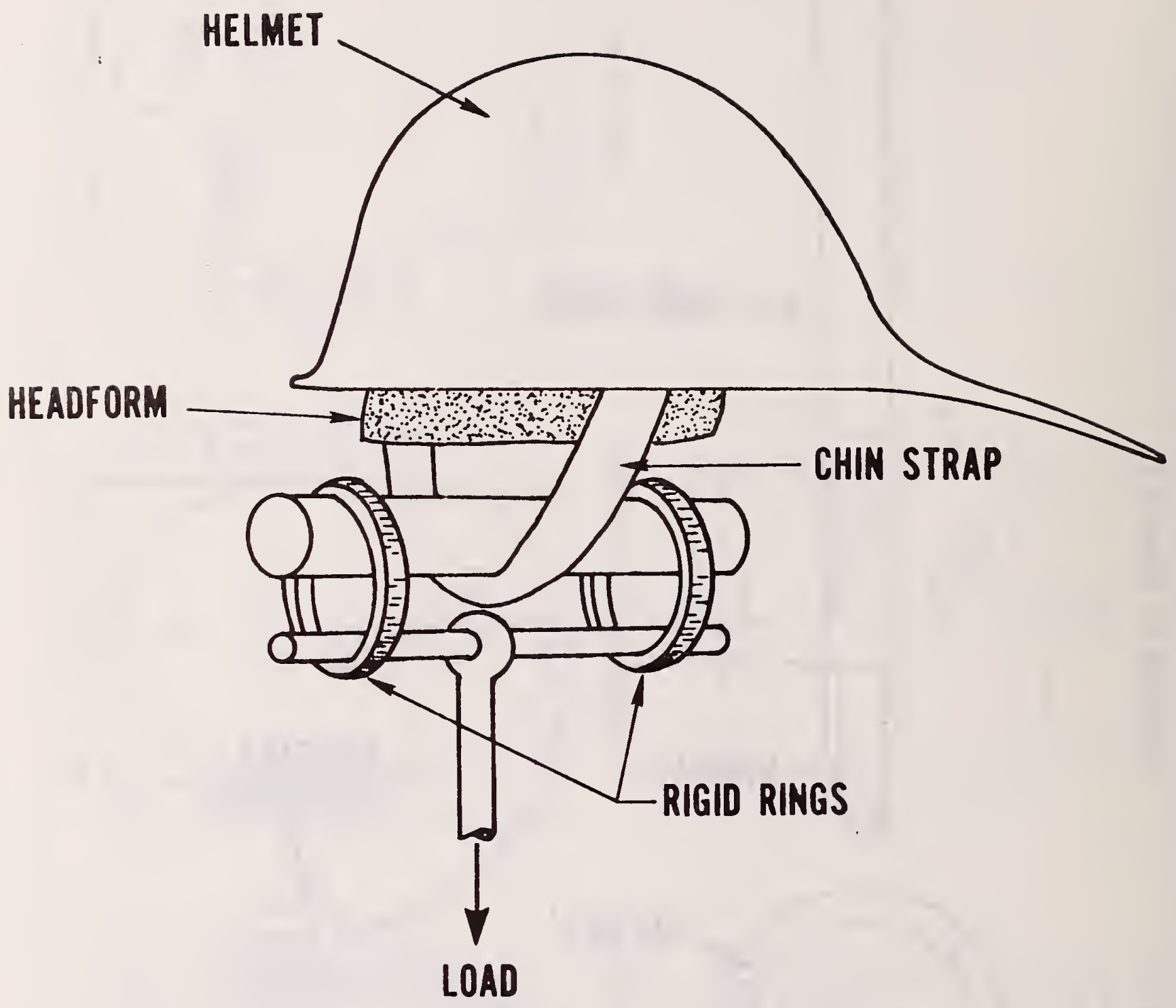

Figure 6. Chin strap/retention system test setup. 

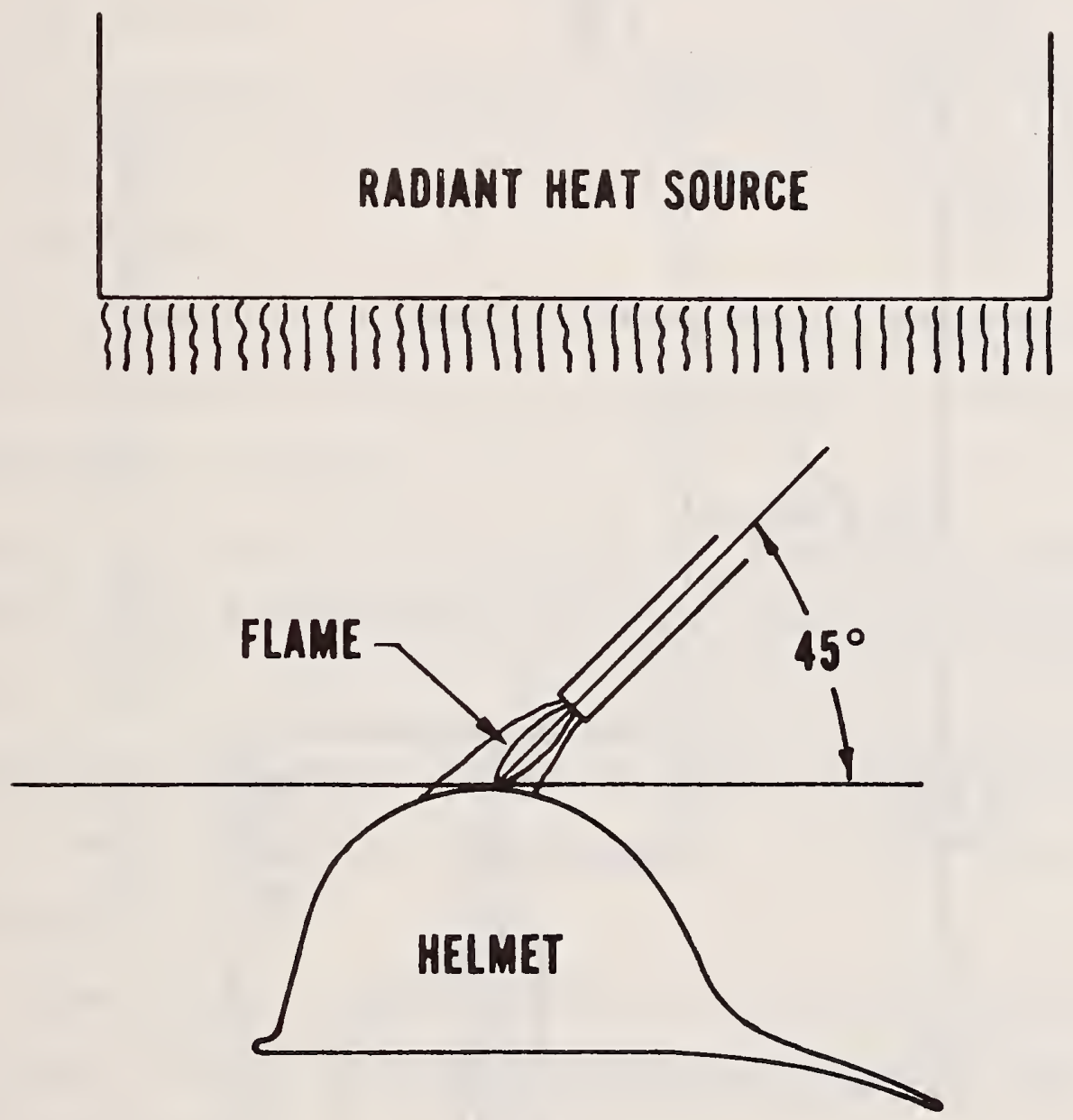

Figure 7. Flame resistance test setup. 


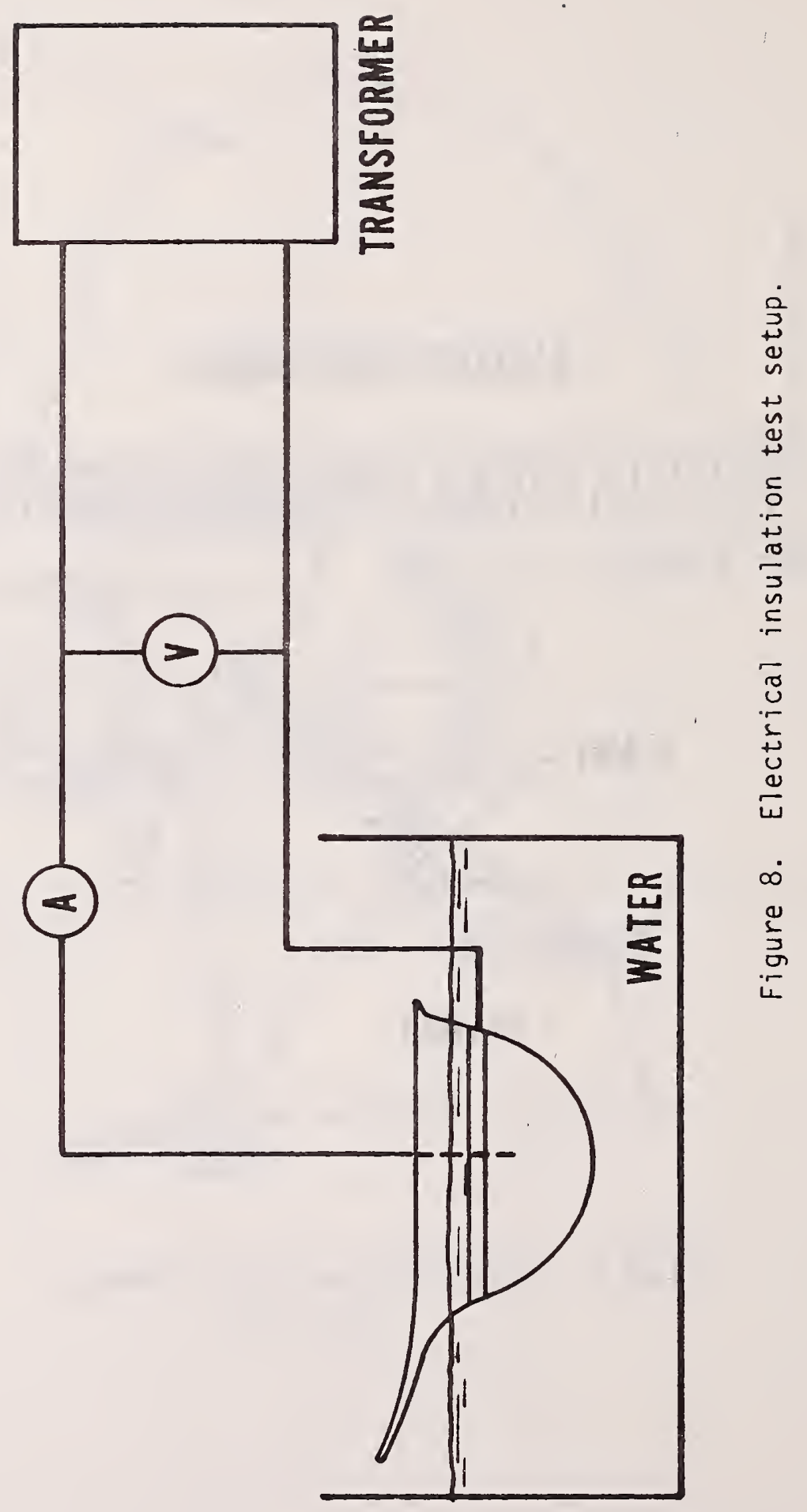




\section{Bibliography}

1. Standard for Protective Headgear for Vehicular Users, ANSI Z90.1, 1973, American National Standards Institute, Inc., 1430 Broadway, New York, New York.

2. Safety Requirements for Industrial Head Protection, ANSI Z89.1, American National Standards Institute, Inc., 1430 Broadway, New York, New York.

3. Surface Flammability of Materials Using a Radiant Energy Source, ASTM E162, American Society for Testing and Materials, 1916 Race St., Philadelphia, PA 19103.

4. Standard for Motorcycle Helmets, FMVSS No. 218, National Highway Traffic Safety Administration, 400 Seventh Street, SW., Washington, D.C.

5. Standard for Riot Helmets, NILECJ STD 0104.00, Department of Justice Law Enforcement Assistance Administration, 633 Indiana Avenue, NW., Washington, D.C.

6. D.L. Simms and P.L. Hinkley, "Protective Clothing Against Flames and Heat," British Information Services, 45 Rockefeller Plaza, New York, New York.

7. SAE Recommended Practice J211b, Society of Automotive Engineers, inc., Two Pennsylvania Plaza, New York, New York.

8. Development of Criteria for Industrial and Firefighters' Head Protective Devices. HEW Publication No. (NIOSH) 75-125, January 1975. 
NBS-II4A (REV. 7-73)

\begin{tabular}{|c|c|c|}
\hline \begin{tabular}{c|c} 
U.S. DEPT. OF COMM. & $\begin{array}{l}\text { 1. PUBLIC ATION OR REPORT NO. } \\
\text { BIBLIOGRAPHIC DATA } \\
\text { SHEET }\end{array}$ \\
\end{tabular} & $\begin{array}{l}\text { 2. Gov't Accession } \\
\text { No. }\end{array}$ & 3. Recipient's Accession No. \\
\hline \multirow{3}{*}{\multicolumn{2}{|c|}{$\begin{array}{l}\text { 4. TITLE AND SUBTITLE } \\
\text { Considerations in Establishing Performance } \\
\text { Criteria for Structural Firefighters' Helmets }\end{array}$}} & 5. Publication Date \\
\hline & & May 1977 \\
\hline & & $\begin{array}{l}\text { 6. Performing Organization Code } \\
446.03\end{array}$ \\
\hline \multicolumn{2}{|l|}{$\begin{array}{l}\text { 7. AUThor(S) } \\
\text { Nicholas J. Calvano }\end{array}$} & 8. Performing Organ. Report No. \\
\hline \multirow{2}{*}{\multicolumn{2}{|c|}{$\begin{array}{l}\text { 9. PERFORMING ORGANIZATION NAME AND ADDRESS } \\
\text { NATIONAL BUREAU OF STANDARDS } \\
\text { DEPARTMENT OF COMMERCE } \\
\text { WASHINGTON, D.C. } 20234\end{array}$}} & 10. Project/Task/Work Unit No. \\
\hline & & 11. Contract/Grant No. \\
\hline \multirow{3}{*}{\multicolumn{2}{|c|}{ 12. Sponsoring Organization Name and Complete Address (Street, City, State, ZIP) }} & $\begin{array}{l}\text { 13. Type of Report \& Period } \\
\text { Covered }\end{array}$ \\
\hline & & Final \\
\hline & & 14. Sponsoring Agency Code \\
\hline
\end{tabular}

15. SUPPI.EMENTARY NOTES

16. ABSTRACT (A 200-word or less factual summary of most significant information. If document includes a significant bibliography or literature survey, mention it here.)

The report describes the development of performance criteria for firefighters' helmets. Biomedical and physiological considerations are discussed. Fire helmet constructions and test methods for impact attenuation, penetration resistance, heat resistance and filammability are described. Results of tests on various types of fire helmets are presented. A proposed standard for fire helmets is included.

17. KEY WORDS (six to twelve entries; alphabetical order; capitalize only the first letter of the first key word unless a proper name, separated by semicolons)

Fire helmet; head injury; head protection; heat resistance; helmet; impact; penetration resistance; test methods

18. AVAIL.ABILITY

XX Unlimited

[ For Official Distribution. Do Not Release to NTIS

[ Order From Sup. of Doc., U.S. Government Printing Office Washington, D.C. 20402, SD Cat. No.C13

XX Order From National Technical Information Service (NTIS) Springfield, Virginia 22151

\begin{tabular}{|c|c|}
\hline $\begin{array}{l}\text { 19. SECURITY CLASS } \\
\text { (THIS REPURT) }\end{array}$ & 110 \\
\hline $\begin{array}{l}\text { 20. SECURITY CLASS } \\
\text { (THIS PAGE) } \\
\text { UNCLASSIFIED }\end{array}$ & $\begin{array}{l}\text { 22. Price } \\
\$ 34 \\
-\$ 5.50\end{array}$ \\
\hline
\end{tabular}




몀 
